\title{
The lactate and ventilatory response to exercise in endurance athletes
}

Citation for published version (APA):

Hoogeveen, A. R. (2001). The lactate and ventilatory response to exercise in endurance athletes.

[Doctoral Thesis, Maastricht University]. Maastricht University. https://doi.org/10.26481/dis.20010510ah

Document status and date:

Published: 01/01/2001

DOI:

10.26481/dis.20010510ah

Document Version:

Publisher's PDF, also known as Version of record

\section{Please check the document version of this publication:}

- A submitted manuscript is the version of the article upon submission and before peer-review. There can be important differences between the submitted version and the official published version of record.

People interested in the research are advised to contact the author for the final version of the publication, or visit the DOI to the publisher's website.

- The final author version and the galley proof are versions of the publication after peer review.

- The final published version features the final layout of the paper including the volume, issue and page numbers.

Link to publication

\footnotetext{
General rights rights.

- You may freely distribute the URL identifying the publication in the public portal. please follow below link for the End User Agreement:

www.umlib.nl/taverne-license

Take down policy

If you believe that this document breaches copyright please contact us at:

repository@maastrichtuniversity.nl

providing details and we will investigate your claim.
}

Copyright and moral rights for the publications made accessible in the public portal are retained by the authors and/or other copyright owners and it is a condition of accessing publications that users recognise and abide by the legal requirements associated with these

- Users may download and print one copy of any publication from the public portal for the purpose of private study or research.

- You may not further distribute the material or use it for any profit-making activity or commercial gain

If the publication is distributed under the terms of Article $25 \mathrm{fa}$ of the Dutch Copyright Act, indicated by the "Taverne" license above, 


\section{The lactate and ventilatory response to exercise in endurance athletes}


Thesis - The lactate and ventilatory response to exercise in endurance athletes by Adwin R. Hoogeveen, Saint Joseph Hospital, Veldhoven, the Netherlands, May 2001.

ISBN: 90-9014735-7

Key words: anaerobic threshold, endurance performance, ventilatory response, lactate steady state, training effects.

Lay out: Henk Dinnissen

Printed by: Ergon bedrijven, Eindhoven, the Netherlands

Covers

Front

E. Merckx in leading position in the Tour de France of 1972. E. Merckx was the most successful endurance athlete in sports history. He was a professional cyclist and scored 525 victories in his carrier, including five times the Tour of France, five times the Tour of Italy, and four times World Champion.

By permission of $\mathrm{E}$. Merckx.

Back

Sentence from the book "De Renner" written by the Dutch author T. Krabbé in 1978.

By permission of T. Krabbé. 


\title{
The lactate and ventilatory response to exercise in endurance athletes
}

\author{
PROEFSCHRIFT
}

ter verkrijging van de graad van doctor aan de Universiteit Maastricht, op gezag van de Rector Magnificus, Prof. dr. A.C. Nieuwenhuijzen Kruseman volgens het besluit van het College van Decanen, in het openbaar te verdedigen op donderdag 10 mei 2001 om 14.00 uur.

door

Adwin Richard Hoogeveen

geboren te Utrecht op 31 augustus 1961 


\section{Promotor:}

Prof. Dr. H. Kuipers

Co-promotor

Dr. H.A. Keizer

\section{Beoordelingscommissie:}

Prof. dr. K.R. Westerterp (voorzitter) (Katholieke Universiteit Leuven)

Prof. dr. H. Th. Folgering (Universitair Longcentrum Dekkerswald, Groesbeek)

Prof. dr. S. Luyendijk

Dr. F.T.J. Verstappen

Dr. M.L. Zonderland (Universitair Medisch Centrum Utrecht)

This thesis was supported by the St Joseph Hospital Veldhoven, the Netherlands, the Dutch Olympic Committee / Dutch Sports Federation (NOC/NSF), and the SMA-Cardiosport, Veldhoven, the Netherlands. 


\section{Contents}

Chapter I Introduction and outline of this thesis.

Chapter II The plasma lactate response to exercise and endurance performance: relationships in elite cyclists

Chapter III The maximal lactate steady state in elite endurance athletes

Chapter IV The ventilatory threshold, heart rate, and endurance performance: relationships in elite cyclists

Chapter $\mathrm{V}$ The effect of endurance training on the ventilatory response to exercise in elite cyclists

Chapter Vl The $\mathrm{VO}_{2}$ overshoot at the onset of constant-load exercise in elite cyclists: an undescribed phenomenon

Chapter VII The effect of endurance training on the $\mathrm{VO}_{2}$ overshoot and the submaximal $\mathrm{VO}_{2}$ during steady-state exercise in competitive cyclists

Chapter VIII General discussion

Chapter IX Summary / Samenvatting

Alfabetische dankwoordenlijst

Curriculum vitae

Publications 

Chopter

Introduction and outline of this thesis 


\section{Chapter 1}

\section{Introduction}

Oxygen uptake reflects the ability of the body to transport oxygen from ambient air to the working muscles where it is utilised. Four systems play important roles in the oxygen uptake $\left(\mathrm{VO}_{2}\right)$; diffusing capacity, cardiac output, oxygen carrying capacity of the blood, and skeletal muscle characteristics $(5,27,72,92)$. The highest oxygen uptake $\left(\mathrm{VO}_{2} \mathrm{max}\right)$ of an individual reflects the optimum interplay between these four systems and is traditionally thought to be highly correlated with endurance performance. $\mathrm{VO}_{2} \mathrm{max}$ is reached during short-term, highintensity exercise $(62,65,72)$. The demonstration of an oxygen consumption plateau, in spite of increasing exercise intensity is thought to imply that the individual who is being tested has reached the limits of the cardiorespiratory and oxidative system and thus has reached the highest attainable oxygen uptake. However, in practice, despite the exhortations of the investigator, a proportion of subjects fails to reach an intended maximum exercise because of symptoms such as muscle weakness, pain, fatigue, and motivation. So in many subjects a satisfactory oxygen consumption plateau cannot be demonstrated and the highest measured oxygen uptake is then called $\mathrm{VO}_{2}$ peak (72), the assumption being made that $\dot{\mathrm{VO}}_{2}$ max has not been reached.

The limiting factors of the $\mathrm{VO}_{2}$ max has been debated vigorously and has been recently reviewed by Bassett and Howley (5) who discussed at length the four limiting factors of $\dot{\mathrm{V}}_{2}$ max: diffusing capacity, cardiac output, oxygen carrying capacity of the blood, and skeletal muscle characteristics. The first three are considered to be central factors and the skeletal muscle is considered a peripheral factor. There is widespread agreement that in healthy humans, at sea level, the ability of the cardiorespiratory system to transport oxygen to the muscles is the factor that limits $\dot{\mathrm{VO}}_{2} \max$ and not the ability of muscle mitochondria to consume oxygen $(5,72)$.

Exercise at $\mathrm{VO}_{2}$ max intensity can only be maintained for a limited period of time. Endurance time in exercise demanding maximum oxygen uptake is limited to $4-10$ minutes $(2,5,56,72)$. Consequently, continuous exercise for 10-20 min and longer must be conducted at submaximal $\mathrm{VO}_{2}$. The limitation of exercise intensities at submaximal $\mathrm{VO}_{2}$ is set by the occurrence of a progressive acidosis in the muscle cells which inhibits glycolytic enzymes and the regeneration of ATP $(71,82)$. Intra- and extra-cellular buffer capacity, lactate transporters, and ventilatory compensation mechanisms regulate this acidosis (13,14$18,27,71,86$ ). These issues will be discussed in this chapter.

In fact, during prolonged high-intensity exercise, a metabolic acidosis occurs which is compensated by the ventilatory system. Based on this concept, multiple authors attempted to investigate the ventilatory and lactate response to exercise, in order to measure the ability for a prolonged period of high-intensity exercise $(24,27,56,65,77,85,94)$. The lactate and ventilatory response are currently generally accepted as a tool for measuring performance, fitness, training effects and for prescribing training schedules (48). In addition, numerous confusing terms such as lactate threshold, ventilatory threshold, and anaerobic threshold have been introduced in order to define the ability for maintaining high-exercise intensity $(27,56,65)$. However, the determination of the different thresholds is poorly defined and the interpretation is influenced by the exercise protocol, method of detection, evaluator and nutritional state of the subjects $(5,21,70,81,97)$. The practical value of the different parameters and the implications are often difficult to interpret in a practical training situation. There are very few studies in which the laboratory tests have been validated for practical 
field test conditions. In this chapter, the current knowledge of the lactate and ventilatory response to exercise will be discussed. An outline of this thesis is presented at the end of this chapter.

\section{The lactate response to exercise}

\section{The role of lactate during exercise: the lactate metabolism}

A few decades ago, according to many authors, lactate was considered as a dead-end waste product of metabolism. The resulting acidosis is viewed as the major factor that causes fatigue and exhaustion during exercise $(8,27,82,85)$. However, several studies indicated that lactate is not a waste dead-end metabolite during exercise and recovery $(13-16,34,35,44)$. In contrast, the results of these studies strongly suggest that lactate plays an important role in metabolism during exercise $(16-18,34,35)$. Skeletal muscle produces and removes lactate at the same time (98). Lactate which is produced in areas with a high glycogenolytic and glycolytic activity (type Illb fibres) is used as a substrate for energy metabolism elsewhere and oxidised in areas with a high oxidative activity (type I and Ila fibres). Brooks et al. called this phenomenon the lactate shuttle (16). Lactate reaches the oxidative areas by diffusion (83) or via the circulation. Lactate is actively metabolised in heart muscle $(13,14,16,34)$. Another function of lactate is maintaining levels of blood glucose as a precursor of liver gluconeogenesis $(14,44,52)$. The glycogen synthesis in the liver is lowered during exercise by a decreased perfusion. In addition, during exercise glucagon levels increase and insulin levels decrease, resulting in an inhibiting effect on glycogen synthesis in the liver $(32,52)$. Recently, Brooks (18) expanded the concept of the lactate shuttle and introduced an additional intracellular lactate shuttle. Brooks (18) suggests that lactate plays a key role in the distribution of carbohydrate among various tissue and cellular compartments such as between: cytosol and mitochondria, muscle and blood, active and inactive muscles, white and red muscle fibres, liver, skin, heart and blood. Most lactate $(75 \%)$ is disposed by oxidation and converted to glucose and glycogen. Lactate turnover and lactate transport across membranes occurs by means of facilitated exchange along $\mathrm{pH}$ and concentration gradients involving a family of lactate transport proteins, called monocarboxylate transporters (MCT's) $(13,18,35,40,98)$. MCT's are abundant in Type Ila and Ilb muscles, and they are markedly lower in Type I muscles (13). An extensive review of monocarboxylate transporters has recently published by Halestrape and Price (40). At present, eight different isoforms of MCT's (MCT1 to MCT8) have been identified in human tissues $(40,98)$. Skeletal muscle expresses MCT1 and MCT4, heart expresses high levels of MCT1 in both human and rats (40). Based on rat studies, data so far available indicate the expression of different MCT isoforms in skeletal and cardiac muscle. Further studies are required to characterise specific cellular distributions since there is a considerably variability among species (98). Based on the distribution of MCT1 and MCT4, it has been proposed that MCT1 in skeletal muscle may reflect the need to take up lactate for oxidative purposes, whereas MCT4 may be important for lactate efflux $(40,98)$.

The efflux of lactate and $\mathrm{H}^{+}$from muscle is important during exercise, since it lowers the intracellular concentration of both species and prevents cellular acidification $(40,98)$. The blood and plasma lactate levels during steady-state exercise are the result of the efflux and uptake of lactate $(14,34,35)$, so lactate levels do not reflect the net turnover of lactate. With 
training, MCT1 and MCT4 are increased in rat muscle (59). Less is known about human muscle, however recently Bonen et al. (12) showed an increase in MCT1 in human muscle following training.

The physiological explanation for the accumulation of lactate during high-intensity exercise is still not elucidated $(27,72)$. To explain this phenomenon, local hypoxia, increasing recruitment of type II-fibres and a shift in the pyruvate-lactate balance has been suggested $(2,88)$. True anaerobic conditions with hypoxia have been viewed traditionally as the reason for the lactate production (88). However this concept has been abandoned (5). High-exercise intensities drive glycolysis resulting in a greater rate of carbohydrate turnover, an accumulation of pyruvate and NADH in the cytoplasm, and an increase in lactate efflux $(43,49)$. The accumulation of lactate in exercising muscles influences the acid-base balance which makes it an important contribution to an individual's overall endurance performance $(27,72)$.

The role of lactate as an acid is still a controversial issue. The acidosis is assumed to inhibit ATP regeneration $(82,85)$. It is well known that severe acidosis inhibits the enzyme phosphofructukinase which is involved in the glycolysis (82). In contrast, acidosis shifts the oxyhaemoglobin-dissociation curve to the right, allowing $\mathrm{O}_{2}$ to unload oxygen from haemoglobin (50). Furthermore the decreasing $\mathrm{pH}$ results in a vasodilatation of the vascular bed in the contracting muscle (50). As a result, both phenomena allow an increasing amount of oxygen to the tissues. The net result may increase rather than decrease endurance performance. In contrast, during submaximal and maximal exercise, low lactate levels are believed to be indicators of overtraining, which is associated with a decreased performance $(47,55,74)$.

\section{Lactate parameters: definitions and measurements in the laboratory}

The usefulness of the maximum oxygen uptake as predictor of endurance performance has been questioned and numerous authors suggested that other parameters measured during submaximal exercise were better indicators of endurance performance than $\mathrm{VO}_{2}$ max $(23,24,53,54)$. They suggested that particularly the blood lactate response to exercise was a better indicator of endurance performance $(23,24,65,95)$. The blood lactate level during incremental exercise shows an exponential course. In rest, blood lactate levels are around $0,5-1,5 \mathrm{mmol}^{-\mathrm{I}^{-1}}(10)$. During incremental exercise the blood lactate level first decreases somewhat at lower workload, at higher workloads the blood lactate levels increase exponential up to $10-15 \mathrm{mmol}^{-1}(10,72,91)$. During the last decades, the blood lactate response to exercise is commonly accepted as a tool for predicting endurance performance and designing training programs $(25,46,58,75,95)$. The blood lactate response has been studied thoroughly during the last decades and has been described using a variety of terms and definitions $(27,51,76,85)$. Since several terms are used, which is quite confusing, we will briefly describe them first.

The anaerobic threshold (AT) has been one of the most commonly used terms for describing the lactate response. AT can be defined as the highest metabolic rate or the highest exercise intensity or highest oxygen consumption at which blood lactate concentration is maintained at a steady state during prolonged exercise $(42,57,76,84,85)$. AT is assumed to reflect the transition of aerobic to anaerobic conditions $(2,85)$. An athlete is assumed to sustain exercise intensities of around AT for a relatively long period of time ( $30 \mathrm{~min}$. up to 11 hour). Exercise intensity slightly above AT results in progressive blood lactate accumulation and the 
athlete is forced to stop or lower the intensity. AT, and in particular the heart rate (HR) and the exercise intensity at AT, has been described as a key parameter that defines the ability to maintain high-intensity exercise $(25,54,89,95)$. AT has been commonly accepted as a tool for predicting endurance performance and designing training programs $(65,80,90,91)$.

The upper limit of blood lactate resulting in a lactate steady state during constant workload is called the maximal lactate steady state (MaxLaSS or MLSS). The determination of MaxLaSS requires the performance of several constant workloads on different days (10). MaxLaSS is expected to correspond to the anaerobic threshold (AT).

The onset of blood lactate accumulation (OBLA) is used for the exercise intensity or $\mathrm{VO}_{2}$ at which the lactate concentrations begins to accumulate i.e. when the lactate production exceeds the elimination rate $(29,60,80,91,95)$.

Another commonly used term to describe the lactate response is the lactate threshold (LT). LT is defined as the highest $\mathrm{VO}_{2}$ or exercise intensity that can be attained during incremental exercise before an elevation in blood lactate is observed $(24,75,88,90)$. Coyle et al. $(22-24)$ defined LT as the lactate level that was 1 mmol. $\mathrm{I}^{-1}$ above baseline during incremental exercise. OBLA and LT are also expected to approximate the anaerobic threshold and the definitions are closely related.

To determine AT, LT, OBLA, and MaxLaSS during incremental exercise tests, numerous concepts and definitions have been published in the last decades. Some investigators proposed a fixed lactate concentration to define and detect AT. Values of 2 mmol. $I^{-1}(53,73)$, $3 \mathrm{mmol}^{-1} \mathrm{I}^{-1}(30)$ and $4 \mathrm{mmol} . \mathrm{I}^{-1}(42,51,57,77)$ have been proposed. In an attempt to detect and define AT, several mathematical models were introduced to analyse the lactate response during incremental exercise $(27,31,76)$, while some investigators described an individual anaerobic threshold (IAT) $(10,26,77)$. The average lactate concentration at AT, LT or IAT in these studies varies from $1.7 \pm 0.3(26)$ to $4.2 \pm 0.8 \mathrm{mmol}^{-\mathrm{I}^{-1}}$ (10).

\section{The lactate response to exercise during field test conditions}

It is remarkable that only few investigators described lactate levels assessed during a practical situation using a field test. Beneke et al. (9) reported blood lactate levels of $4-6.5$ mmol. $\mathrm{I}^{-1}$ in well-trained speed skaters. Pages et al. (68) described lactate values of $4.95 \pm 0.5$ mmol. $\mathrm{I}^{-1}$ in 7 triathletes during a triathlon race. However these triathletes were only moderately trained and the duration of the total triathlon had an average of almost 3 hours, so these lactate values can not be considered as the maximal steady-state values. Furthermore, steady state was not controlled and lactate in these studies was assessed only post-exercise.

Several authors evaluated the lactate response to steady-state exercise in a laboratory. In 8 elite cyclists, Jenkins et al. (47) observed a mean lactate concentration of $8.9 \pm 1.6 \mathrm{mmol.I^{* }}$ 1 on a cycle ergometer during 30 minutes exercise. However, in 6 subjects the workload used in this experiment was decreased during the test when the initial workload could not be maintained. For this reason, these lactate values can not be interpreted as steady-state values, but these observations were an indication that endurance-trained cyclists can tolerate high blood lactate levels for at least 30 minutes. Coyle et al. (24) observed lactate values of $7.2 \pm$ 0.7 mmol. $\mathrm{I}^{-1}$ in 15 elite cyclists during a laboratory test with a constant workload. 


\section{The lactate responses and their relationship to performance}

In the literature the lactate response appears to be highly correlated to various types of endurance performance $(22-25,30,53,54,95)$. The correlation varies from 0.80 up to 0.99 . Most studies concerned runners $(30,53,54,95)$ and only few authors evaluated the lactate response assessed in a laboratory with cyclists or triathletes during a field test. The problem in these studies is that most studies concerned moderately trained subjects $(22,30,65)$, and / or subjects with a significant difference in performance $(23,24,30,65)$. For example, Coyle et al. (24) observed a high correlation $(r=0.88)$ between the workload during a 1 hour duration laboratory test at a constant load and a time trial of $40 \mathrm{~km}$. This workload was strongly correlated $(r=0.93)$ with the lactate threshold which was defined as the lactate level that was $1 \mathrm{mmol} . \mathrm{l}^{-1}$ above baseline during incremental exercise. However, in Coyle's study (24), the road racing time of the subjects varies from 51 up to 65 minutes, and $\mathrm{VO}_{2}$ at the lactate threshold from 3.08 up to $4.40 \mathrm{l} \cdot \mathrm{min}^{-1}$. As a consequence, significant correlations between the lactate response and performance are easily found, but the predictive value is limited due to a high interval of confidence. This problem also accounts for all previously mentioned correlations observed by other investigators. O'Toole et al. (67) observed no significant correlation between the $\dot{\mathrm{VO}}_{2}$ at the lactate threshold (according to Coyle et al. (24); see above) and the cycling time during an ultra triathlon (180 km).

\section{Training effects on the lactate response}

The training effect on the lactate response has been studied extensively $(27,48,56,91)$. It is commonly accepted that following endurance training, a subject will have lower blood lactate levels for the same work rate in combination with an increased maximum performance. These lower lactate levels should not be confused with the lower lactate levels during overtraining, overreaching or exhaustion which are conditions associated with a decreased performance $(48,55)$.

\section{The ventilatory response to exercise}

During prolonged high-intensity exercise the intra- and extra-cellular lactate acidosis that occurs, is compensated by the ventilatory system. The plasma and intra-muscular $\mathrm{pH}$ depends on the lactate production, lactate efflux and the buffer capacity. The phosphate buffers form the major intracellular buffering system (71). The hydrogen carbonate buffer is the major extracellular buffering system, in which hydrogen carbonate absorbs protons and the carbonic acid formed decomposes into water and $\mathrm{CO}_{2}(71,72)$. The excess $\mathrm{CO}_{2}$ is removed by increased ventilation. The ventilatory response to exercise has been studied thoroughly during the past decades $(27,56,85,87)$ on the basis of this concept. Since the introduction of the term anaerobic threshold (AT) in 1964 (85), AT was associated with an increased blood lactate concentration, increased ventilation, increased $\mathrm{CO}_{2}$ excretion and a decreasing bicarbonate concentration. It was suggested that these phenomena reflected a shift from aerobic to anaerobic metabolism $(27,73,85,88)$.

Several ventilatory thresholds (VT) have been described based on different ventilatory parameters during incremental exercise tests. These ventilatory thresholds were expected to correspond with AT. Initially, it was suggested that departures from the linearity of the minute ventilation ( $\dot{\mathrm{VE}})$, and the carbon dioxide output $\left(\mathrm{VCO}_{2}\right)$ plus an abrupt increase in 
the gas exchange ratio (RQ) could be used as markers for the onset of a metabolic acidosis $(27,86)$. Later the criterion was adjusted as a systematic increase in the ventilatory equivalent for $\mathrm{VO}_{2}\left(\hat{\mathrm{VEV}} \mathrm{VO}_{2}\right)$ without a concomitant increase in $\mathrm{VE} / \mathrm{VCO}_{2}(19,27,87)$. According to Wasserman et al. (89), AT can be determined during an incremental exercise test using the following ventilatory parameters: 1 . Steeper increase of $\mathrm{VCO}_{2}$ as compared to $\mathrm{VO}_{2}(\mathrm{~V}$-slope method); 2 . Respiratory exchange ratio $=0.95 ; 3 . \mathrm{VE} / \mathrm{VO}_{2}$ increase.

\section{The $\mathrm{VO}_{2}$ kinetics and the $\hat{\mathrm{VO}}_{2}$ response to constant-load exercise}

The increase in $\mathrm{VO}_{2}$ that accompanies an increase in exercise intensity is immediate, but it takes time to reach a steady-state condition $(36,38,39,93,96)$. The time to reach steady state requires several minutes depending upon the magnitude of the increment and the fitness of the individual (39). Because of the time delay in attaining the steady-state $\mathrm{VO}_{2}$, part of the energy must be provided by creatine phosphate hydrolysis and glycolysis to enable continued muscle contraction. This is called the oxygen deficit $(20,63,92)$.

The $\mathrm{VO}_{2}$ response following a step increase in work rate has been characterised as consisting of an early cardiodynamic component with unchanged mixed-venous $\mathrm{O}_{2}$-content (phase I) and a subsequent metabolic component (phase II) starting when venous blood from the muscle arrives at the lungs (96).

The metabolic component of the $\mathrm{V}_{2}$ response at the onset of constant-load exercise (phase II) has been recently extensively reviewed by $\mathrm{Xu}$ and Rhodes (93). The response to exercise intensity below the lactate threshold can be described by a mono-exponential mathematical equation. During high-intensity exercise, the $\mathrm{V}_{2}$ response becomes more complex and consists of two components. The initial response increases still exponential, however an additional response is developed slowly after some minutes causing an increasing $\mathrm{VO}_{2}$ during the constant load ( $\mathrm{VO}_{2}$ drift). The possible mechanisms of these fast and slow components are not elucidated yet. The $\mathrm{VO}_{2}$ kinetics nowadays receive increasingly attention of researchers since enhanced $\mathrm{VO}_{2}$ kinetics during submaximal exercise may be an indicator of an increased endurance-trained state in cardiovascular patients $(6,41)$, healthy subjects $(3,37,39)$, and cyclists $(4,66)$. As endurance training can decrease the time to steady state, it also decreases the oxygen deficit $(20,27,69)$.

\section{The ventilatory response to exercise and its relationships to endurance performance}

In the literature, the different ventilatory thresholds described above have not been compared and validated in practice using a field test. It is remarkable that only a few investigators compared physiological parameters assessed in a laboratory with a practical situation using a field test. In the literature, VT $(23-25,54,65)$ appears to be highly correlated to various types of endurance performance.

The correlation in these studies varies from 0.70 up to 0.94 . However, the problem in most of these studies is that they concerned moderately trained subjects, or subjects with a significant difference in performance. As a consequence, significant correlations between the ventilatory response and performance are easily found, but the predictive value is limited due to a large interval of confidence.

\section{Training effects on the ventilatory response}

The studies concerning the effect of endurance training on the ventilatory response are numerous. However, these studies were all focused on the training effects of the $\mathrm{VO}_{2}$ max, 


\section{Chapter 1}

and the ventilatory threshold $(11,56,89)$. It is commonly accepted that endurance training will improve $\mathrm{VO}_{2}$ max and the $\mathrm{VO}_{2}$ at $\mathrm{VT}$, and that detraining will reduce these parameters $(11,20,23,56,64)$. The majority of these studies concerned patients and relatively untrained subjects.

A minority of the studies investigated the effect of training on the ventilatory response to exercise at submaximal exercise intensity $(4,11,33,37,39,41)$. The effect of training on the ventilatory response in these studies are conflicting, especially concerning the $\mathrm{V}_{2}$ : following endurance training, the oxygen consumption at submaximal levels has been described to be higher $(37,41,64)$, lower (4) or unchanged (39). Despite these conflicting results, lower submaximal $\mathrm{VO}_{2}$ values for the same work rate is accepted as an indicator of economy in various sports $(1,23,24,28,33,78,79)$. However the studies in which economy of locomotion was investigated and the previous mentioned studies, concerned different groups of subjects, trained and untrained. These studies were not focused on the training effects of the same subjects after a period of training.

\section{Summary and questions}

The lactate and ventilatory responses to exercise are described and defined in different ways by numerous authors. The methodology of the studies that tried to compare laboratory data to field situations is generally poor. The lactate and ventilatory thresholds are poorly defined and the moments of occurrence are influenced by the exercise protocol (97), method of detection, and evaluator. The $\mathrm{VO}_{2}$ kinetics and lactate kinetics are still poorly understood. Data concerning the training effects on the ventilatory response to exercise are conflicting. $\mathrm{V}_{2}$ kinetics in patients is now increasingly receiving the attention of researchers.

The general aim of this thesis is to investigate the lactate and ventilatory response to exercise and evaluate the different measurements as a tool for predicting performance, measuring training effects, and training management. This thesis consists of different chapters in which specific research questions are addressed.

In chapter II, a study is presented in which the relationship between different lactate responses and performance has been investigated in elite triathletes. The main question in this study is which of the various lactate responses described in the literature during an incremental exercise test is the best indicator of endurance performance assessed during a field test.

In chapter III, a study is presented in which the maximal lactate steady state during a field test has been investigated in elite endurance athletes. The main question in this study is whether the plasma lactate concentration during steady state exercise in elite endurance athletes corresponded with the levels of lactate steady state observed by other investigators in a laboratory setting.

In chapter IV, the ventilatory response to exercise is investigated using a field test in elite cyclists. The purpose of this study is to evaluate the relationships between the different ventilatory thresholds assessed during an incremental exercise test, the heart rate, and endurance performance assessed during a field test. 
In chapter $\mathbf{V}$, a study is presented in which training effects are investigated on the ventilatory response to a one-minute incremental exercise test. The aim of this study is to investigate effect on the ventilatory response to incremental exercise in a group of elite cyclists during a relatively untrained period compared to a period in which they were in an extensively endurance-trained state.

In chapter VI, a new phenomenon in exercise physiology concerning $\mathrm{VO}_{2}$ kinetics is described: the $\mathrm{VO}_{2}$ overshoot at the onset of steady-state exercise.

In chapter VII a study is presented in which the effect of training on the $\mathrm{VO}_{2}$ response to steady-state exercise and in particular the $\mathrm{VO}_{2}$ kinetics has been investigated. The main objective of this study is to investigate the $\mathrm{VO}_{2}$ kinetics at the onset of constant-load exercise in competitive cyclists during a relatively untrained period compared to a period in which they were in an excellent endurance-trained state.

In chapter VIII the results of the different studies are discussed and the conclusions are enumerated.

In chapter IX the studies are summarised.

\section{References}

1. Anderson T. Biomechanics and running economy. Sports Med 1996: 22: 76-89

2. Astrand P-O, Rodahl K. Textbook of work physiology 1985 (3rd ed.). New York: McGraw-Hill

3. Babcock MA, Paterson DH, Cunningham DA. Effects of aerobic training on gas exchange kinetics of older men. Med Sci Sports Exerc 1994; 26: 447-52

4. Barbeau $\boldsymbol{P}$, Seresse $\boldsymbol{O}$, Boulay $\boldsymbol{M R}$. Using submaximal aerobic variables to monitor elite cyclists during a season. Med Sci Sports Exerc 1993; 25: 1062-9

5. Bassett DR, Howley ET. Limiting factors for maximum oxygen uptake and determinants of endurance performance. Med Sci Sports Exerc 2000; 32: 70-84

6. Bauer TA, Regensteiner JG, Brass EP, Hiat WR. Oxygen uptake kinetics during exercise are slowed in patients with arterial disease. J Appl Physiol 1999: 87: 809-16

7. Becque MD, Katch V, Marks $\boldsymbol{C}$, Dyer $\boldsymbol{R}$. Reliability and within subject variability of $\dot{V}$, $\mathrm{VO}_{2}$, heart rate and blood pressure during submaximum cycle ergometry. Int J Sports Med 1993; 14: 220-3

8. Beelen A, Sargeant AJ. Effect of lowered muscle temperature on the physiological response to exercise in men. Eur J Appl Physiol 1994; 63: 387-92 


\section{Chapter 1}

9. Beneke $\boldsymbol{R}$, Boldte $\boldsymbol{F}$, Meller $\boldsymbol{W}$, and Behn $\boldsymbol{C}$. Das maximale laktate-steady state (Maxclass) im eisschnellauf. Leistungsdiagnostik 1991; 10: 766-7

10. Beneke $\boldsymbol{R}$. Anaerobic threshold, individual anaerobic threshold, and maximal lactate steady state in rowing. Med Sci Sports Exerc 1995; 27: 863-7

11. Bhambhani $\mathbf{Y}, \mathbf{M}$ Singh $\boldsymbol{M}$. The effects of three training intensities on $\dot{V} \mathrm{O}_{2}$ max and $\dot{V}$ E $\dot{V} \mathrm{O}_{2}$ ratio. Can J Appl Sport Sci 1985;10: 44-51

12 Bonen A, McCullagh KJ, Putman CT, Hultman E, Jones NL, Heigenhauser GJ. Short-term training increases human muscle MCT1 and femoral venous lactate in relation to muscle lactate. Am J Physiol 1998; 274: 102-7

13. Bonen A. Lactate transporters (MCT proteins) in heart and skeletal muscles. Med Sci Sports Exerc 2000; 32: 778-89

14. Brooks GA, Gaesser GA. End points of lactate and glucose metabolism after exhausting exercise. J Appl Physiol 1980; 49: 1057-69

15. Brooks GA. Anaerobic threshold: review of the concept and directions for future research. Med Sci Sports Exerc 1985; 17: 22-31

16. Brooks GA. The lactate shuttle during exercise and recovery. Med Sci Sports Exerc 1986; 18:360-8

17. Brooks GA. Current concepts in lactate exchange. Med Sci Sports Exerc 1991; 23: 895906

18. Brooks GA. Intra- and extra-cellular lactate shuttles. Med Sci Sports Med 2000; 32: 790-9

19. Caiozzo VJ, Davis JA, Ellis JF, Azus JL, Vandagriff R, Prietto CA, McMaster WC. A comparison of gas exchange indices used to detect the anaerobic threshold. J Appl Physiol 1982; 53: 1184-9

20. Charlton GA, Crawford MH. Physiologic consequences of training. Cardiol clin 1997; $15,345-54$

21. Cooper CB, Beaver WL, Cooper DM, Wasserman $\mathbf{K}$ Factors affecting the components of the alveolar $\mathrm{CO}_{2}$ output- $\mathrm{O}_{2}$ uptake relationship during incremental exercise in man. Exp Physiol 1992; 77: 51-64

22. Coyle EF, Martin WH, Ehsani AA, Hagberg JM, Bloomfield SA, Sinacore DR, Holloszy JO. Blood lactate threshold in some well-trained ischaemic heart disease patients. J Appl Physiol 1983: 54: 18-23 
23. Coyle EF, Coggan AR, Hopper MK, Walters TJ. Determinants of endurance in welltrained cyclists. J Appl Physiol 1988; 64: 2622-30

24. Coyle EF, Feltner ME, Kautz S, Hamilton MT, Montain SJ, Baylor AM, Abraham ID, Petrek GW. Physiological and biomechanical factors associated with elite endurance cycling performance. Med Sci Sports Exerc 1990; 23: 93-107

25. Craig NP, Norton KI, Bourdon PC, Woolford SM, Stanef T, Squires B, Olds TS, Conyers $\boldsymbol{R A J}$, Walsh $\boldsymbol{C B V}$. Aerobic and anaerobic indices contributing to track endurance cycling performance. Eur J Appl Physiol 1993; 67: 150-8

26. Davis JA, Caiozzo VJ, Lamarra N, Ellis JF, Vadagriff R, Prietto CA, McMaster WC. Does the gas exchange anaerobic threshold occur at a fixed blood lactate concentration of 2 or $4 \mathrm{mM}$ ? Int J Sports Med 1983; $4: 89-93$

27. Davis JA. Anaerobic threshold: review of the concept and directions for future research. Med Sci Sports Exerc 1985; 17: 6-18

28. Di Prampero PE, Cortili G, Mognoni P, Saibene F. Equation of motion of a cyclist. J Appl Physiol 1979; 47: 201-6

29. Farrell PA, Wilmore JH, Coyle EF, Billing JE, Costill DL. Plasma lactate accumulation and distance running performance. Med Sci Sports exerc 1979; 11: 33844

30. Föhrenbach $\boldsymbol{R}$, Mader A, Hollmann $\boldsymbol{W}$. Determination of endurance capacity and prediction of exercise intensities for training and competition in marathon runners. Int J Sports Med 8: 11-18, 1987

31. Foster C, Crowe MP, Holum D, Sandvig S, Schrager M, Snyder AC, Zajakowski S. The bloodless lactate profile. Med Sci Sports Exerc 1995; 27: 927-33

32. Galbo H. Hormonal and Metabolic Adaption to exercise. Stuttgart: G. Thieme Verlag, 1983: $76-84$

33. Gissane C, Corrigan DL, White JA. Gross efficiency responses to exercise in adult males of various ages. J Sports Sci 1991; 9(4): 383-91

34. Gladden LB. Muscle as consumer of lactate. Med Sci Sports Exerc 2000; 32 (4): 764-7I

35. Gladden LB. The role of skeletal muscle in lactate exchange during exercise: introduction. Med Sci Sports Exerc 2000; 32: 753-5

36. Green HJ, Coates $\boldsymbol{G}$ Sutton JR, Jones $\boldsymbol{S}$. Early adaptions in gas exchange, cardiac function and heamatology to prolonged exercise training in man. Eur J Appl Physiol 1991: 63 (1): 17-23 
37. Greenleaf JE, Ertl AC, Bernauer EM. Submaximal exercise $\dot{V}_{2}$ and Qc during 30-day 6 degrees head-down bed rest with isotonic and isokinetic exercise training. Aviat.Space.Enviro. Med. 1996; 67 (4): 314-9

38. Hagberg HA, Mullin JP, Nagle FJ. Oxygen consumption during constant-load exercise. J Appl Physiol 1978; 45: 381-4.

39. Hagberg JM, Hickson RC, Ehsani AA, Holloszy JO. Faster adjustment to and recovery from submaximal exercise in the trained state. J Appl Physiol 1980; 48: 21824

40. Halestrap AP, Price NT. The proton-linked monocarboxylate transporter (MCT) family: structure, function and regulation. Biochem 1999; 343: 281-99

41. Hambrecht $\boldsymbol{R}$, Niebauer J, Fiehn E, et al. Physical training in patients with stable chronic heart failure: Effects on cardiorespiratory fitness and ultrastructural abnormalities of leg muscles. J Am Coll Cardiol 1995; 25: 1239-49

42. Heck H, Mader A, Hess G, Mucke S, Muller R, Hollmann W. Justification of the 4mmol/ lactate threshold. Int J Sports Med 1985; 6: 117-30

43. Holloszy JO, Coyle EF. Adaptions of skeletal muscle to endurance exercise and their metabolic consequences. J Appl Phusiol 1984; 56: 831-8

44. Holloszy JO, Kohrt WM, Hanse PA. The regulation of carbohydrate and fat metabolism during and after exercise. Front Biosci 1998; 15: 1011-27

45. Jacobs I. Blood lactate: implications for training and sports performance. Sports Med 1986: $3: 10-25$

46. Jenkins DG, Quigley BM. Blood lactate in trained cyclists during cycle ergometry. Eur J Appl Physiol 1990; 61: 278-83

47. Jeukendrup AE, Hesselink MKC. Overtraining: what do lactate curves tell us. Br J Sports Med 1994: 28: 239-40

48. Jones $\boldsymbol{A M}$, Carter $\boldsymbol{H}$. The effect of endurance training on parameters of aerobic fitness. Sports Med 2000: 29: 373-8

49. Katz A, Sahlin K. Regulation of lactate acid production during exercise. J Appl Physiol 1988: $65: 509-18$

50. Kilmartin $\boldsymbol{J}$, Rossi-Bernardi L. Interaction of haemoglobin with hydrogen ions, carbon dioxide, and organic phosphates. Physiol Rev 1973: 53: 836-90 
51. Kindermann $\boldsymbol{K}$, Simon $\boldsymbol{G} \mathbf{K e u l} \boldsymbol{J}$. The significance of the aerobic-anaerobic transtion for the determination of work load intensities during endurance training. Eur $J$ Appl Physiol 1979: 42: 25-34

52. Kreisberg RA, Pennington LF, Boshell BR. Lactate turnover and gluconeogenesis in normal and obese humans. Diabetes 1970; 19: 53-63

53. La Fontaine TP, Londeree BR, Spath WK. The maximal steady state versus selected running events. Med Sci Sports Exerc 1981: 13: 190-2

54. Lehmann M, Berg A, Kapp R, Wessinghage T, Keul J. Correlations between laboratory testing and distance running performance in marathoners of similar performance ability. Int J Sports Med 1983; 4: 226-30

55. Lehmann M, Foster $\boldsymbol{C}$, Keul J. Overtraining in endurance athletes: a brief review: Med Sci Sports Exerc 1993; 25: 854-62

56. Londeree BR. Effects of training on lactate-ventilatory thresholds: a meta-analysis. Med Sci.Sports Exerc 1997: 29(6): 837-43

57. Mader A, Liesen H, Heck H, Philippi H, Rost $\boldsymbol{R}$, Schürch P, Hollmann W. Zur beurteilung der sportartspezifischen ausdauerleistungsfahigkeit im labor. Sportarzt Sportsmed 1976; $4: 80$

58. Maffuli $\boldsymbol{N}$, Testa $\boldsymbol{V}$, Capasso $\boldsymbol{G}$ Anaerobic threshold determination in master endurance runners. J Sports Med Phys Fitness 1994; 34: 242-9

59. McDermott JC, Bonen A. Endurance training increases skeletal muscle lactate transport. Acta Physiol Scand 1993; 147: 323-7

60. McLellan T. Ventilatory and plasma lactate response with different exercise protocols: a comparison of methods. Int J Sports Med 1985; 6: 30-5

61. Mero A, Rusko H, Peltola ESA, Pullinen T, Nummela ARI, Hirvonen J. Aerobic charasteristics, oxygen debt and blood lactate in speed endurance athletes during training. J Sports Med Phys Fitness 1993; 33: 130-6

62. Mitchell JH, Blomqvist G Maximal oxygen consumption. N Eng J Med 1972; 284 : $1018-22$

63. Miyamoto $\boldsymbol{Y}$, Niizeki $\boldsymbol{K}$. Dynamics of ventilation, circulation, and gas exchange to incremental and decremental ramp exercise. J Appl Physiol 1992; 72: 2244-54

64. Morgan DW, Daniels JT. Relationship between $\mathrm{VO}_{2}$ max and the anaerobic demand of running in elite distance runners. Int J Sports Med 1994: 15: 426-9 
65. Noakes TD. Implications of exercise testing for prediction of athletic performance: $A$ contemporary perspective. Med Sci Sports Exerc 1988; 4: 319-30

66. Norris SR, Petersen SR. Effects of endurance training on transient oxygen uptake responses in cyclists. J Sports Sci 1998; 16: 733-8

67. O'Toole ML, Douglas PS, Hiller WD. Lactate, oxygen uptake, and cycling performance in triathletes. Int J Sports Med 1989; 10: 413-8

68. Pages T, Murtra J, Ibanez J, Rama R, Callis A, Palcios L. Changes in blood ammonia and lactate levels during a triathlon race. J Sports Med Phys Fitness 1994; 34: 351-6

69. Phillips SM, Green JH, MacDonald JM, Hughson RL. Progressive effect of endurance training on $\mathrm{VO}_{2}$ kinetics at the onset of submaximal exercise. J Appl Physiol 1995; 79: 1914-20

70. Potteiger $\boldsymbol{J A}$, Weber $\boldsymbol{S} \boldsymbol{F}$. Rating and perceived exercertion and heart rate as indicators of exercise intensity in different environmental temperatures. Med Sci Sports Exerc 1994: $26: 791-6$

71. Sahlin $\boldsymbol{K}$. Intracellular $\mathrm{pH}$ and energy metabolism in skeletal muscle of man with special reference to exercise. Thesis. Acta Physiol Scan 1978; suppl 455.

72. Shepard RJ and Astrand PO. Endurance in Sports. Oxford Blackwell Scientific Publications 1992: 192.

73. Skinner JS, McLellan $\boldsymbol{T H}$. The transition from aerobic to anaerobic metabolism. Res $Q$ Exer Sport 1980; 51: 234-48

74. Snyder AC, Jeukendrup AE, Hesselink MKC, Kuipers H, Foster C. A physiological / psychological indicator of overreaching during intensive training. Int J Sports Med 1993; 14: 29-32

75. Steed J, Gaesser GA, Weltman A. Rating of perceived exertion and blood lactate concentration during submaximal running. Med Sci Sports Exerc 1994: 26: 797-803

76. Stegmann $\boldsymbol{H}, \mathbf{K i n d e r m a n n} \boldsymbol{W}, \boldsymbol{S c h n a b e l} \boldsymbol{A}$. Lactate kinetics and individual anaerobic threshold. Int J Sports Med 1981; 2: 160-5

77. Stegmann $\boldsymbol{H}, \mathbf{K i n d e r m a n n} \boldsymbol{W}$. Comparison of prolonged exercise tests at the individual anaerobic threshold and the fixed anaerobic threshold of $4 \mathrm{mmol} / \mathrm{lactate}$. Int J Sports Med 1982; 3: 105-10

78. Swain DP, Coast JR, Clifford PS, Milliken MC, Stray-Gundersen J. Influence of body size on oxygen consumption during bicycling. J Appl Physiol 1987: 62: 668-72 
79. Swain DP. Is there an optimum body size for competitive bicycling. In: Burke RE. Newson M.N.: Medical and scientific aspects of cycling: 1988; $39-46$

80. Tanaka $\boldsymbol{K}$. Lactate related factors as a critical determinant of endurance. Ann Physiol Anthrop 1990; 9: 191-202

81. Thorland W, Podolin DA, Mazzeo RS. Coincidence of lactate threshold and HR-power output threshold under varied mutritional states. Int J Sports Med 1994; 15: 301-4

82. Triveldi B, Danforth $\boldsymbol{W H}$. Effect of $\mathrm{Ph}$ on the kinetics of frog muscle phosphofructokinse. J Biol Chem 1966; 241: 4110-4

83. Trosper TL,Philipson KD. Lactate transport by cardiac sacrolemmal vesicles. Am J Physiol 1987; 252: 483-9

84. Urhausen A, Coen B, Weiler B, Kindermann $\boldsymbol{W}$. Individual anaerobic threshold and maximal lactate steady state. Int J Sports Med 1993; 14: 134-9

85. Wasserman $\mathbf{K}, \mathbf{M c l l}$ roy MB. Detecting the threshold of anaerobic metabolisme in cardiac patients during exercise. Am J Cardiol 1964; 14: 844-52

86. Wasserman K, Whipp BJ, Koyal SN, Beaver WL. Anaerobic threshold and respiratory gas exchange during exercise. J Appl Physiol 1973; 35: 236-40

87. Wasserman K. Breathing during exercise. New Engl J Med 1978; 298: 780-5

88. Wasserman $\boldsymbol{K}$, Beaver WL, Whip BJ. Mechanism and patterns of blood lactate increase during exercise in man. Med Sci Sports Exerc 1986; 18: 344-52

89. Wasserman K, Stringer WW, Casaburi R, Koike A, Cooper CB. Determination of the anaerobic threshold by gas exchange. Biochemical considerations, methodology and physiological effects. Z Kardiol 1994: 83: 1-12

90. Weltman A, Snead D, Seip R, Schurrer R, Levine S, Rutt R, Reilly T, Weltman T, Rogol A. Prediction of lactate threshold and fixed blood lactate concentrations from 3200-m running performance in male runners. Int J Sports Med 1987; 8: 401-6

91. Weltman A. The blood lactate response to exercise. Human Kinetics I995; ISBN 087322-769-7

92. Wilmore JH, Costill. DL. Physiology of sport and exercise. Human Kinetics Champaign 1994: $111: 221$

93. $\boldsymbol{X}$ u F, Rhodes EC. Oxygen uptake kinetics during exercise. Sports Med 1999; 27: $313-$ 27 
94. Yoshida T, Suda Y, Takeuchi N. Endurance training regimen based upon arterial blood lactate: effects on anaerobic threshold. Eur J App Physiol 1982; 49: 223-30

95. Yoshida T, Chida M, Ichioka M, Suda $\mathbf{Y}$. Blood lactate parameters related to aerobic capacity and endurance performance. Eur J Appl Physiol 1987; 56: 7-11

96. Yoshida T, Yamamoto $\boldsymbol{K}$, Udo $\boldsymbol{M}$. Relationship between cardiac output and oxygen uptake at the onset of exercise. Eur J Appl Physiol 1993; 66: 155-60

97. Zhang YY, Johnson MC, Chow N, Wasserman K. Effect of exercise testing protocol on parameters of aerobic function. Med Sci Sports Exerc 1991; 23: 625-30

98. Zorzano A, Fandos C, Palacin M. Role of plasma membrane transporters in muscle metabolism. Biochem J 2000; 349: 667-88 


\section{Cloapter}

\section{The plasma lactate response to exercise and endurance performance: relationships in elite triathletes.}

A.R. Hoogeveen and G. Schep

International Journal of Sports Medicine 1997; 18: 526-30

Acknowledgements: This study was supported by the Dutch Olympic Committee/ Dutch Sports Federation (NOC/NSF), the St Joseph Hospital Veldhoven, the Netherlands, and the Dutch Triathlon Association (NTB). 


\section{Summary}

The lactate response to exercise has been studied thoroughly during the last decades and it has been described using a variety of terms and definitions. Numerous investigations observed relationships between the lactate response and endurance performance. The main question in this study was which of the various lactate responses during incremental exercise described in the literature was the best indicator of endurance performance.

The plasma lactate response (PLR) was assessed during an incremental exercise test on 13 male elite triathletes (age $25.5 \pm 5.8$ years; height $179.7 \pm 5.4 \mathrm{~cm}$; body mass $71.3 \pm 4.7 \mathrm{~kg}$ ) on a bicycle ergometer. The load was started at $2.5 \mathrm{~W}_{\mathrm{kg}}{ }^{-1}$ and increased by $40 \mathrm{~W}$ every 4 $\min$.

We evaluated the following PLR-parameters: the workloads at the fixed lactate levels of $2,3,4,5,6,7$, and 8 mmol..$^{-1}$, which were assessed by extrapolation from a workload-lactateheart rate curve (P2,P3,P4,P5,P6,P7,P8 respectively), the lactate threshold which was defined as the workload at the point at which a non-linear increase of blood lactate occurred $\left(\mathrm{P}_{\mathrm{LT}}\right)$, and the workload at the lactate level that was 1 mmol. $\mathrm{I}^{-1}$ above the baseline $(\mathrm{P}+1)$. Four to seven weeks after the laboratory test, heart rate and lactate levels were assessed during a 40-km long lasting time trial on a bicycle. Two parameters were considered as indicative of endurance performance: the road-racing time (Tt), and the workload extrapolated from the workload-lactate-heart rate curve at the heart rate and lactate levels observed during the time trial $(\mathrm{Pt})$.

Only P2 showed a significant correlation with $\mathrm{Tt}(\mathrm{r}=-0.65 ; \mathrm{p}<0.05 ; \mathrm{se}=72.5 \mathrm{~s})$. Multiple regression analysis with the anthropometric parameters height and body mass as additional independent parameters did not change the predictive value. We concluded that for predicting the cycling performance of similarly well-trained subjects the predictive value of PLR is negligible. 


\section{Introduction}

The traditional parameter to describe endurance performance is the maximum oxygen uptake $(18,19)$. The usefulness of the maximum oxygen uptake $\left(\mathrm{VO}_{2} \max \right)$ as predictor of endurance performance has been questioned since numerous authors suggested that other parameters measured during submaximal exercise were better indicators of endurance performance than $\dot{\mathrm{VO}}_{2} \max (4,5,15,16)$. They suggested that particularly blood lactate response to exercise was a better indicator of endurance performance $(4,5,19,30)$. Nowadays, the lactate response to exercise is commonly accepted as a tool for predicting endurance performance and designing training programs $(6,12,23)$. It is also commonly accepted that following endurance training, a subject will have lower blood lactate levels for the same work rate in combination with an increased maximum performance (7). The lactate response has been studied thoroughly during the last decades and has been described using a variety of terms and definitions $(7,14,24,27)$.

The anaerobic threshold (AT) has been one of the most commonly used terms for describing the lactate response. AT can be defined as the highest metabolic rate or the highest exercise intensity at which blood lactate concentration is maintained at a steady state during prolonged exercise $(11,24,26,27)$. An athlete is assumed to sustain exercise intensities of around AT for a relatively long period ( $30 \mathrm{~min}$. up to 1 1/2 hour). Exercise intensity slightly above AT results in progressive lactate accumulation and the athlete is forced to stop or lower the intensity.

To determine AT, numerous concepts and definitions have been published in the last decades. Some investigators proposed a fixed lactate concentration to define and detect AT. Values of 2 mmol. $\mathrm{I}^{-1}(15,21), 3 \mathrm{mmol} . \mathrm{I}^{-1}(10)$ and $4 \mathrm{mmol}^{-\mathrm{I}^{-1}}(11,14)$ have been proposed. In order to detect and define AT, several mathematical models were introduced to analyse the lactate response during incremental exercise $(2,7,24)$.

Another commonly used term to describe the lactate response or AT is the lactate threshold (LT). LT is defined as the highest $\mathrm{VO}_{2}$ or exercise intensity that can be attained during incremental exercise before an elevation in blood lactate is observed $(23,28)$. Coyle et al. defined LT as the lactate level that was $1 \mathrm{mmol}^{-1} \mathrm{I}^{-1}$ above baseline during incremental exercise (3). In this study we evaluated the plasma lactate response to exercise (PLR) as a predictor of endurance performance in 13 male elite triathletes. The main question in this study was which of the various lactate responses described in the literature during an incremental exercise test is the best indicator of endurance performance assessed during a field test.

\section{Materials and Methods}

\section{Subjects}

Thirteen male elite triathletes volunteered to participate in this study (age $25.5 \pm 5.8$ years) after giving written informed consent. The subjects were free from serious diseases and took no drug or medication during the course of the study. On the test days no one showed any sign of disease or infection. The subjects had trained regularly for at least 4 years $(13 \pm 3.5$ years). The mean training duration was $16 \pm 3.7$ hours a week.

The mean height of the 13 subjects was $179.7 \pm 5.4 \mathrm{~cm}$, the mean body mass was $71.3 \pm 4.7$ $\mathrm{kg}$. The percentage of body fat, estimated using the measurements of four skinfolds according to Durnin and Womersley (9) was $7.8 \pm 1.1 \%$. 


\section{Testing procedure}

The measurements in the laboratory took place under the same temperature $\left(20^{\circ} \mathrm{C}\right)$ and humidity $(60 \%)$ conditions. Subjects had refrained from intensive exercise in the previous 24 hours and they were instructed to take a carbohydrate-rich meal before the testing day. The sitting position on the cycle-ergometer (Excalibur-sport, Lode, Groningen) was individually adapted for each subject to create the same position as in competition. A 12-lead ECG was made every minute. After a warming up, in which the load increased linearly to $2.5 \mathrm{~W}$ per $\mathrm{kg}$ body mass in $5 \mathrm{~min}$, the load increased by $40 \mathrm{~W}$ every $4 \mathrm{~min}$ until exhaustion. Before the test an elastic canula (Venflon, Helsingborg, Sweden) was inserted into the antecubital vein. Approximately $1 \mathrm{ml}$ of blood was taken at rest before the warming up, at the end of every period of four minutes and at maximal performance to determine lactate concentration. Before every sample, $1 \mathrm{ml}$ of blood was taken and not used for analysis. The test resulted in 6-8 samples for each subject. A workload lactate-heart rate curve was fitted to the data. The maximal workload (Wmax) was determined using the following formula:

Wmax $=$ Wstage $+(t / 240) * 40$

Wstage is the workload of the last completed stage and $t$ is the time in seconds in the final stage. The workloads at the fixed lactate levels of $2,3,4,5,6,7$, and $8 \mathrm{mmol}^{-\mathrm{I}^{-1}}$ were assessed by extrapolation from this curve (PLR parameters: P2, P3, P4, P5, P6, P7, and P8 respectively). The workload at $\mathrm{LT}\left(\mathrm{P}_{\mathrm{LT}}\right)$ was defined as the point just before the curvilinear increase in blood lactate occurred (24). According to Coyle et al. (3) the workload was also assessed at the lactate level that was 1 mmol. $\mathrm{I}^{-1}$ above the baseline $(\mathrm{P}+1)$

\section{Tìme trial}

After a period of 4 to 7 weeks following the laboratory test, the subjects were instructed to ride an individual time trial on a flat circuit of $4.05 \mathrm{~km}$ that had to be covered ten times. The subjects started at one-minute intervals. Heart rate was measured every $5 \mathrm{~s}$ with a heart rate monitor (Polar, Electro OY, Finland). The subjects were all motivated triathletes and they were experienced in riding a time trial. They were instructed by their coaches to perform maximally. Steady state was controlled by the heart rate and by timing every course run.

Before warming up, during and immediately after exercise, $1 \mathrm{ml}$ of blood was taken from the antecubital vein using a needle to determine lactate concentration. Subjects were stopped after completing five laps and detained for $150 \mathrm{~s}$ while a blood sample was obtained. Every sample was taken within $30 \mathrm{~s}$. Before every sample, $1 \mathrm{ml}$ of blood was taken and not used for analysis.

The mean heart rate was determined for the last $20 \mathrm{~min}$ of the first, and for the last $20 \mathrm{~min}$ of the second half of the time trial. The subjects were instructed not to sprint before the blood sample was taken. To be sure that the subject had not sprinted before sampling, the mean heart rate was also determined for the last two minutes, just before the blood sample was taken. On the day of the contest the temperature was $14-17^{\circ} \mathrm{C}$, humidity was $70 \%$, there was no wind and the sky was clear.

Two parameters were considered to represent endurance performance: the road-racing time (Tt), and the workload extrapolated from the workload-lactate-heart rate curve at the heart rate and lactate level during the time trial $(\mathrm{Pt})$. 


\section{Analytical methods}

All blood assays took place in the clinical laboratory of the St Joseph Hospital, Veldhoven, the Netherlands. The collection tubes for lactate contained potassium fluoride. All blood samples were kept in melting ice and were analysed within one hour. The blood samples were centrifuged immediately after submission at the laboratorium $(3000 \mathrm{rpm}, 1590 \mathrm{G}$ $20^{\circ} \mathrm{C}$ ). The plasma lactate concentration was determined using a Cobas enzymatic test kit (Boehringer, Mannheim, Germany).

\section{Statistical methods}

SPSS version 5.0 was used to analyse the data (17). Statistical comparisons between the lactate levels, the heart rates, and the speeds were made using a paired T-test. Pearson's Product Moment Correlation was used to calculate correlation coefficients.

Since level cycling performance also depends on air and rolling resistance $(8,25)$, multiple regression analyses were performed with performance as dependent variable and height, body mass and PLR parameters as independent variables. The level of significance was set at 0.05 .

\section{Results}

\section{Laboratory test}

The mean maximum and resting lactate levels are shown in Figure 1. The mean maximum heart rate was $183.5 \pm 7.9$ beats. $\min ^{-1}$. The mean maximum workload $(\mathrm{Wmax})$ and the workloads according to the different PLR definitions described in the section Material and Methods are shown in Figure 2.

\section{Time trial}

The mean road-racing time ( $\mathrm{Tt}$ ) was $3551 \pm 88 \mathrm{~s}$ (speed $41.1 \pm 1.0 \mathrm{~km} \cdot \mathrm{h}^{-1}$ ). There was no difference in the speeds during the two parts of the time trial. The standard deviation of the 10 course run times varied per subject with a range from $1.9 \mathrm{~s}$ up to $3.4 \mathrm{~s}$ indicating an almost constant speed for each subject. The mean and standard deviation of the performance parameter $\mathrm{Pt}$ is shown in Figure 2. Between $\mathrm{Pt}$ and $\mathrm{Tt}$ we observed a significant correlation $(r=-0.67 ; p<0.01)$.

The mean resting lactate level and the mean lactate level in the first part $(20 \mathrm{~km})$ of the time trial and in the second part $(40 \mathrm{~km})$ are shown in Figure 1. The difference of $0.6 \mathrm{mmol}^{-\mathrm{I}^{-1}}$ between the 2 values during the time trial was not statistically significant and they showed a significant correlation $(r=0.93 ; p<0.00001)$. The mean of the two values for plasma lactate during the time trial was $7.9 \pm 2.4$ mmol. $\mathrm{I}^{-1}$.

The mean heart rates during the first part of the time trial showed no significant difference from the second part $\left(171.3 \pm 8.6\right.$ and $170.9 \pm 7.2$ beats. $\mathrm{min}^{-1}$ respectively). The mean heart rate in the last two minutes prior to the two blood samples showed no significant difference $\left(171.4 \pm 9.3\right.$ and $171.7 \pm 7.0$ beats. $\mathrm{min}^{-1}$ respectively), nor was there a difference from the previous period. 
Figure 1

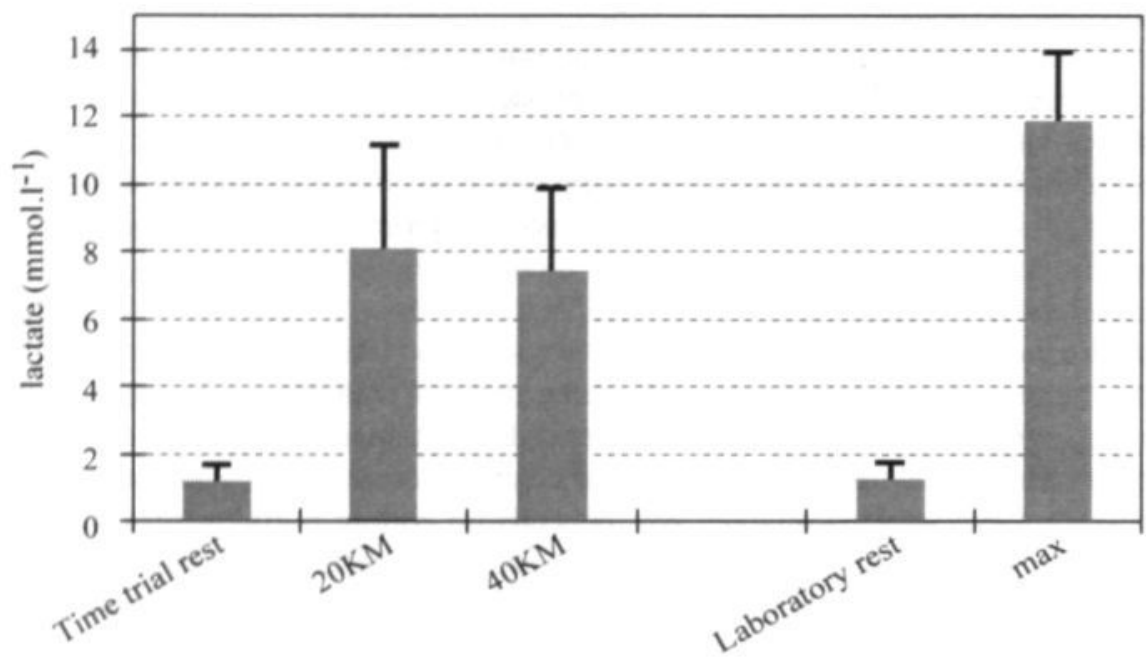

The results of the time trial: the mean resting lactate level and the mean lactate levels in the first part (20 km) and in the second part $(40 \mathrm{~km})$, and the laboratory test; the mean maximum and resting lactate levels.

\section{Figure 2}

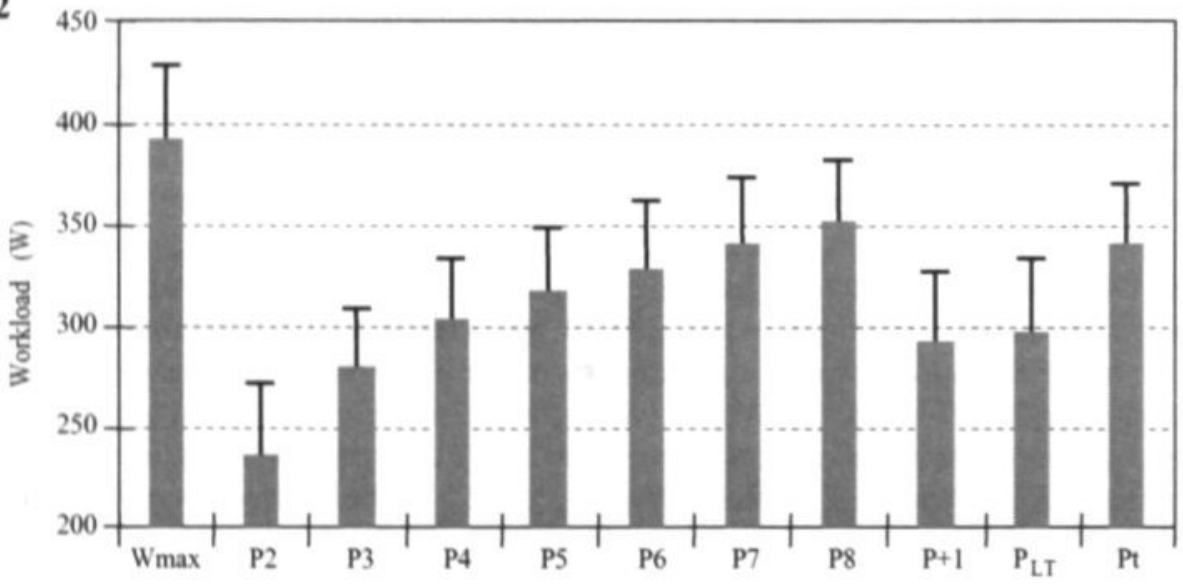

The mean maximum workload (Wmax), the workloads according to the different PLR parameters (for abbreviations see text). and the load extrapolated from the workload-lactate-heart rate curve at the mean lactate level during the time trial (Pt).

\section{Relations between laboratory parameters and performance.}

The correlations between PLR parameters and the parameters of endurance performance Pt and $\mathrm{Tt}$ are shown in Table 1. Multiple regression with Pt and $\mathrm{Tt}$ as dependent and the PLRparameters and the anthropometric parameters height and body mass as independent variables did not improve the correlations or standard errors. Multiple regression with $\mathrm{Tt}$ as dependent and $\mathrm{Wmax}$, height and body mass as independent parameters showed a significant correlation. $(r=0,81 ; p<0.05 ;$ se $62 \mathrm{~s})$. 
Relations between lactate-heart-rate curve and the lactate values and heart rates during the time trial.

There was no significant difference between the resting levels of lactate before the laboratory test and the levels before the time trial. The mean lactate level, estimated for each subject from the lactate curve at the mean heart rate during the time trial, was $7.4 \pm 2.0 \mathrm{mmol} . \mathrm{I}^{-1}$. Compared with the mean lactate levels during the time trial there was a difference of 0.5 mmol. $\mathrm{I}^{-1}$. This difference was not significant and the two levels showed a positive correlation $(r=0.91 ; p<0.001)$. There was no significant correlation between the resting levels and the maximum lactate levels in the laboratory and the lactate levels during the time trial.

\section{Table 1. The correlations between the different plasma lactate responses and the performance parameters $\mathrm{Pt}$ and $\mathrm{Tt}$. For abbreviations see text.}

\begin{tabular}{lll}
\hline & Pt & Tt \\
\hline P+1 & 0.36 & $-0,15$ \\
P & 0.37 & -0.27 \\
P2 & 0.49 & $-0.65^{*}$ \\
P3 & 0.38 & -0.37 \\
P4 & 0.38 & -0.36 \\
P5 & 0.33 & -0.34 \\
P6 & 0.36 & -0.36 \\
P7 & 0.37 & -0.38 \\
P8 & 0.38 & -0.40 \\
Wmax & 0.58 & -0.45 \\
\hline
\end{tabular}

$*=p<0.05$

\section{Discussion}

In the current study we evaluated the relationship between the plasma lactate response to exercise (PLR) and endurance performance. Main question in this study was which of the various lactate responses during incremental exercise described in the literature was the best indicator of endurance performance.

In the literature the lactate response appears to be highly correlated to various types of endurance performance $(3-6,10,15,16,30)$. The correlation in these studies varies from 0.80 up to 0.99 . However, most studies concerned runners $(10,15,16,30)$, so the results of these studies can not be easily compared with the current study.

Only few authors evaluated the lactate response assessed in a laboratory with cyclists or triathletes during a field test. Coyle et al. (5) observed a high correlation $(r=0.88 ; p<0.001)$ between the workload during a 1 hour lasting laboratory test at a constant load and a time trial of $40 \mathrm{~km}$. This workload was strongly correlated $(r=0.93 ; p<0.001)$ with the lactate threshold which was defined as the lactate level that was $1 \mathrm{mmol} . \mathrm{I}^{-1}$ above baseline during incremental exercise. However, in Coyle's study, the road-racing time of the subjects varies 
from 51 up to 65 minutes, and $\mathrm{VO}_{2}$ at the lactate threshold from 3.08 up to $4.401 . \mathrm{min}^{-1}$. As a consequence, significant correlations between the lactate response and performance are easily found, but the predictive value is limited due to a high interval of confidence. This problem also accounts for the previously mentioned correlations observed by other investigators, in which most studies concerned moderately trained subjects $(3,10,19)$, or subjects with a significant difference in performance $(4,5,10,19)$. O'Toole et al. (20) observed no significant correlation between the $\mathrm{VO}_{2}$ at the lactate threshold (according to Coyle; see above) and the cycling time during an ultra triathlon $(180 \mathrm{~km})$. The results of this study are also not comparable with the current study since the duration of the field test was significant longer.

In the current study, only P2 showed a slight correlation with Tt. The predictive value of this correlation is limited $(90 \%$ interval of confidence $= \pm 130 \mathrm{~s})$. Multiple regression analyses with the anthropometric parameters as additional independent variables did not change the predictable value of the different PLR parameters. Although multiple regression with height and body mass as additional independent parameters showed a significant correlation for Wmax, the predictive value of this regression equation value is also limited. ( $90 \%$ interval of confidence $= \pm 114 \mathrm{~s}$ ). The data suggest that in similarly well-trained subjects, endurance performance is not predictable from PLR or Wmax.

An additional important observation in the current study was that the mean lactate level during the time trial was $7.9 \pm 2.4 \mathrm{mmol}^{-\mathrm{I}^{-1}}$. The large level of individual variability is conspicuous (range $4.5-12.2 \mathrm{mmol}^{\mathrm{l}} \mathrm{I}^{-1}$ ). Since the heart rate and the course-run times remained almost constant during the time trial, we considered that the intensity remained at a steady state. Three subjects maintained plasma lactate levels which exceeded 10 mmol. $\mathrm{I}^{-1}$ or more for almost 1 hour. These values exceeded all previous data from other investigators and the levels are significantly higher than the PLR parameters commonly used for predicting a steady-state intensity. The individual variability will complicate every attempt to predict endurance performance and design training programs from a single lactate curve. Coyle et al. (5) observed lactate values of $7.2 \pm 0.7 \mathrm{mmol}^{-1} \mathrm{I}^{-1}$ in 15 elite cyclists during a laboratory test with a constant workload. However, these values are not quite comparable with our data since the standard deviation is significantly lower. Furthermore, the initial workload in Coyle's study was altered during this test. The initial workload was started at the lactate threshold, defined according to Coyle's definition (see above). It is remarkable that the authors did not explain the difference between the lactate level at Coyle's lactate threshold and the lactate levels during the constant workload test.

It should be considered that the lactate concentration in the current study was assessed in plasma while in some of the above mentioned studies lactate was assessed in whole blood $(4,5,6,10,20)$. Since it is known that there are differences in the lactate concentrations of whole blood and plasma (29), this may have influenced the comparison with the data of other studies. However, the resting values, the maximum levels and the plasma lactate values at $\mathrm{P}+1$ and $\mathrm{P}_{\mathrm{LT}}$ in the current study are comparable with the studies which assessed lactate concentration in whole blood $(2,5,23,26)$, so a significant error may be excluded.

When we compare laboratory findings with field tests we have to consider that environmental factors like temperature and humidity may influence the results (1). For example, the temperature in the laboratory was $20^{\circ} \mathrm{C}$ while outdoor temperature was $14-17^{\circ} \mathrm{C}$. This difference may have affected the comparison of heart rates during the time trial and the incremental exercise test and this can explain the difference between the 
calculated lactate levels and the measured lactate concentration during the time trial. However, this difference was not significant and both variables showed a significant correlation, so the data of our study may be valid.

Summarising, we have observed in similarly well-trained triathletes that endurance performance is not significantly related to PLR. Although measurements of lactate may be useful to indicate early overtraining $(13,22)$ and the monitoring of training effects, the role of PLR as parameter of endurance performance is questionable.

\section{References}

1. Beelen A, Sargeant AJ. Effect of lowered muscle temperature on the physiological response to exercise in men. Eur J Appl Physiol 1994: 63: 87-392

2. Billat V, Dalmay $\boldsymbol{F}$, Antonioni MT, Chaussain AP. A method for determining the maximal steady state of blood lactate concentration from two levels of submaximal exercise. Eur J Appl Physiol 1994; 69: 196-202

3. Coyle EF, Martin WH, Ehsani AA, Hagberg JM, Bloomfield SA, Sinacore DR, Holloszy JO. Blood lactate threshold in some well-trained ischaemic heart disease patients. J Appl Physiol 1983; 54: 18-23

4. Coyle EF, Coggan AR, Hopper MK, Walters TJ. Determinants of endurance in welltrained cyclists. J Appl Physiol 1988; 64: 2622-30

5. Coyle EF, Feltner ME, Kautz S, Hamilton MT, Montain SJ, Baylor AM, Abraham ID, Petrek GW. Physiological and biomechanical factors associated with elite endurance cycling performance. Med Sci Sports Exerc 1990; 23: 93-107

6. Craig NP, Norton KI, Bourdon PC, Woolford SM, Stanef T, Squires B, Olds TS, Conyers RAJ, Walsh CBV. Aerobic and anaerobic indices contributing to track endurance cycling performance. Eur J Appl Physiol 1993; 67: 150-8

7. Davis JA. Anaerobic threshold: review of the concept and directions for future research. Med Sci Sports Exerc 1985; 17: 6-18

8. Di Prampero PE, Cortili G, Mognoni P, Saibene F. Equation of motion of a cyclist. J Appl Physiol 1979: 47: 201-6

9. Durnin JVGA, Womersly J. Body fat assessed from total body density and its estimation from skinfold thickness: measurements on 481 men and women from 16 to 72 years. $\mathrm{Br}$ J of Nutr 1974: 32: 77-97

10. Föhrenbach $\boldsymbol{R}$, Mader A, Hollmann W. Determination of endurance capacity and prediction of exercise intensities for training and competition in marathon runners. Int J Sports Med 8; 11-8: 1987. 
11. Heck H, Mader A, Hess G, Mucke S, Muller R, Hollmann W. Justification of the 4mmol/l lactate threshold. Int J Sports Med 1985; 6: 117-30

12. Jacobs I. Blood lactate: implications for training and sports performance. Sports Med 1986; $3: 10-25$

13. Jeukendrup AE, Hesselink MKC. Overtraining: what do lactate curves tell us. Br J Sports Med 1994; 28: 239-40

14. Kindermann $\boldsymbol{K}$, Simon $\boldsymbol{G}, \mathbf{K e u l} \boldsymbol{J}$. The significance of the aerobic-anaerobic transition for the determination of work load intensities during endurance training. Eur J Appl Physiol 1979; 42: 25-34

15. La Fontaine TP, Londeree BR, Spath WK. The maximal steady state versus selected running events. Med Sci Sports Exerc 1981; 13: 190-2

16. Lehmann M, Berg A, Kapp R, Wessinghage T, Keul J. Correlations between laboratory testing and distance running performance in marathoners of similar performance ability. Int J Sports Med 1983; 4: 226-30

17. Marija J. Norusis/SPSS/PC+version 5.0, SPSS inc: Chigaco, 1992.

18. Mitchell JH, Blomqvist $\boldsymbol{G}$ Maximal oxygen consumption. N Eng J Med 1972; 284: $1018-22$

19. Noakes TD. Implications of exercise testing for prediction of athletic performance: $A$ contemporary perspective. Med Sci Sports Exerc 1988; 4: 319-30

20. O'Toole ML, Douglas PS, Hiller WD. Lactate, oxygen uptake, and cycling performance in triathletes. Int J Sports Med 1989: 10: 413-8

21. Skinner JS, McLellan $\boldsymbol{T H}$. The transition from aerobic to anaerobic metabolism. Res $Q$ Exer Sport 1980; 51: 234-48

22. Snyder AC, Jeukendrup AE, Hesselink MKC, Kuipers H, Foster C. A physiological / psychological indicator of overreaching during intensive training. Int J Sports Med 1993: 14: $29-32$

23. Steed J, Gaesser GA, Weltman A. Rating of perceived exertion and blood lactate concentration during submaximal running. Med Sci Sports Exerc 1994: 26: 797-803

24. Stegmann $\boldsymbol{H}, \mathbf{K i n d e r m a n n} \boldsymbol{W}, \boldsymbol{S c h n a b e l}$ A. Lactate kinetics and individual anaerobic threshold. Int J Sports Med 1981; 2: 160-5

25. Swain DP, Coast JR, Clifford PS, Milliken MC, Stray-Gundersen J. Influence of body size on oxygen consumption during bicycling. J Appl Physiol 1987: 62: 668-72 
26. Urhausen A, Coen B, Weiler B, Kindermann $\boldsymbol{W}$. Individual anaerobic threshold and maximal lactate steady state. Int J Sports Med 1993; 14: 134-9

27. Wasserman $\boldsymbol{K}$, Mcllroy MB. Detecting the threshold of anaerobic metabolism in cardiac patients during exercise. Am J Cardiol 1964; 14: 844-52

28. Wasserman $\boldsymbol{K}$, Beaver WL, Whip BJ. Mechanism and patterns of blood lactate increase during exercise in man. Med Sci Sports Exerc 1986; 18: 344-52

29. Williams JR, Amstrong N, Kirby BJ. The influence of the site of sampling and assay medium upon the measurements and interpretation of blood lactate responses to exercise. J Sports Sci 1992; 10: 95-107

30. Yoshida T, Chida M, Ichioka M, Suda $\boldsymbol{Y}$. Blood lactate parameters related to aerobic capacity and endurance performance. Eur J Appl Physiol 1987; 56: 7-11 


\section{Chaptere}

The maximal lactate steady state in elite endurance athletes.

A.R. Hoogeveen, J. Hoogsteen, and G. Schep

Japanese Journal of Physiology 1997; 47: 481-5

Acknowledgements: This study was supported by the Dutch Olympic Committee/ Dutch Sports Federation (NOC/NSF), the St Joseph Hospital Veldhoven, the Netherlands, the Dutch Triathlon Association (NTB) and the Royal Dutch Cycling Association (KNWU). 


\section{Summary}

The upper limit of blood lactate resulting in a lactate steady state during prolonged exercise is called the maximal lactate steady state (MaxLaSS). The purpose of this study was to investigate the lactate response to steady-state exercise during a field test in elite endurance athletes. Plasma lactate levels were assessed in 13 elite triathletes and 13 elite cyclists (mean \pm sd; age $23.7 \pm 5.1$ years; height $180.2 \pm 6.3 \mathrm{~cm}$; body mass $70.3 \pm 5.9 \mathrm{~kg} ; \mathrm{VO}_{2} \max 68 \pm$ $3.7 \mathrm{ml} \cdot \mathrm{min}^{-1} \cdot \mathrm{kg}^{-1}$ ) during a $40 \mathrm{~km}$-long lasting time trial on a bicycle (10 times $\left.4 \mathrm{~km}\right)$. Steady state was demonstrated by monitoring the heart rate and by timing every course run. The lactate levels were expected to correspond to MaxLaSS. The mean level of lactate during the time trial was $7.4 \pm 2.5$ mmol..$^{-1}$. Five athletes maintained plasma lactate levels, which exceeded $10 \mathrm{mmol}^{-1} \mathrm{I}^{-1}$ or more for almost 1 hour. The large level of individual variability was conspicuous (range $3.2-12.2 \mathrm{mmol}^{-\mathrm{I}^{-1}}$ ). These values exceeded all previous reported levels for MaxLaSS from other investigators. Our observations are important in sport medical practice since the different lactate responses to exercise are used as parameters in training management. 


\section{Introduction}

The upper limit of blood lactate resulting in a lactate steady state during constant workload is called the maximal lactate steady state (MLSS or MaxLaSS). The determination of MaxLaSS requires the performance of several constant workloads on different days (3). MaxLaSS is expected to correspond to the anaerobic threshold (AT) which reflects the transition of aerobic to anaerobic conditions $(10,25)$. An athlete is assumed to sustain exercise intensities of around AT and MaxLaSS for a relatively long period of time ( $20 \mathrm{~min}$ up to $11 / 2$ hour). The lactate level during steady-state exercise is assumed to be within defined values. Some investigators proposed a fixed lactate concentration of 4 mmol. $\mathrm{I}^{-1}$ (10). In an attempt to define AT, some investigators described an individual anaerobic threshold (IAT) $(3,9)$ and a lactate threshold $(\mathrm{LT})(8,26)$. The average lactate concentration at AT, LT or IAT in these studies varies from $1.7 \pm 0.3$ (9) to $4.2 \pm 0.8 \mathrm{mmol}^{-\mathrm{I}^{-1}}$ (3). It is remarkable that only very few investigators compared these laboratory data with the values assessed during a practical situation in a field test $(2,19)$. However, these studies concerned moderately-trained subjects. In addition lactate in these studies was assessed only post exercise, and steady state was not controlled. Therefore in this study we determined the lactate steady-state level in elite endurance athletes during a field test. The main question was whether the plasma lactate concentration during steady-state exercise in elite endurance athletes corresponded with the limited levels of lactate observed by numerous investigators in a laboratory setting.

\section{Materials and methods}

\section{Subjects}

Thirteen elite triathletes and 13 elite cyclists (mean \pm sd; age $23.7 \pm 5.1$ years; height 180.2 $\pm 6.3 \mathrm{~cm}$; body mass $70.3 \pm 5.9 \mathrm{~kg}$ ) volunteered to participate in this experiment after giving written informed consent. The mean $\mathrm{VO}_{2} \max$, determined 4 weeks before the time trial during an incremental exercise $\left(20 \mathrm{~W} \cdot \mathrm{min}^{-1}\right)$ on a cycle ergometer, was $68 \pm 3.7 \mathrm{ml} \cdot \mathrm{min}^{-1} \cdot \mathrm{kg}^{-1}$. The 26 subjects were free from serious diseases and took no drug or medication during the course of the study. On the test days no one showed any sign of disease or infection. The 26 subjects had trained regularly for at least 4 years $(10 \pm 3$ years). The mean training duration was $14 \pm 4.2$ hours a week. The percentage of body fat, estimated using the measurements of four skinfolds according to Durnin and Womersley (10) was $8.1 \pm 3.3$.

\section{Field test}

After a period of 4 weeks following the laboratory tests the subjects were instructed to ride an individual time trial on a flat circuit of $4.05 \mathrm{~km}$ which had to be covered ten times. On the day of the triathletes contest, the temperature was $14-17^{\circ} \mathrm{C}$, humidity was $70 \%$, there was no wind and the sky was clear. On the day of the cyclists contest, the temperature was 15 $18^{\circ} \mathrm{C}$, humidity was $40 \%$, there was no wind and the sky was clear. The subjects had refrained from intensive exercise in the previous 24 hours and they were instructed to take a carbohydrate-rich meal before the day of the time trial. The subjects started at one-minute intervals. Heart rate was measured every 5 seconds with a heart rate monitor (Polar, Electro OY, Finland). Steady state was demonstrated by the heart rate and by timing every course run. 


\section{Chapter 3}

Before warming up, during and immediately after exercise, $1 \mathrm{ml}$ of blood was taken from the antecubital vein with a needle to determine lactate concentration. Subjects were stopped after completing five laps and detained for 150 seconds while a blood sample was obtained. Every sample was obtained within 30 seconds.

The mean heart rate was determined for the last 20 minutes of the first and second half of the time trial. The subjects were instructed not to sprint before the sample was taken. To be sure that the subject had not sprinted before sampling, the mean heart rate was also computed for the last two minutes just before sampling.

\section{Analytical methods}

The collection tubes for lactate contained potassium fluoride. Plasma lactate concentration was determined using a Cobas enzymatic test kit (Boehringer, Mannheim, Germany). All blood samples were kept in melting ice and were centrifuged $\left(3,000 \mathrm{rpm}, 1590 \mathrm{G}, 20^{\circ} \mathrm{C}\right)$ and analysed within one hour.

\section{Statistical methods}

The mean lactate levels and mean heart rates in the first part of the time trial were compared with those in the second part using a paired t-test. Pearson's Product Moment Correlation was used to calculate correlation coefficients. The level of significance was set at 0.05 .

\section{Results}

The mean speed was $41.3 \pm 1.0 \mathrm{~km} \cdot \mathrm{h}^{-1}$ and $41.5 \pm 1.0 \mathrm{~km} \cdot \mathrm{h}^{-1}$ respectively during the two parts of the time trial. According to the course run times of each individual, all subjects performed at nearly constant exercise intensity. The standard deviation of the 10 course run times varied per subject with a range of $1.9 \mathrm{~s}$ up to $2.9 \mathrm{~s}$.

The mean resting lactate level was $1.4 \pm 0.4 \mathrm{mmol} . \mathrm{l}^{-1}$ and the mean lactate level of the 2 samples during the time trial was $7.4 \pm 2.5 \mathrm{mmol}^{-\mathrm{I}^{-1}}$ (Figure 1). The mean lactate concentrati-

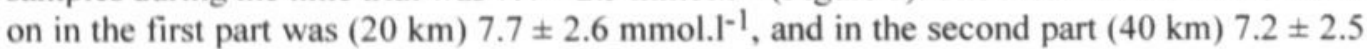
mmol. $\mathrm{I}^{-1}$. The difference of $0.5 \mathrm{mmol}^{-\mathrm{I}^{-1}}$ between the two lactate values during the time trial was not statistically significant and they showed a significant correlation $(\mathrm{r}=0.89$, $\mathrm{p}<0.00001$ ).

The mean heart rate during the first and second part showed no significant difference (173.7 \pm 7.1 and $174.3 \pm 8.1$ respectively). The mean heart rate in the last two minutes before the two blood samples showed no significant difference, nor was there a difference between the previous periods ( $173.4 \pm 7.6$ and $174.2 \pm 7.4$ respectively).

There was no significant difference between cyclists and triathletes considering height, body mass, percentage of body fat, and speeds during the time trial. Considering the lactate levels at rest and during the time trial, there was no significant difference between triathletes and cyclists. The heart rates during the time trial did not show significant differences between the 2 groups. We observed no correlation between anthropometrics, speed, resting levels of lactate, and the lactate levels during the time trial. 
Figure 1

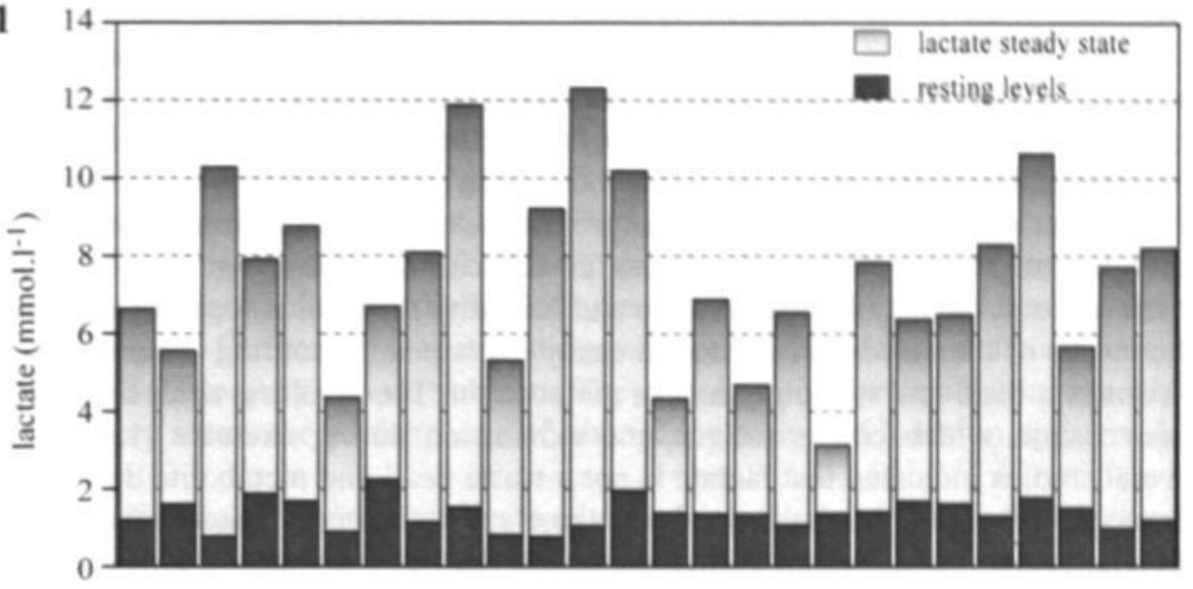

The resting levels of lactate and the mean of the no levels during the time trial.

\section{Discussion}

The most important observation in this study was that the mean plasma lactate level during steady-state exercise was extremely high. The large level of individual variability was conspicuous (range $3.2-12.2 \mathrm{mmol}^{-1} \mathrm{I}^{-1}$ ). Three triathletes and two cyclists maintained plasma levels which exceeded $10 \mathrm{mmol}^{-\mathrm{I}^{-1}}$ or more for almost 1 hour. These values exceeded all previous lactate levels at AT, LT, IAT and MaxLaSS observed in a laboratory $(3,9,12,18,19,21,22)$. Since it is known that there are differences in the lactate concentration of whole blood and plasma, this may have influenced the comparison with other studies (27). However, in the studies we compared, lactate was assessed in plasma $(12,18,21,22)$ as well as in whole blood $(9,14,19)$. In addition, it would be theoretically possible that some subjects did not reach their maximal steady state during the time trial for psychological reasons. This possibility makes our data even more remarkable.

The time trial in the current study is considered to be a steady-state exercise since the course run time and the heart rate remained constant during the whole time trial. Since all subjects were experienced cyclists to ride a time trial at maximal steady-state intensity, the measured lactate values during the time trial should approximate MaxLaSS.

Only a few investigators described lactate levels assessed during a field test. Beneke et al. (2) reported blood lactate levels of $4-6.5$ mmol..$^{-1}$ in well-trained speed skaters. Pages et al. (19) described lactate values of $4.95 \pm 0.5 \mathrm{mmol}^{-1} \mathrm{I}^{-1}$ in 7 triathletes during a triathlon race, which is considerably lower than our observations. However these triathletes were only moderately trained and the duration of the total triathlon had an average of 2.50 hours, so these lactate values can not be considered as maximal steady-state values.

Several authors evaluated the lactate response to steady-state exercise in a laboratory. In 8 elite cyclists, Jenkins et al. (14) observed a mean lactate concentration of $8.9 \pm 1.6$ mmol.1${ }^{1}$ on a cycle ergometer during 30 minutes exercise. However, in 6 subjects the workload used in this experiment was decreased during the test when the initial workload could not be maintained. For this reason, these lactate values can not be interpreted as steady-state values, but these observations were an indication that endurance-trained cyclists can tolerate high 


\section{Chapter 3}

blood lactate levels for at least 30 minutes. Coyle et al. (8) observed lactate values of $7.2 \pm$ 0.7 mmol. $\mathrm{I}^{-1}$ in 15 elite cyclists during a laboratory test with a constant workload. However, the lactate values of Coyle et al. (8) are not quite comparable with our data since the standard deviation is significantly lower than ours. Furthermore, the initial workload in Coyle's study was altered during this test.

The current study was a field test study. When we compare laboratory observations from other investigators with the field test in the current study, we have to consider that environmental factors like temperature and humidity may influence the comparison (1).

The results of the current study are not easily explained. According to many authors, lactate is seen as a dead-end waste product of metabolism. The resulting acidosis is viewed as the major factor, which causes fatigue and exhaustion during exercise $(1,10,25)$. However, several studies indicated that lactate is not a waste dead-end metabolite during exercise and recovery $(5,6)$. In contrast, the results of these studies strongly suggest that lactate plays an important role in metabolism during exercise $(5,6)$. Lactate which is produced in areas with a high glycogenolytic and glycolytic activity (type Ilb fibres) is oxidised in areas with a high oxidative activity (type I and IIa fibres). Brooks et al. called this phenomenon the lactate shuttle (6). Lactate reaches the oxidative areas by diffusion (24) or by the circulation. The lactate levels during steady state exercise are the result of the production and elimination of lactate (4), so these levels do not reflect the net turnover of lactate. A second function of lactate is maintaining levels of blood glucose as a precursor of liver gluconeogenesis (4). The glycogen synthesis in the liver is lowered during exercise by a decreased perfusion. In addition, during exercise glucagon levels increase and insulin levels decrease, resulting in an inhibiting effect on glycogen synthesis in the liver (13).

The role of lactate as an acid is still a controversial issue. Acidosis is assumed to inhibit ATP regeneration $(1,23)$. There have been indications that acidosis inhibits the enzyme phosphofructokinase which is involved in the glycolysis (23). However, plasma lactate levels does not reflect intracellular acidosis which can be regulated by lactate efflux out of the cell and by several buffering mechanisms $(7,16)$. In addition, another consequence of acidosis is a shift of the oxyhaemoglobin dissociation curve to the right allowing oxygen to unload from haemoglobin (16). Furthermore the decreasing extracellular $\mathrm{pH}$ results in a vasodilatation of the vascular bed in the contracting muscle (16). As a result, both phenomena allow an increasing amount of oxygen to the tissues and a better endurance performance. So it may be favourable to have high levels of lactate in combination with a high intracellular buffer capacity.

The physiological explanation for the accumulation of lactate during exercise is also still not elucidated (10). To explain this phenomenon, local hypoxia, increasing recruitment of type II-fibres and a shift in the pyruvate-lactate balance has been described (10).

This study proved that endurance-trained athletes could maintain extremely high levels of lactate during steady-state endurance exercise. Our data suggest an individual lactate tolerance with a great individual variation. Of course, high levels of lactate during steady-state exercise do not prove that lactate plays a positive role but the high values of plasma lactate concentration in this study certainly do not support a negative role. We hypothesised that high levels of lactate during exercise may be necessary to provide a concentration gradient for some tissues to maintain the higher metabolic demand (for example the heart and the contracting muscles). This hypothesis may be supported by recent studies in which measurements of lactate concentrations may be very useful to indicate early overtraining 
$(15,21)$ : low submaximum and maximum lactate levels are believed to be indicators of overtraining, which is associated with a decreased performance.

In our opinion, the results of the present study are in contradiction with those of previous investigators and the different definitions of the lactate response to exercise. According to these definitions and observations the lactate concentration during steady-state exercise is expected to be within defined levels (ref. see introduction). Therefore it must be concluded that these definitions may be not valid for a practical situation. This may be caused by the fact that in most studies the different definitions were based upon empiricism and different scientific backgrounds. Furthermore most studies were not evaluated for a practical situation or were concerned moderately-trained subjects. The only way to approach the lactate steady state in a laboratory seems the performance of several constant workloads on different days (3).

Summarising, endurance athletes can tolerate extreme high levels of lactate during steadystate exercise. We hypothesised that lactate may not be a waste product but a major metabolite during steady-state exercise. It is possible, and it may be favourable and even necessary, for an athlete to have high levels of lactate during steady-state exercise. This view is very important in sport medical practice since the lactate response has been accepted as a measure of endurance capacity $(26,28)$. Our data strongly suggest that the practical usefulness of these parameters is less significant than has been assumed.

\section{References}

1. Beelen A, Sargeant AJ. Effect of lowered muscle temperature on the physiological response to exercise in men. Eur J Appl Physiol 1991; 63: 387-92

2. Beneke $\boldsymbol{R}$, Boldte $\boldsymbol{F}$, Meller $\boldsymbol{W}$, Behn $\boldsymbol{C}$. Das maximale laktate-steady state (MaxLass) im eisschnellauf. Leistungsdiagnostik 1991; 10: 766-7

3. Beneke $\boldsymbol{R}$. Anaerobic threshold, individual anaerobic threshold, and maximal lactate steady state in rowing. Med Sci Sports Exerc 1995; 27: 863-7

4. Brooks GA, Gaesser GA. End points of lactate and glucose metabolism after exhausting exercise. J Appl Physiol 1980; 49: 1057-69

5. Brooks GA. Anaerobic threshold: review of the concept and directions for future research. Med Sci Sports Exerc 1985; 17: 22-31

6. Brooks GA. The lactate shuttle during exercise and recovery. Med Sci Sports Exerc 1986; $18: 360-8$

7. Brooks GA. Current concepts in lactate exchange. Med Sci Sports Exerc 1991; 23: 895906 
8. Coyle EF, Feltner ME, Kautz S, Hamilton MT, Montain SJ, Baylor AM, Abraham ID, Petrek GW. Physiological and biomechanical factors associated with elite endurance cycling performance. Med Sci Sports Exerc 1990; 23: 93-107

9. Davis JA, Caiozzo VJ, Lamarra N, Ellis JF, Vadagriff R, Prietto CA, McMaster WC. Does the gas exchange anaerobic threshold occur at a fixed blood lactate concentration of 2 or $4 \mathrm{mM}$ ? Int J Sports Med 1983; 4: 89-93

10. Davis JA. Anaerobic threshold : review of the concept and directions for future research. Med Sci Sports Exerc 1985; 17: 6-18

11. Durnin JVGA, Womersly J. Body fat assessed from total body density and its estimation from skinfold thickness: measurements on 481 men and women from 16 to 72 years. $\mathrm{Br}$ J Nutr 1974; 32: 77-97

12. Farrell PA, Wilmore JH, Coyle EF, Billing JE, Costill DL. Plasma lactate accumulation and distance running performance. Med Sci Sports exerc 1979; 11: 33844

13. Galbo H. Hormonal and Metabolic Adaption to exercise. Stuttgart: G. Thieme Verlag, 1983: 76-84

14. Jenkins DG, Quigley BM. Blood lactate in trained cyclists during cycle ergometry. Eur J Appl Physiol 1990; 61: 278-83

15. Jeukendrup AE, Hesselink MC. Overtraining: what do lactate curves tell us. Br J Sports Med 1994: 28: 239-40

16. Kilmartin $\boldsymbol{J V}$, Rossi-Bernardi L. Interaction of haemoglobin with hydrogen ions, carbon dioxide, and organic phosphates. Physiol Rev 1973; 53: 836-90

17. Kreisberg RA, Pennington LF, Boshell BR. Lactate turnover and gluconeogenesis in normal and obese humans. Diabetes 1970; 19: 53-63

18. Lehmann M, Berg A, Kapp R, Wessinghage T, Keul J. Correlations between laboratory testing and distance running performance in marathoners of similar performance ability. Int J Sports Med 1983; 4: 226-30

19. Pages T, Murtra J, Ibanez J, Rama R, Callis A, Palcios L. Changes in blood ammonia and lactate levels during a triathlon race. J Sports Med Phys Fitness 1994: 34: 351-6

20. Snyder AC, Jeukendrup AE, Hesselink MKC, Kuipers H, Foster C. A physiological psychological indicator of overreaching during intensive training. Int J Sports Med 1993: 14: 29-32 
21. Tanaka $\boldsymbol{K}$. Lactate related factors as a critical determinant of endurance. Ann Physiol Anthrop 1990; 9: 191-202

22. Thorland W, Podolin DA, Mazzeo RS. Coincidence of lactate threshold and HR-power output threshold under varied mutritional states. Int J Sports Med 1994; 15: 301-4

23. Triveldi B, Danforth $\boldsymbol{W H}$. Effect of $\mathrm{Ph}$ on the kinetics of frog muscle phosphofructokinse. J Biol Chem 1966; 241: 4110-4

24. Trosper TL,Philipson KD. Lactate transport by cardiac sacrolemmal vesicles. Am J Physiol 1987; 252: 483-9

25. Wasserman $\boldsymbol{K}$, Mcllroy MB. Detecting the threshold of anaerobic metabolism in cardiac patients during exercise. Am J Cardiol 1964: 14: 844-52

26. Weltman A, Snead D, Seip R, Schurrer R, Levine S, Rutt R, Reilly T, Weltman T, Rogol A. Prediction of lactate threshold and fixed blood lactate concentrations from 3200-m running performance in male runners. Int J Sports Med 1987; 8: 401-6

27. Williams JR, Armstrong N, Kirby BJ. The influence of the site of sampling and assay medium upon the measurements and interpretation of blood lactate responses to exercise. J Sports Sci 1992; 10: 95-107

28. Yoshida T, Suda $\mathbf{Y}$, Takeuchi $\mathbf{N}$. Endurance training regimen based upon arterial blood lactate: effects on anaerobic threshold. Eur J App Physiol 1982; 49: 223-30 



\section{Chapter}

The ventilatory threshold, heart rate, and endurance performance: relationships in elite cyclists.

A.R. Hoogeveen, G. Schep, and J. Hoogsteen

International Journal of Sports Medicine 1999; 20: 114-7

Acknowledgements: This study was supported by the St Joseph Hospital Veldhoven, the Netherlands, the Dutch Olympic Committee/ Dutch Sport Federation (NOC/NSF), and the Royal Dutch Cycling Association (KNWU). 


\section{Summary}

The purpose of this study was to investigate the validity of the ventilatory response during incremental exercise as indicator of endurance performance during prolonged high-intensity exercise under field test conditions in elite cyclists.

The ventilatory threshold (VT) was assessed in 14 male elite cyclists (age $22.4 \pm 3.4$ years, height $181 \pm 6 \mathrm{~cm}$, body mass $\left.69.2 \pm 6.8 \mathrm{~kg}, \mathrm{VO}_{2} \max 69 \pm 7 \mathrm{ml} \cdot \mathrm{min}^{-1} \cdot \mathrm{kg}^{-1}\right)$ during an incremental exercise test $\left(20 \mathrm{~W} \cdot \mathrm{min}^{-1}\right)$. Heart rate and oxygen uptake were assessed at the following ventilatory parameters: 1 . Steeper increase of $\mathrm{VCO}_{2}$ as compared to $\mathrm{VO}_{2}$ (V-slope method); 2 . Respiratory exchange ratio $(\mathrm{RQ})=0.95$ and $1.00 ; 3 . \dot{\mathrm{VE}} / \mathrm{VO}_{2}$ increase without a concomitant $\mathrm{VE} / \mathrm{VCO}_{2}$ increase $\left(\mathrm{V} E / \mathrm{VO}_{2}\right.$ method). Three weeks following the laboratory tests, the ability to maintain high-intensity exercise was determined during a $40 \mathrm{~km}$ time trial on a bicycle. During this time trial the mean heart rate $\left(\mathrm{HR}_{\mathrm{TT}}\right)$ and the road-racing time (TT) were assessed.

The V-slope method and the $\mathrm{VE} / \mathrm{VO}_{2}$ method showed significant correlations with TT (Vslope: $\mathrm{r}=-0.82 ; \mathrm{p}<0.001 ; 90 \%$ interval of confidence $= \pm 82 \mathrm{sec} ; \mathrm{VE} / \mathrm{VO}_{2}: \mathrm{r}=-0.81 ; \mathrm{p}<0.01$; $90 \%$ interval of confidence $= \pm 81 \mathrm{sec}$ ). Heart rate at the ventilatory parameters and at the maximum heart rate $\left(\mathrm{HR}_{\max }\right)$ showed significant correlations with $\mathrm{HR}_{\mathrm{TT}}$. The V-slope method is the preferred method to predict heart rate during prolonged high-intensity exercise ( $r=0.93 ; p<0.0001 ; 90 \%$ interval of confidence: \pm 4.8 beats. $\mathrm{min}^{-1}$ ). For predicting heart rate during prolonged high-intensity exercise using an incremental exercise test $\left(20 \mathrm{~W} \cdot \mathrm{min}^{-1}\right)$, without assessment of ventilatory parameters, we recommend to use the regression formula: $\mathrm{HR}_{\mathrm{TT}}=0.84 . \mathrm{HR}_{\max }+14.3$ beats.min ${ }^{-1} \quad(\mathrm{r}=0.85 ; \mathrm{p}<0.001)$. 


\section{Introduction}

The anaerobic threshold has been studied thoroughly during the past decades and it has been described using a variety of confusing terms and definitions $(6,20)$. Since the introduction of the term anaerobic threshold (AT) in 1964 (20), AT was associated with an increased blood lactate concentration, an increased ventilation, an increased $\mathrm{CO}_{2}$ excretion and a decreasing bicarbonate concentration. It was suggested that these phenomena reflected a shift from aerobic to anaerobic metabolism $(6,20,23)$. A common definition of AT is the highest metabolic rate (or the highest exercise intensity or the highest oxygen uptake) at which blood lactate concentration is maintained at a steady state during prolonged exercise $(9,13,16,19,20)$. AT, and in particular the heart rate (HR) and the exercise intensity at AT, has been described as a key parameter that defines the ability to maintain high-intensity exercise in $(5,11,23,25)$. AT has been commonly accepted as a tool for predicting endurance performance and designing training programs $(23,24)$.

Several ventilatory thresholds (VT) have been described based on different ventilatory parameters during incremental exercise tests. These ventilatory thresholds (VT) were expected to correspond with AT. Initially, it was suggested that departures in the linearity of the ventilation ( $\dot{\mathrm{VE}})$, and the carbon dioxide output $\left(\mathrm{VCO}_{2}\right)$ plus an abrupt increase in the gas exchange ratio (RQ or RER) could be used as markers for the onset of a metabolic acidosis $(6,21)$. Later the criterion was a systematic increase in the ventilatory equivalent for $\dot{\mathrm{VO}}_{2}\left(\dot{\mathrm{VE}} / \mathrm{VO}_{2}\right)$ without a concomitant increase in $\dot{\mathrm{V}} / \mathrm{VCO}_{2}(2,6,22)$. According to Wasserman et al (23), AT can be determined during an incremental exercise test using the following ventilatory parameters: 1 . Steeper increase of $\mathrm{VCO}_{2}$ as compared to $\mathrm{VO}_{2}(\mathrm{~V}$-slope method); 2. Respiratory exchange ratio $=0.95 ; 3 . \dot{\mathrm{VE}} / \mathrm{VO}_{2}$ increase.

In the literature, the different VT's described above have not been compared and validated in practice using a field test. Therefore, the aim of this study was to investigate the relationship between the above-described VT's assessed during an incremental exercise test and the ability to maintain high-intensity exercise during prolonged exercise.

\section{Materials and Methods}

\section{Subjects}

Fourteen male elite cyclists volunteered for this study (age $22.4 \pm 3.4$ years) after having given written informed consent. The subjects were free from serious diseases and took no drugs or medication during the course of the study. On the test days, none showed any sign of disease or infection. The subjects had trained regularly for at least 4 years $(6.1 \pm 2.5$ years The mean training duration was $13 \pm 4.2$ hours a week.

Mean height of the 14 subjects was $181.0 \pm 6.0 \mathrm{~cm}$, mean body mass was $69.2 \pm 6.8 \mathrm{~kg}$. The percentage of body fat, estimated using the measurements of four skinfolds according to Durnin and Womersley (7) was $8.3 \pm 4.2 \%$.

\section{Testing procedure}

All measurements took place over two days under the same conditions of temperature $\left(20^{\circ}\right.$ C) and humidity (55\%). Subjects refrained from intensive exercise in the previous 24 hours and they were instructed to take a carbohydrate rich diet before the laboratory test and the 
field test. The sitting position on the cycle ergometer (Excalibur-sport, Lode, Groningen) was adapted individually for each subject to create the same position as in competition. A 12 lead ECG was performed every minute.

After a warming-up period, in which the workload increased linearly to $2.0 \mathrm{~W}$ per kilogram of body mass in 5 minutes, the load increased by $20 \mathrm{~W}$ every minute until exhaustion. The subjects breathed through a mask, which was connected with an elastic tube to an oxymeter (Oxycon, Jaeger BeNeLux BV, Breda, Netherlands). The volume transducer was calibrated before every test using a calibration syringe. The $\mathrm{CO}_{2}$ and $\mathrm{O}_{2}$ gas analyser was calibrated manual by means of a gas bag with a known calibration gas sampled via the twin tube, and automatically using a bottle of calibration gas by means of a computer controlled manoeuvre. A fully automatic pneumatic system check of the analysers and sampling system was performed every test including the tubes and valves and the calibration factors of the analysers.

Expired gases were continuously sampled and analysed for $\mathrm{O}_{2}, \mathrm{CO}_{2}$ and volume. These instruments were coupled with a computer, which plotted workload against $\mathrm{VO}_{2}, \dot{\mathrm{VCO}}_{2}$, and heart rate. The heart rate and $\mathrm{VO}_{2}$ used for statistical calculations was the mean of every 30 seconds.

Heart rate and $\mathrm{V}_{2}$ were assessed at the following ventilatory parameters (see Fig 1): 1 . Clear steeper increase of $\mathrm{VCO}_{2}$ as compared to $\mathrm{VO}_{2}$ (V-slope method); 2. Respiratory exchange ratio $(\mathrm{RQ})=0.95$, and $1.00 ; 3 . \mathrm{VE} / \mathrm{VO}_{2}$ increase without concomitant increase in $\dot{\mathrm{VE}} / \mathrm{VCO}_{2}\left(\mathrm{HR}_{\mathrm{VSL}} ; \mathrm{HR}_{\mathrm{RQ}=0.95}, \mathrm{HR}_{\mathrm{RQ}=1.00}\right.$, and $\mathrm{HR} \dot{\mathrm{VE} / \mathrm{VO} 2}$ respectively $)$. The curves were analysed by two independent observers.

\section{Figure 1}

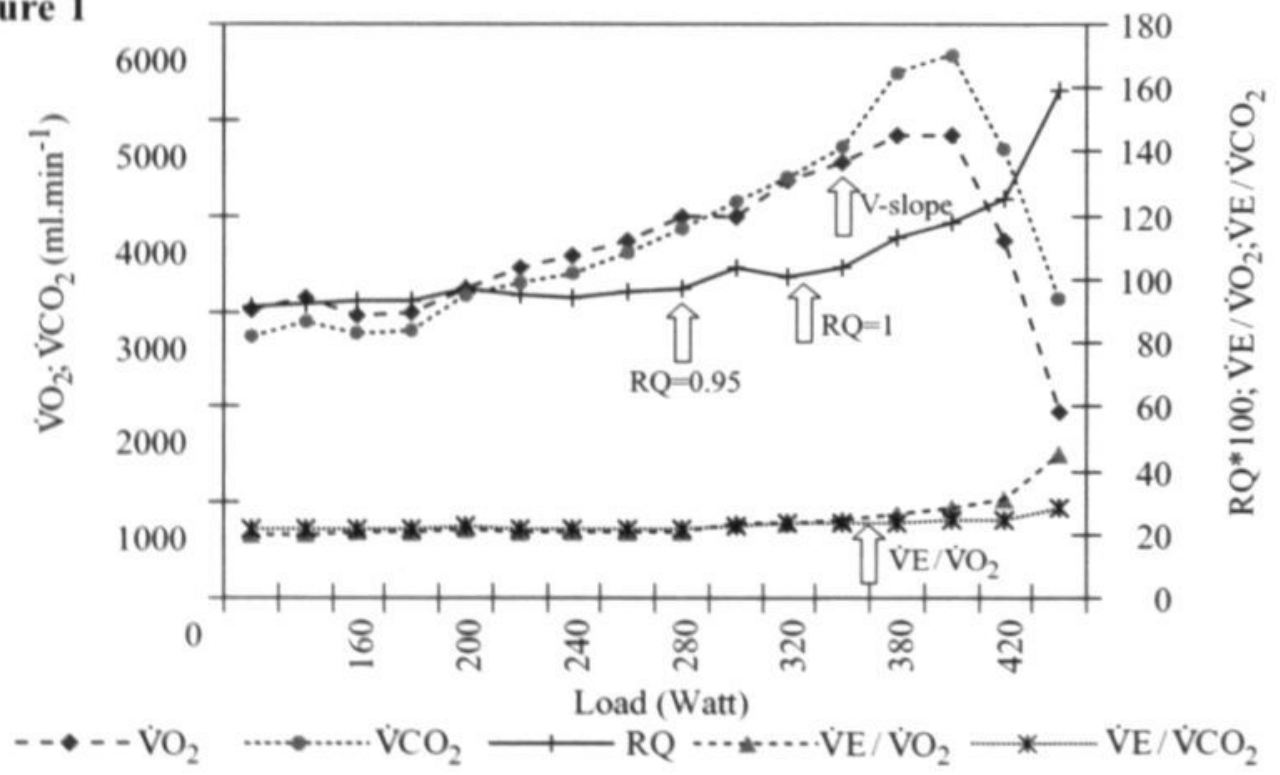

An example of the ventilatory response of a one of the subjects. The different ventilatory parameters assessed during the laboratory test are indicated by the arrows. On the $X$-axis: the incremental workload. On the left $Y$-axis: the $\mathrm{CO}_{2}$ output ( $\left(\dot{\mathrm{V}} \mathrm{CO}_{2}\right)$ and $\mathrm{O}_{2}$ uptake ( $\left(\mathrm{O}_{2}\right)$. On the right $Y$-axis: the respiratory quotient times 100. and the ventilatory equivalents for $\mathrm{O}_{2}$ and $\mathrm{CO}_{2}(\mathrm{VE} / \mathrm{VO}$, and $\mathrm{VE} / \mathrm{VCO}$ ). 


\section{Time-trial}

After a period of 2-3 weeks following the laboratory tests, the subjects were instructed to ride an individual time trial on a flat circuit of $5.0 \mathrm{~km}$, which had to be covered 8 times. The time of every course run and the total road racing time (TT) was registered. The subjects started at one-minute intervals. All subjects were experienced cyclists and able to perform a time trial at a maximum attainable level.

Heart rate was measured every 5 seconds with a heart rate monitor (Polar, Electro OY, Finland). On the day of the test the temperature was $15-18^{\circ} \mathrm{C}$, humidity was $40 \%$, and there was no wind.

\section{Statistical methods}

The SPSS version 5.0 was used to analyse the data (12). Differences and relations between the heart rates were analysed with a paired T-test and using Pearson's Product Moment Correlation. The relation between road racing time and laboratory parameters was analysed using Pearson's Product Moment Correlation. Since level cycling performance depends on air and rolling resistance (18), multiple regression analysis was performed with TT as dependent variable and height, body mass and laboratory parameters as independent variables. The level of significance was set at 0.05 .

\section{Results}

\section{The laboratory test}

The mean duration of the laboratory test was $20 \pm 1.8 \mathrm{~min}$. The mean maximum workload was $440 \pm 33 \mathrm{~W}$, the mean $\mathrm{VO}_{2}$ max was $69 \pm 7 \mathrm{ml} \cdot \mathrm{min}^{-1} \cdot \mathrm{kg}^{-1}$. A clear levelling off of $\mathrm{VO}_{2}$ occurred in all subjects. Mean maximum heart rate $\left(\mathrm{HR}_{\max }\right)$ and the mean of $\mathrm{HR}_{\mathrm{VSL}}$, $\mathrm{HR}_{\mathrm{RQ}=0.95}, \mathrm{HR}_{\mathrm{RQ}=1.00}$, and $\mathrm{HR}_{\mathrm{VE} / \mathrm{VO} 2}$ are shown in Table 1.

\section{Time trial}

The average speed was $41.6 \pm 1.0 \mathrm{~km} \cdot \mathrm{h}^{-1}$. The mean duration was $3478 \pm 82 \mathrm{sec}$. There were no significant differences between the speed of each course run time for each individual. The mean heart rate during the time trial was $175.3 \pm 7.1$ beats. $\mathrm{min}^{-1}$. The mean heart rates during the first and second parts of the time trial showed no significant differences (175.4 \pm 6.9 and $175.1 \pm 7.2$ respectively).

\section{Relationships between laboratory parameters and field test parameters}

The correlations between the laboratory parameters and the field test parameters TT and $\mathrm{HR}_{\mathrm{TT}}$ are shown in Table 1. There were no significant difference between $\mathrm{HR}_{\mathrm{TT}}, \mathrm{HR}_{\mathrm{VSL}}$ and $\mathrm{HR}_{\mathrm{VE} / \mathrm{VO} 2} \cdot \mathrm{HR}_{\mathrm{RQ}=1}$ and $\mathrm{HR}_{\mathrm{RQ}=0.95}$ showed a significant difference to $\mathrm{HR}$ TT. The regression formula that describes the relation between $\mathrm{HR}_{\mathrm{TT}}$ and the maximum heart rate $\left(\mathrm{HR}_{\max }\right)$ during the incremental exercise test was:

\section{$\mathrm{HR}_{\mathrm{TT}}=0.84 . \mathrm{HR}_{\max }+14.3$ beats. $\mathrm{min}^{-1}\left(\right.$ s.e. $=4.3$ beats. $\mathrm{min}^{-1}$ )}

Multiple regression analyses with TT as dependent variable and the laboratory parameters and the anthropometrics as independent variable did not change or improve the correlations or the standard errors. 


\begin{tabular}{|c|c|c|c|c|c|c|}
\hline & \multicolumn{3}{|c|}{ Oxygen uptake } & \multicolumn{3}{|l|}{ Heart rate } \\
\hline & $\begin{array}{l}\mathrm{ml} \cdot \mathrm{min}^{-1} \cdot \mathrm{kg}^{-1} \\
\text { mean } \pm \mathrm{sd}\end{array}$ & $\begin{array}{l}\% \text { of } \\
\mathrm{VO}_{2} \max \end{array}$ & $\begin{array}{l}\text { correlation } \\
\text { with TT }\end{array}$ & $\begin{array}{l}\text { beats. } \min ^{-1} \\
\text { mean } \pm \text { sd }\end{array}$ & $\begin{array}{l}\% \text { of } \\
H R_{\max }\end{array}$ & $\begin{array}{l}\text { correlation } \\
\text { with } \mathrm{HR}_{\mathrm{TT}}\end{array}$ \\
\hline V-Slope & $4299 \pm 336$ & 90.0 & $-0.82 * *$ & $174 \pm 9$ & 90.1 & $0.93 * *$ \\
\hline $\mathrm{RQ}=0.95$ & $3435 \pm 555$ & 72.9 & ns & $152 \pm 13$ & 79.2 & ns \\
\hline$R Q=1.00$ & $3998 \pm 373$ & 83.7 & ns & $166 \pm 10$ & 86.5 & $0.76^{*}$ \\
\hline$\dot{\mathrm{VE}} / \mathrm{V}_{2}$ & $4350 \pm 340$ & 91.1 & $-0.81^{*}$ & $176 \pm 8$ & 91.6 & $0.90^{* *}$ \\
\hline Max & $4775 \pm 484$ & 100 & $-0.71^{*}$ & $192 \pm 8$ & 100 & $0.85^{* *}$ \\
\hline$*=p<0.01$ & $* *=p<0.001$ & $\mathrm{~ns}=\mathrm{nc}$ & gnificant & & & \\
\hline
\end{tabular}

\section{Discussion}

The purpose of this study was to evaluate the relationships between the different ventilatory thresholds assessed during an incremental exercise test and the heart rate and endurance performance assessed during a field test.

It is remarkable that only a few investigators compared physiological parameters assessed in a laboratory with a practical situation using a field test. In the literature, VT $(3,4,5,11,14)$ appears to be highly correlated to various types of endurance performance. The correlation in these studies varies from \pm 0.70 up to \pm 0.94 . So the correlations observed in the current study can be compared with those of other investigations. The most significant indicator of performance in the current study is the $\dot{\mathrm{VO}}_{2}$ obtained by the $\mathrm{V}$-slope method ( $\mathrm{r}=-0.82$; $p<0.001 ; 90 \%$ interval of confidence $= \pm 82 \mathrm{sec}$ ). It is obvious that the interval of confidence is too large to use this parameter to predict performance in similar-trained individuals.

As far as we know, no investigator compared the heart rate at VT assessed in a laboratory with the heart rate during a field test. A few investigators described the heart rate at the anaerobic threshold based on the lactate response. Craig et al. (5) observed a mean heart rate of $144 \pm 11$ beats. min $^{-1}$ at the lactate threshold in 18 elite endurance and sprint cyclists. This was $73 \%$ of the maximum heart rate $(197 \pm 9)$. Foster et al $(8)$ observed a percentage of 84 $92 \% \mathrm{HR}_{\max }$ at the onset of blood lactate accumulation. Kindermann et al. (10) reported a heart rate of $174 \pm 8$ at the $4 \mathrm{mmol}^{-1} \mathrm{l}^{-1}$ lactate threshold in elite cross country skiers $(91 \%$ $H R_{\max }$ ). Comparable values are reported by Lehmann et al. (11) in marathon runners and by Stegmann and Kindermann (17) in rowers. In our study $\mathrm{HR}_{\mathrm{TT}}$ was expected to correspond with the heart rate at AT and/or VT. Apart from the observations of Craig et al. (5), the above- 
described values are comparable with the present study.

In the current study the heart rates at the different ventilatory thresholds and $\mathrm{HR}_{\max }$ in both tests showed usable correlations with $\mathrm{HR}_{\mathrm{TT}}$. For training management we recommend using the V-slope method to assess $\mathrm{HR}_{\mathrm{TT}}(\mathrm{r}=0.93 ; \mathrm{p}<0.001 ; 90 \%$ interval of confidence $= \pm 4.8$ beats. $\mathrm{min}^{-1}$ ). The relation between $\mathrm{HR}_{\mathrm{TT}}$ and $\mathrm{HR}_{\max }$ is not simply a fixed percentage (see section results). For predicting the heart rate during prolonged high-intensity exercise $\left(\mathrm{HR}_{\mathrm{TT}}\right)$ in elite endurance athletes without assessment of VR parameters, we recommend to assess $\mathrm{HR}_{\max }$ during an incremental exercise test $\left(20 \mathrm{~W} \cdot \mathrm{min}^{-1}\right)$ and the use of the regression formula shown in the results section.

The use of a one-minute incremental exercise test may have influenced the results of the current study. One minute may have been too short to reach a steady state. Thus, on the measured values the ventilatory and circulatory variables may have lagged behind. However, Zhang et al. (26) compared the ventilatory response $\left(\mathrm{VO}_{2}, \dot{\mathrm{V}} \mathrm{CO}_{2}, \mathrm{VE}\right.$, and $\left.\mathrm{AT}\right)$ in four different protocols of increasing work rate (ramp and 1-min, 2-min, and 3-min steps) to maximum exercise. He and his co-workers observed no significant differences among the four work rate protocols. Therefore, we think that our observations will not have been influenced by the shortness of the steps in our exercise protocol.

When laboratory parameters, in particular the heart rate are compared with measurements during a field test, we have to consider that environmental factors like temperature, and humidity may have influenced the results in the current study (1). Furthermore training effects in the period between the tests may have influenced the results. However, concerning temperature, Potteiger and Weber (15) showed that during steady-state exercise in cyclists, there were no differences between the heart rate at the onset of blood lactate accumulation at different environmental temperatures $\left(14,22\right.$, and $\left.30^{\circ} \mathrm{C}\right)$.

In the current study we investigated the practical value of different ventilatory thresholds assessed in a laboratory. We concluded that in elite cyclists, VT assessed using the V-slope method and the $\mathrm{VE} / \mathrm{VO}_{2}$ method are preferred as indicators of performance and for the use of heart rate training management. We think that the results of this study are usable in sports medicine practice and training management of elite endurance athletes.

\section{References}

1. Beelen A, Sargeant AJ. Effect of lowered muscle temperature on the physiological response to exercise in men. Eur J Appl Physiol 1991; 63: 387-92

2. Caiozzo VJ, Davis JA, Ellis JF, Azus JL, Vandagriff R, Prietto CA, McMaster WC. A comparison of gas exchange indices used to detect the anaerobic threshold. J Appl Physiol 1982; 53: 1184-9

3. Coyle EF, Coggan AR, Hopper MK, Walters TJ. Determinants of endurance in welltrained cyclists. J Appl Physiol 1988; 64: 2622-30

4. Coyle EF, Feltner ME, Kautz S, Hamilton MT, Montain SJ, Baylor AM, Abraham ID, Petrek GW. Physiological and biomechanical factors associated with elite endurance cycling performance. Med Sci Sports Exerc 1990; 23: 93-107 
5. Craig NP, Norton KI, Bourdon PC, et al. Aerobic and anaerobic indices contributing to track endurance cycling performance. Eur J Appl Physiol 1993; 67: 150-8

6. Davis JA. Anaerobic threshold: review of the concept and directions for future research. Med Sci Sports Exerc 1985; 17: 6-18

7. Durnin JVGA, J Womersly J. Body fat assessed from total body density and its estimation from skinfold thickness: measurements on 481 men and women from 16 to 72 years. Br J Nutr 1974; 32: 77-97

8. Foster C, Crowe MP, Holum D, Sandvig S, Schrager M, Snyder AC, Zajakowski S. The bloodless lactate profile. Med Sci Sports Exerc 1995; 27: 927-33

9. Heck H, Mader A, Hess G, Mucke M, Muller M, Hollmann W. Justification of the 4mmo/ll lactate threshold. Int J Sports Med 1985 6: 117-30

10. Kindermann $\boldsymbol{W}$, Simon $\boldsymbol{G}, \mathbf{K e u l} \boldsymbol{J}$. The significance of the aerobic-anaerobic transition for the determination of work load intensities during endurance training. Eur J Appl Physiol 1979: 42: 25-34

11. Lehmann M, Berg A, Kapp R, Wessinghage T, and J. Keul J. Correlations between laboratory testing and distance running performance in marathoners of similar performance ability. Int J Sports Med 1983: 4: 226-30

12. Marija J. Norusis/SPSS/PC+ version 5.0, SPSS inc: Chigaco, 1992.

13. McLellan T. Ventilatory and plasma lactate response with different exercise protocols: a comparison of methods. Int J Sports Med 1985; 6: 30-5

14. Noakes TD. Implications of exercise testing for prediction of athletic performance: A contemporary perspective. Med Sci Sports Exerc 1988; 4: 319-30

15. Potteiger JA, Weber $\mathbf{S F}$. Rating and perceived exercertion and heart rate as indicators of exercise intensity in different environmental temperatures. Med Sci Sports Exerc 1994: 26: 791-6

16. Stegmann H, Kindermann $\boldsymbol{W}$, Schnabel A. Lactate kinetics and individual anaerobic threshold. Int J Sports Med 1981: 2: 160-5

17. Stegmann $\boldsymbol{H}, \mathbf{K i n d e r m a n n} \boldsymbol{W}$. Comparison of prolonged exercise tests at the individual anaerobic threshold and the fixed anaerobic threshold of $4 \mathrm{mmol}$ lactate. Int J Sports Med 1982: 3: 105-10

18. Swain DP. Is there an optimum body size for competitive bicycling. In: Burke RE. Newson M.N.: Medical and scientific aspects of cycling 1988: 39-46 
19. Urhausen A, Coen B, Weiler B, Kindermann $\boldsymbol{W}$. Individual anaerobic threshold and maximal lactate steady state. Int J Sports Med 1993; 14: 134-9

20. Wasserman K, Mcllroy MB. Detecting the threshold of anaerobic metabolism in cardiac patients during exercise. Am J Cardiol 1964; 14: 844-52

21. Wasserman $\boldsymbol{K}$, Whipp BJ, Koyal SN, Beaver WL. Anaerobic threshold and respiratory gas exchange during exercise. J Appl Physiol 1973; 35: 236-40

22. Wasserman K. Breathing during exercise. New Engl J Med 1978; 298: 780-5

23. Wasserman $\mathbf{K}$, Stringer WW, Casaburi R, Koike A, Cooper CB. Determination of the anaerobic threshold by gas exchange. Biochemical considerations, methodology and physiological effects. Z Kardiol 1994; 83: 1-12

24. Weltman A. The blood lactate response to exercise. Human Kinetics 1995; ISBN 087322-769-7

25. Yoshida T, Chida M, Ichioka M, Suda $\boldsymbol{Y}$. Blood lactate parameters related to aerobic capacity and endurance performance. Eur J Appl Physiol 1987; 56: 7-11

26. Zhang YY, Johnson MC, Chow N, Wasserman $\boldsymbol{K}$. Effect of exercise testing protocol on parameters of aerobic function. Med Sci Sports Exerc 1991; 23: 625-30 



\section{Chapter}

The effect of endurance training on the ventilatory response to exercise in elite cyclists.

A.R. Hoogeveen

European Journal of Applied Physiology 2000; 82: 45-51

Acknowledgements: This study was supported by the St Joseph Hospital Veldhoven, the Netherlands. 


\section{Chapter 5}

\section{Summary}

The purpose of this study was to investigate the effects of endurance training on the ventilatory response to acute incremental exercise in elite cyclists. Fifteen male elite cyclists (age $24.3 \pm 3.3$ years, height $179 \pm 6 \mathrm{~cm}$, body mass $71.1 \pm 7.6 \mathrm{~kg}$ ) underwent two exercise tests on a cycle ergometer. The first test was assessed in December, 6 weeks before the beginning of the cycling season. The second test was performed in June, in the middle of the season, during which period the subjects where expected to be in a highly endurance-trained state. The ventilatory response was assessed during an incremental exercise test ( $20 \mathrm{~W}$. $\mathrm{min}^{-}$ 1). Oxygen consumption $\left(\mathrm{V}_{2}\right)$, carbon-dioxide production $\left(\mathrm{VCO}_{2}\right)$, minute ventilation (VE), and heart rate (HR) were assessed at the following points: $200 \mathrm{~W}, 250 \mathrm{~W}, 300 \mathrm{~W}, 350$ $\mathrm{W} 400 \mathrm{~W}$, maximal, at a respiratory exchange ratio of 1.00 , and at the ventilatory threshold (VT) determined using the V slope-method.

The mean post-training $\mathrm{VO}_{2}$ max was increased from the pre-training level of $69 \pm 7 \mathrm{ml}^{-\mathrm{min}^{-}}$ ${ }^{1} . \mathrm{kg}^{-1}$ (range $61.4-78.6$ ) to $78 \pm 6 \mathrm{ml} \cdot \mathrm{min}^{-1} \cdot \mathrm{kg}^{-1}$ (range 70.5-86.3). The mean post-training $\mathrm{VO}_{2}$ was significantly higher than the pre-training value $(\mathrm{p}<0,01)$ at all work rates, at $\mathrm{VT}$ and at $\mathrm{RQ}=1$. $\mathrm{VCO}_{2}$ was also higher at all work rates except for $200 \mathrm{~W}$ and $250 \mathrm{~W}$. VE was significantly higher at $\mathrm{VT}$ and $\mathrm{RQ}=1 . \mathrm{HR}$ at all workloads was not significantly changed post training. An explanation for the higher post-training $\mathrm{VO}_{2}$ at the same workload is not clear, but it may be caused by accelerated $\mathrm{V}_{2}$ kinetics.

The results of this study suggest the following practical recommendations for training management in elite cyclists: 1. During a short-step incremental exercise test ( $\left.20 \mathrm{~W} \cdot \mathrm{min}^{-1}\right)$, the $\mathrm{VO}_{2}$ for a subject at the same work rate may be an indicator of the endurance-training state: the higher the $\mathrm{VO}_{2}$, the higher the endurance-trained capacity. 2 . The need for multiple exercise tests for determining HR at VT during a cycling season is doubtful since this parameter does not differ much following endurance training. 


\section{Introduction}

The ventilatory response to exercise has been studied extensively during the last decades $(6,8,20,26)$. The maximum oxygen consumption $\left(\mathrm{VO}_{2} \max \right)$ and the ventilatory threshold (VT) have been commonly accepted as key parameters for the capacity of endurance performance $(2,20,21)$. VT has been described based on different ventilatory parameters during incremental exercise tests. The ventilatory threshold (VT) is expected to correspond to the anaerobic threshold (AT), which can be defined as the highest oxygen consumption at which blood lactate concentration is maintained at a steady state during prolonged exercise $(18,20)$.

The studies concerning the effect of endurance training on the ventilatory response are numerous. These studies were all focused on the training effects of the $\mathrm{VO}_{2}$ max, and the ventilatory and lactate threshold $(7,20,26)$. It is commonly accepted that endurance training will improve $\mathrm{VO}_{2}$ max and the $\hat{\mathrm{O}}_{2}$ at $\mathrm{VT}$, and detraining will reduce these parameters $(7,11,20)$. The majority of these studies concerned patients and relatively untrained subjects. Several studies investigated the effect of training on the ventilatory response to exercise at submaximal levels $(4,7,13,15,16,23,24,28)$. The effect of training on the ventilatory response in these studies are conflicting, especially concerning the $\mathrm{VO}_{2}$ : following endurance training. the oxygen consumption at submaximal levels during incremental and submaximal exercise tests has been described to be higher $(15,17,24)$, lower (4) and unchanged (14).

Despite these conflicting results, lower submaximal $\mathrm{VO}_{2}$ values for the same work rate is accepted as an indicator of economy in various sports $(1,11,16,23)$. However, the studies in which moving economy was investigated and several of the previous mentioned studies concerned different groups of subjects, trained and untrained, were not focused on the training effects of individual subjects after a period of training. Furthermore different protocols were used.

The aim of this study was to investigate the ventilatory response to incremental exercise in a group of elite cyclists during a relatively untrained period compared to an extensively endurance-trained state.

\section{Materials and Methods}

\section{Subjects}

Six male elite amateur and nine professional cyclists volunteered for this study (age 24.3 \pm 3.3 years) after having given written informed consent. The subjects were free from serious diseases and took no drugs or medication during the course of the study. Since a drug-free state of elite cyclists is not easily ascertained, some blood was taken before every test to determine hematocrite values. The subjects were all familiar with the testing procedure in a laboratory and all of them had been tested here four times or more before.

The subjects underwent two incremental exercise tests. The first test was assessed in December, six weeks before the beginning of the cycling season (= pre training). The second test was performed in June, in the middle of the season in which the subjects where expected to be highly-endurance trained (= post training).

On the test days, none showed any sign of disease or infection. The subjects had trained regularly for at least 4 years $(8.1 \pm 3.5$ years. $)$. The exact volume of training and competition 
can not easily be established. The mean training duration including competition was $13.3 \pm$ 4.6 hours a week before the first test and $23.7 \pm 6.4$ in the period before the second test. Competition started in February. The period between the two tests they had 40-60 days of competition with a range in length of $120-220 \mathrm{~km}$ a day. In the period of 5 months between the two laboratory tests 11 subjects suffered from a common cold.

\section{Testing procedure}

All measurements took place under the same conditions of temperature $\left(22^{\circ} \mathrm{C}\right)$ and humidity $(55 \%)$. Subjects refrained from intensive exercise in the previous 24 hours. The diet before the tests and between the test was not changed and they were instructed to take a carbohydrate rich diet before the exercise tests. In the three days before the testing procedure the subjects had not competed. The sitting position on the cycle ergometer (Excalibur sport, Lode, Groningen) was adapted individually for each subject to create the same position as in competition. A 12-lead ECG was performed every minute.

After a warming-up period of 5-10 minutes, the workload increased linearly to $140 \mathrm{~W}$ in 5 minutes, then the load was increased by $20 \mathrm{~W}$ every minute. They were expected to have reached their maximum when the subjects couldn't maintain a pedalling speed above $80 \mathrm{rpm}$ or when the oxygen uptake did not increase despite a higher workload. The subjects used their own choice of pedalling speed but above 80 and below $110 \mathrm{rpm}$, in which range the workload remains constant.

The subjects breathed through a mask, which was connected by an elastic tube to an oxymeter (Oxycon, Jaeger BeNeLux BV, Breda, Netherlands). The mask dead space was 70 $\mathrm{ml}$. Expired gases were continuously sampled and analysed tor $\mathrm{U}_{2}, \mathrm{CU}_{2}$ and volume. These instruments were coupled to a computer, which plotted workload against $\dot{V O}_{2}, \dot{\mathrm{VCO}_{2}}$, and heart rate (Software Jaeger, Netherlands). The heart rate and $\mathrm{V}_{2}$ used for sampling and statistical calculations was the mean of every 30 seconds.

The volume transducer was calibrated before every test using a calibration syringe. The $\mathrm{CO}_{2}$ and $\mathrm{O}_{2}$ gas analyser was calibrated manual by means of a gas bag with a known calibration gas sampled via the twin tube, and automatically using a bottle of calibration gas by means of a computer controlled manoeuvre. A fully automatic pneumatic system check of the analysers and sampling system was performed every test including the tubes and valves and the calibration factors of the analysers.

$\dot{\mathrm{V}} \mathrm{O}_{2}, \dot{\mathrm{V}} \mathrm{CO}_{2}$, minute ventilation ( $\left.\dot{\mathrm{VE}}\right)$, and heart rate (HR) were assessed at the following workloads: at $200 \mathrm{~W}, 250 \mathrm{~W}, 300 \mathrm{~W}, 350 \mathrm{~W} 400 \mathrm{~W}$, and at maximal performance. Furthermore, $\dot{\mathrm{VO}}_{2}, \dot{\mathrm{VCO}}_{2}$, minute ventilation ( $\left.\mathrm{VE}\right)$, and heart rate were assessed at a respiratory exchange ratio of 1.00 and at the ventilatory threshold. The ventilatory threshold was assessed at a steeper increase of $\mathrm{VCO}_{2}$ compared to $\mathrm{VO}_{2}$ (V-slope method). The curves were analysed by two independent observers. The maximum work rate (Wmax) was determined using the following formula: $\mathbf{W m a x}=\mathbf{W s t a g e}+(\mathbf{t} / \mathbf{6 0}) * \mathbf{2 0}$, where Wstage is the work rate of the last completed stage and $\mathrm{t}$ is the time in seconds in the final stage.

\section{Statistical methods}

Differences and relations between the different ventilatory parameters, the heart rate, hematocrite values, and cadence rate were analysed using a paired T-test and using Pearson's Product Moment Correlation respectively. The level of significance was set at 0.05 . Unless stated otherwise, the results are given as the mean \pm standard deviation. 


\section{Analytical methods}

Hematocrite values were assessed using a Coulter STKS by means of a conductivity principal (Coulter, Mijdrecht, Netherlands.

\section{Results}

The mean height of the 15 subjects was $179 \pm 6 \mathrm{~cm}$. In Table 1, mean maximum work rate, $\mathrm{VO}_{2}$ max, work rate at VT, body mass and percentage of body fat, estimated using the measurements of four skin folds according to Durnin and Womersley (12), are shown pre and post training.

A clear levelling-off of $\mathrm{VO}_{2}$ curve occurred in all subjects in both tests (Fig 1 and 2). A representative pre- and post-training test of one of the subjects is shown in Figure 1 and 2. The mean of $\dot{V O}_{2}, \dot{V} \mathrm{CO}_{2}, \dot{V E}$, and heart rate at the different loads and at VT and $\mathrm{RQ}=1$ are shown in Figure 3 to 6 respectively. In these figures, the level of significance between the two tests is indicated. Since 3 subjects did not reach $400 \mathrm{~W}$, the mean at this point of measurement was computed for 12 subjects.

Post training, the mean increment in $\mathrm{VO}_{2} \max$ was $10 \pm 6 \%$ and $11 \pm 6 \%$ at VT. There was a significant correlation between the increment in VT and the increment of $\mathrm{VO}_{2}$ at 200, 250, 300 and $350 \mathrm{~W}(\mathrm{r}=0.60 ; 0.71 ; 0.72 ; 0.77$ respectively and $\mathrm{p}<0.01 ; 0.01 ; 0.01 ; 0.001$ respectively). There was no significant correlation between the increment in $\mathrm{VO}_{2} \mathrm{max}$ and the increment of $\mathrm{VO}_{2}$ at the different parameters. There was a correlation of $0.79(\mathrm{p}<0.001)$ between $\mathrm{HR}_{\max }$ and pre- and post-training $\mathrm{HR}_{\mathrm{VT}}$.

The post-training $\dot{\mathrm{VE}} / \mathrm{VO}_{2}$ was significantly lowered at 250,300 and $350 \mathrm{~W}(\mathrm{p}<0.001)$. $\dot{\mathrm{VE}} / \mathrm{VCO}_{2}$ was post training significantly lowered at $350 \mathrm{~W}$ and at $\mathrm{RQ}=1(\mathrm{p}<0.001)$.

The pre-training cadence rate was $91.7 \pm 3.6 \mathrm{rpm}$ (range $85-97$ ) and post training $92.1 \pm$ $3.5 \mathrm{rpm}$ (range 86 - 97). The difference between these values was not significant.

The mean pre-training hematocrite value was $43.7 \pm 3.2 \%$ and the post-training value was $42.9 \pm 2.3 \%$. There was no difference between these values.

\section{Table 1. The body mass, percentage of fat, maximal oxygen consumption $\mathrm{VO}_{2}$, maximum work rate (Wmax), and work rate at the ventilatory threshold (VT). Data are expressed as the mean \pm sd.}

\begin{tabular}{|lrccc|}
\hline & Pre training & Post training & significance \\
\hline Body mass $(\mathrm{kg})$ & $71.1 \pm 7.6$ & $69.4 \pm 7.0$ & not significant \\
Fat percentage $(\%)$ & $10.5 \pm 2.1$ & $9.3 \pm 1.4$ & $\mathrm{p}<0.001$ \\
$\mathrm{VO}_{2}$ max $\left(\mathrm{ml} \cdot \mathrm{min}^{-1} \mathrm{~kg}^{-1}\right)$ & $69 \pm 7$ & 78 & \pm 6 & $\mathrm{p}<0.001$ \\
Wmax (W) & $449 \pm 46$ & 459 & \pm 46 & $\mathrm{p}<0.05$ \\
Work rate at VT $(\mathrm{W})$ & $376 \pm 38$ & 396 & \pm 36 & $\mathrm{p}<0.001$ \\
\hline
\end{tabular}


Figure 1

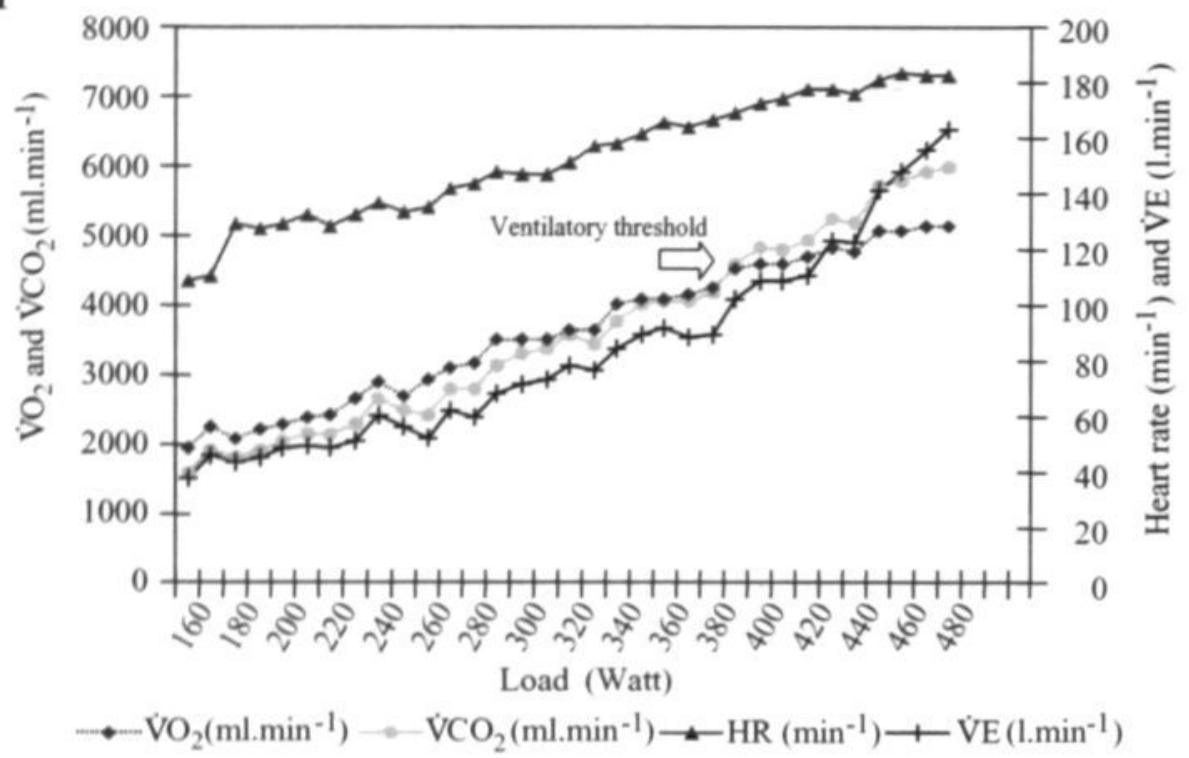

Results of the pre-training incremental exercise test of one of the subjects. The ventilatory threshold assessed using the V-slope method (see text) is indicated by the arrow.

Figure 2

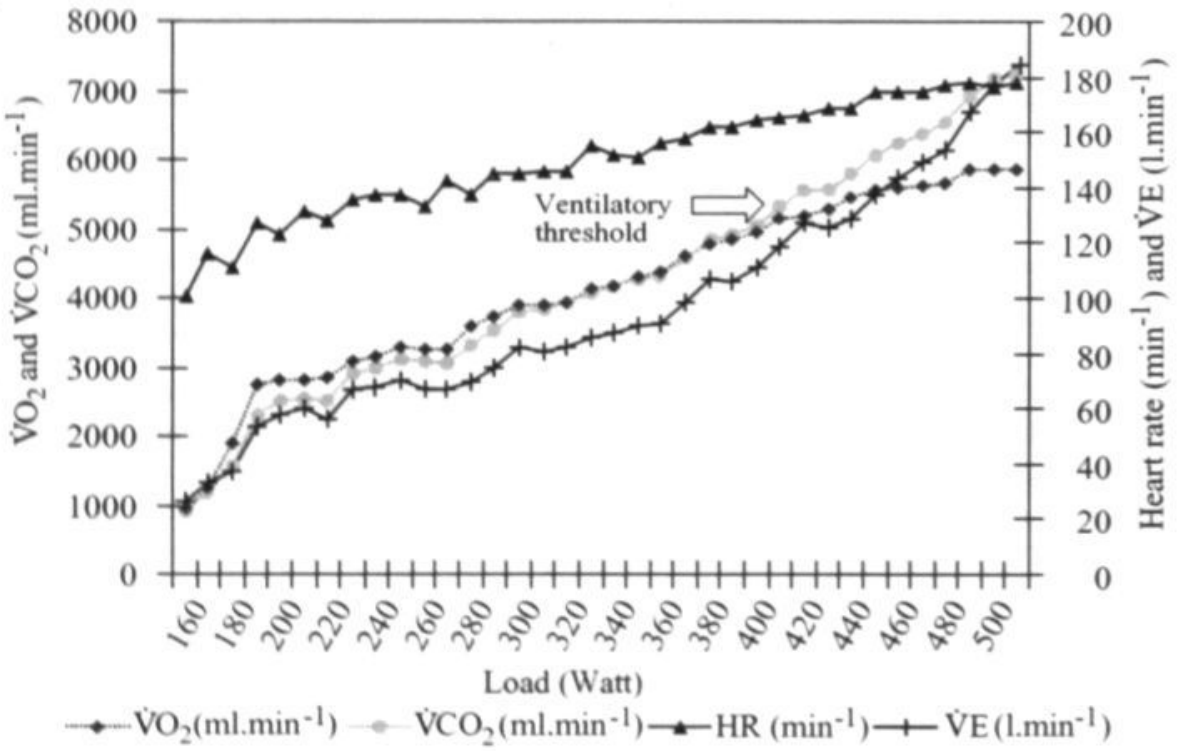

Results of the post-training incremental exercise test of one of the same subject shown in Fig 1. The ventilatory threshold assessed using the V-slope method (see text) is indicated by the arrow: 
Figure 3

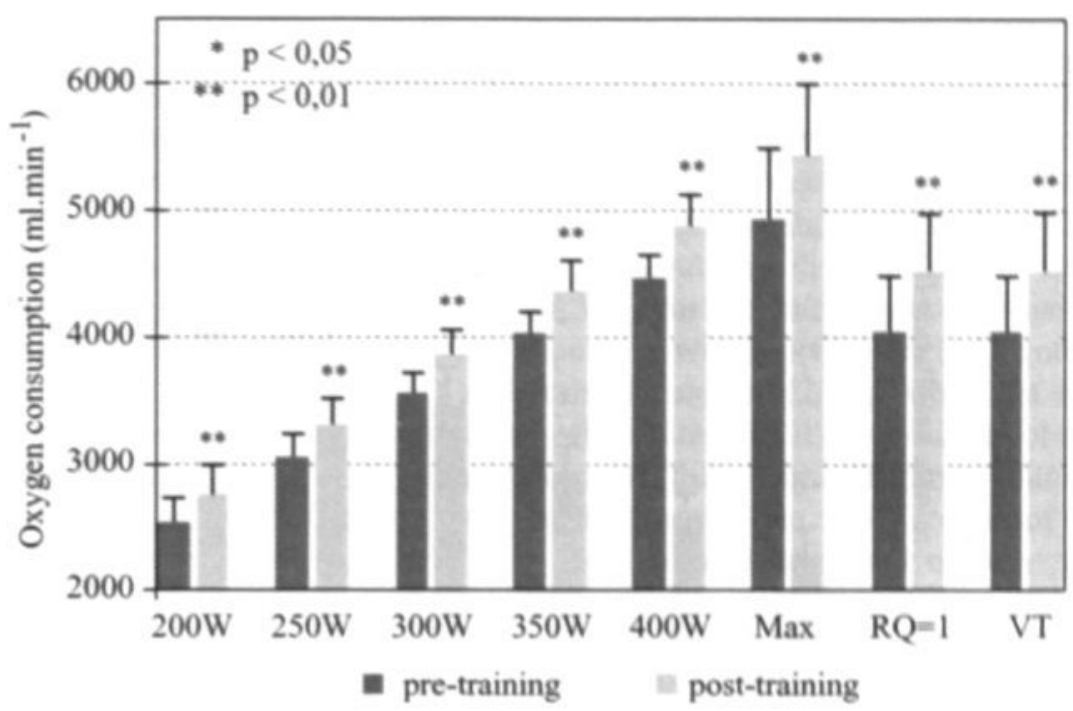

The mean pre- and post-training oxygen consumption (VO,) at the different workloads tested (200. 250. 300,350 , and $400 \mathrm{~W}$. the subject's maximum workload (Max), and at the ventilatory threshold (VT). The error bars represent sd.

Figure 4

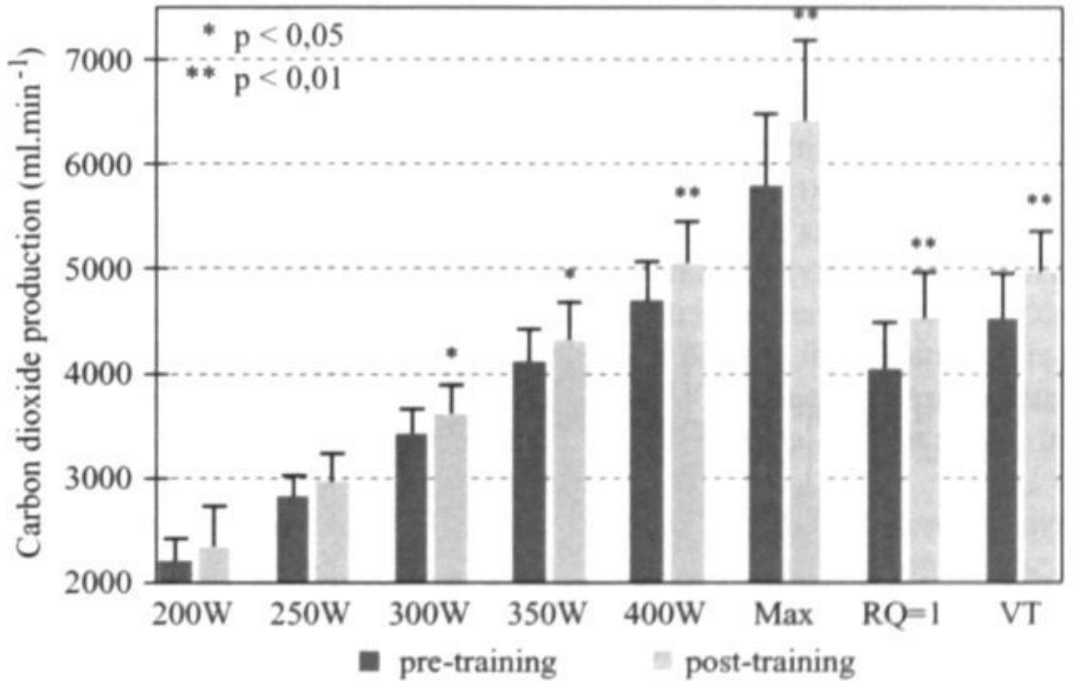

The mean pre- and post-training carbon-dioxide production $\left(\mathrm{VCO}_{2}\right.$, at the different workloads tested, at $R Q=1$, and at $V T$. 
Chapter 5

Figure 5

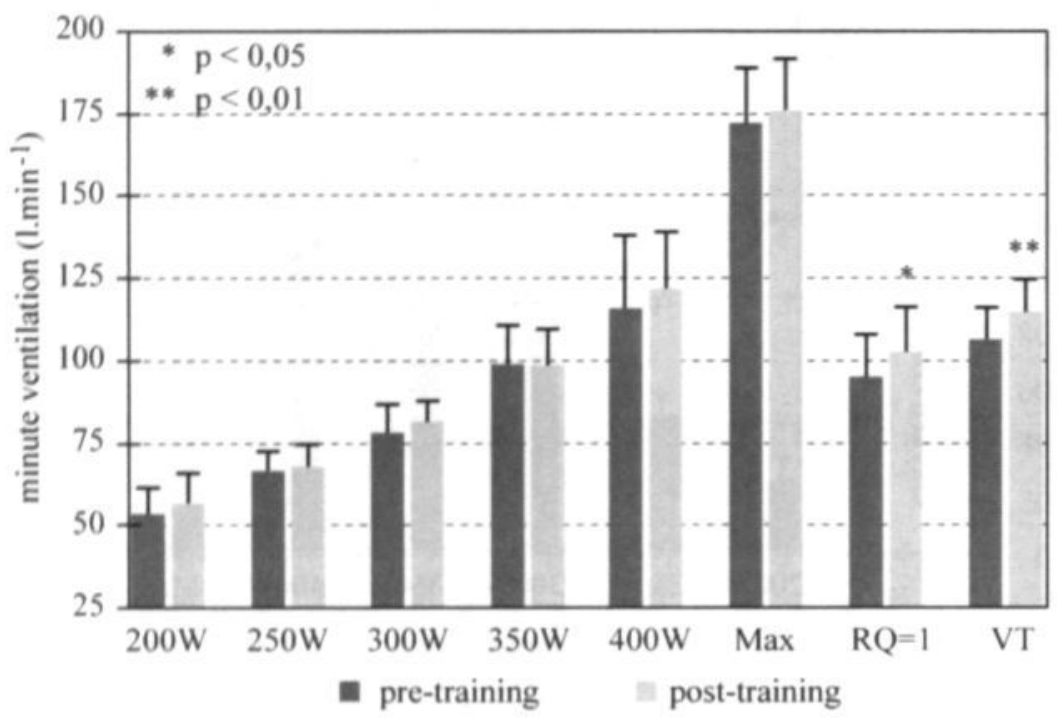

The mean pre-and post-training mimute ventilation (VE) at the different workloads tested, at $R Q=I$, and at $V T$.

Figure 6

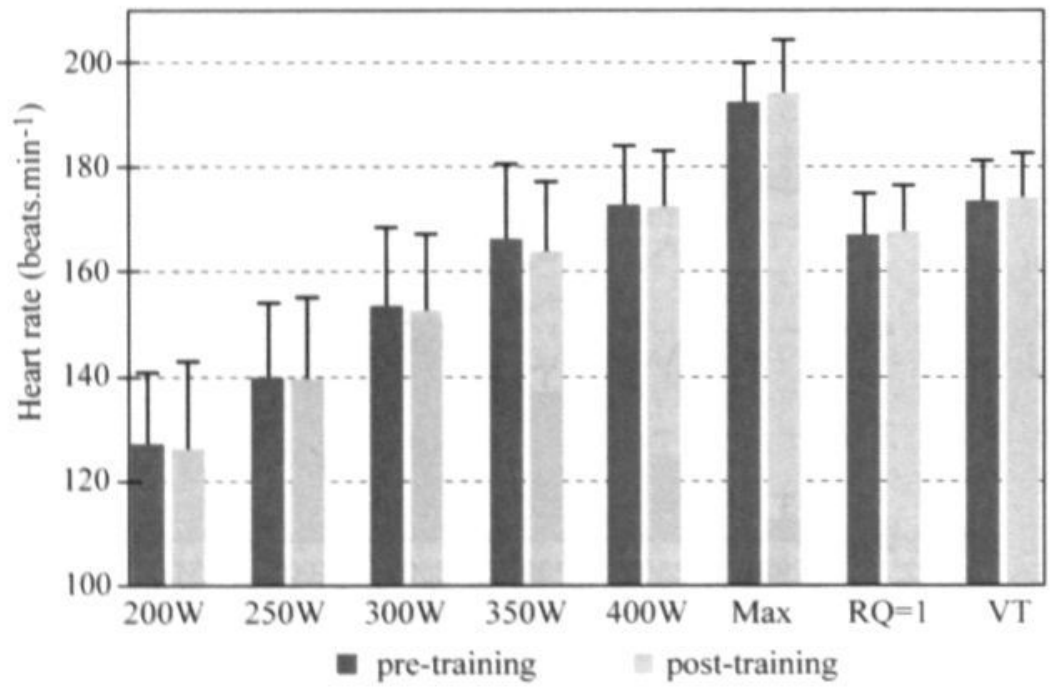

The mean pre- and post-training heart rate at the different workloads tested. at $R Q=1$, and at $V T$. 


\section{Discussion}

In this study, the ventilatory response to acute incremental exercise was investigated in elite cyclists. A curious observation in this study is the higher $\mathrm{VO}_{2}$ value for the same work rate and at the same heart rate following endurance training. This observation is not easy to explain and the results from the literature are conflicting. Astrand and Rodahl (2) has described the linear relation between workload and $\mathrm{VO}_{2}$, but they did not describe training effects. Using an incremental exercise test, higher $\mathrm{VO}_{2}$ for the same work rate has been described to occur following endurance training in patients with heart failure (17), untrained healthy subjects $(3,15)$, elite runners (23) and trained subjects (24). Barbeau et al. (4) observed lower post-training $\mathrm{VO}_{2}$ in elite cyclists, while Green et al. (14) did not observed changes in oxygen consumption at the same work rate following endurance training in healthy males. An explanation for the conflicting results may be that in the studies of Green et al. (14) and Barbeau et al. (4) the incremental exercise tests consisted of steps with a significant longer duration than those used in the other studies and in the present study. The ventilatory response in the first minute of each step was not reported in the studies of Barbeau et al. (4) and Green et al. (14). In addition the subjects in the different studies were not similar-trained.

Bhambhani et al. (7) reported lowered equivalents for $\dot{\mathrm{VO}} \mathrm{O}_{2}\left(\mathrm{~V} E / \mathrm{VO}_{2}\right)$ and $\dot{\mathrm{V}} \mathrm{CO}_{2}$ $\left(\mathrm{VE} / \mathrm{VCO}_{2}\right.$ ) at submaximal work rate following endurance training. This was primarily the result of lowered ventilation volume. In the current study, the $\mathrm{VE} / \mathrm{VO}_{2}$ was lowered posttraining at 250,300 and $350 \mathrm{~W}$. $\mathrm{VE} / \mathrm{VCO}_{2}$ was lowered post training at $350 \mathrm{~W}$ and at $\mathrm{RQ}=1$. However, both equivalents in the current study were decreased, caused by a significantly increased $\mathrm{VO}_{2}$ and $\dot{\mathrm{CO}}_{2}$. This difference may be due to the fact that in Bhambhani's study (7), the subjects concerned were moderately trained subjects.

Gissane et al. (13) studied the response to standardised exercise on a cycle ergometer and observed in untrained males a tendency that post-training oxygen consumption may be reduced due to an increased efficiency. Also in elite swimmers (16), runners (1), and cyclists (11), efficiency has been associated with lower $\mathrm{VO}_{2}$ values for the same work rate. At first sight, this does not appear to be the case in elite cyclist. Perhaps, in elite cyclists, efficiency has already been well developed in the previous years of training and efficiency does not, therefor, play a role during the competition season. A major point in this discussion is that in the above mentioned studies $(1,11,16)$, the observed lower $\mathrm{VO}_{2}$ values were associated with different groups of subjects, i.e. trained and untrained, while in the current study, training effects are described for the same group of subjects.

The dynamics and interpretation of ventilation and gas exchange during exercise have been studied thoroughly, and these issues are very complicated, so an explanation for the higher $\mathrm{VO}_{2}$ cost for the same work rate cannot easily be given $(10,22,28)$. Based on Fick's principles, an increased oxygen uptake is the result of an increased cardiac output or arterialvenous oxygen difference: $(\mathrm{a}-\mathrm{v}) \mathrm{O}_{2}$. In the current study the post-training heart rate did not change so the increased oxygen uptake should be the result of an increased stroke volume or an increased $(\mathrm{a}-\mathrm{v}) \mathrm{O}_{2}$. Both mechanisms are possible or a combination of the two. Stroke volume is likely to increase since it has been described as a consequence of training (9). In addition, increased capillarisation could enhance muscle perfusion resulting in faster and/or more oxygen extraction. In the present study the increased $\mathrm{VO}_{2}$ is established without increased ventilation, which suggest more efficient ventilation expressed by the equivalents 
for oxygen uptake ( $\left.\mathrm{VE} / \mathrm{VHO}_{2}\right)$.

A possible explanation may be that in an endurance-trained state, the ventilatory adaptation to an exercise stimulus with higher intensity occurs faster than when the subject is less trained. Lowered oxygen kinetics in untrained patients compared to trained subjects has already been described by Bauer et al. (5). In addition faster $\mathrm{VO}_{2}$ kinetics has also been described following training in older men (3) and cyclists (24). The use of a one-minute interval ramp protocol may have influenced the oxygen kinetics and thus the results of the current study. The measured values of the oxygen uptake may have lagged behind. The differences in oxygen uptake at a certain pre- and post-training workload might not have been observed using a protocol with longer steps. On the contrary, using longer steps, $\mathrm{V}_{2}$ might even have been lower following endurance training. Even if this were true, the observations are still usable. Concerning this issue, Zhang et al. (29) compared the ventilatory response $\left(\mathrm{VO}_{2}, \dot{\mathrm{V}} \mathrm{CO}_{2}, \dot{\mathrm{VE}}, \mathrm{VT}\right)$ in four different protocols of increasing work rate (ramp and 1-min, 2-min, and 3-min steps) to maximum exercise. He and his co-workers observed no significant differences among the four work-rate protocols.

Another explanation may be that, at higher workloads, the work power in the less endurancetrained state has to be overcome using a significantly higher anaerobic part. This will result in a higher $\mathrm{O}_{2}$-deficit compared to a trained subject. In practice, this phenomenon can be most clearly observed when an untrained subject is compared with a highly trained subject. At the maximum load of the untrained subject, for example $250 \mathrm{~W}$, the trained subject will overcome the major part of the load aerobically and the $\mathrm{VO}_{2}$ curve will not show a levelling off. In the untrained subject, a significant part of the work power is generated anaerobically and the $\mathrm{VO}_{2}$ will stagnate a few minutes before reaching $\mathrm{V}_{2}$ max. Consequently, oxygen uptake at $250 \mathrm{~W}$ is clearly lower in the untrained subject. This would explain at least the higher $\mathrm{V}_{2}$ observed at loads above the anaerobic threshold.

Further investigation may possibly clarify the observations in the current study. Apart from the possible mechanism, the results of the present study suggest that training effects can already be observed using a short-step incremental exercise test without reaching the maximum workload. While it is not permissible to extrapolate these observations to patients or fully untrained subjects, the results of this may also be a major observation in training management and revalidation schedules in patients.

The effect of endurance training on the heart rate response at submaximal levels has already been described but the literature is conflicting. Barbeau et al. (4) and Wilmore and Costill (27) reported a lowered post-training heart rate at the same work rate. Babcock et al. (3) and Norris and Petersen (24) did not observe a change in heart rate post endurance training, which is in accordance with the results of this study. Little is known about the heart rate at $\mathrm{VT}$. In the current study the heart rate at VT remained unchanged pre and post training which is comparable with the literature (4). The heart rate at VT showed a significant correlation with the maximum heart rate, which has already been described in a recently presented study (19).

The study protocol of the current study without a control group may be a point of criticism. However, a control group implies an untrained group, which is difficult to achieve in professional cyclists. Also when a group of non-cyclists were used as control group one would expect training differences between summer and winter since most people are more physically active in the summer. In the discussion mentioned previously, only Hambrecht et al. (16) studied cardiac patients and used a control group and observed exactly the same 
pattern as in the current study. In the present study the training intensity between the two tests of the subjects was not clearly described. However, the mean training duration in a cycling season normally is progressively increased from January until June, so in this study the subjects were all expected to have an improved endurance capacity.

When laboratory parameters, in particular the heart rate, are studied we have to consider that environmental factors like temperature, and humidity may have influenced the results in the current study. However, concerning temperature, Potteiger and Weber (25) showed that during steady state exercise in cyclists, there were no differences between the heart rate at the onset of blood lactate accumulation at different environmental temperatures $(14,22$, and $30^{\circ} \mathrm{C}$ ).

Another point that has to be discussed is the assumption that an error was systematically made between the pre and post-training tests. However, the equipment was calibrated for every test and the last three years I have observed the same pattern in athletes and patients (unpublished data). Furthermore, it would be unlikely that the observed post-training increase in Wmax could be attributable to a systematic error.

To summarise, in the study presented here, the effect of endurance training on the ventilatory response to short-step incremental exercise was investigated in elite cyclists. A key finding was an increased oxygen uptake for the same work rate following endurance training. Another observation was that the heart rate at VT does not differ much during a cycling season. The results of this study are useful in sports medicine practice and training management of elite endurance athletes. These results suggest the following practical recommendations in the training management of elite cylists: 1 . Using a one-minute ramp protocol, the oxygen consumption for an individual at a certain submaximal work rate is an indicator of the endurance training state, such that the higher the oxygen consumption at a certain work rate, the higher the endurance-trained capacity, and 2 . The need for multiple determinations of the heart rate at VT during a cycling season is doubtful since the heart rate at VT does not appear to differ much during the season.

\section{References}

1. Anderson T. Biomechanics and running economy. Sports Med 1996; 22: 76-89

2. Astrand P-O, Rodahl K. Textbook of work physiology 1985 (3rd ed.). New York: McGraw-Hill

3. Babcock MA, Paterson DH, Cunningham DA. Effects of aerobic training on gas exchange kinetics of older men. Med Sci Sports Exerc 1994; 26: 447-52

4. Barbeau $\boldsymbol{P}$, Seresse $\boldsymbol{O}$, Boulay $\boldsymbol{M R}$. Using submaximal aerobic variables to monitor elite cyclists during a season. Med Sci Sports Exerc 1993; 25: 1062-9

5. Bauer TA, Regensteiner JG, Brass EP, Hiat WR. Oxygen uptake kinetics during exercise are slowed in patients with arterial disease. J Appl Physiol 1999; 87: 809-16 
6. Becque MD, Katch V, Marks $\boldsymbol{C}$, Dyer R. Reliability and within subject variability of $\dot{V} E$, $\dot{V} \mathrm{O}_{2}$, heart rate and blood pressure during submaximum cycle ergometry. Int J Sports Med 1993; 14: 220-3

7. Bhambhani $\boldsymbol{Y}, \boldsymbol{M}$ Singh $\boldsymbol{M}$. The effects of three training intensities on $\dot{V}_{2}$ max and $\dot{V E} / \mathrm{VO}_{2}$ ratio. Can J Appl Sport Sci 1985;10: 44-51

8. Caiozzo VJ, Davis JA, Ellis JF, Azus JL, Vandagriff $R$, Prietto CA, McMaster WC. A comparison of gas exchange indices used to detect the anaerobic threshold. $J$ Appl Physiol 1982; 53: 1184-9

9. Charlton GA, Crawford MH. Physiologic consequences of training. Cardiol clin 1997; 15, 345-54

10. Cooper CB, Beaver WL, Cooper DM, Wasserman $\boldsymbol{K}$ Factors affecting the components of the alveolar $\mathrm{CO}_{2}$ output- $\mathrm{O}_{2}$ uptake relationship during incremental exercise in man. Exp Physiol 1992; 77: 51-64

11. Coyle EF, Coggan AR, Hopper MK, Walters TJ. Determinants of endurance in welltrained cyclists. J Appl Physiol 1988; 64: 2622-30

12. Durnin JVGA, Womersly J. Body fat assessed from total body density and its estimation from skinfold thickness: measurements on 481 men and women from 16 to 72 years. $\mathrm{Br}$ J Nutr 1974: 32: 77-97

13. Gissane C, Corrigan DL, White JA. Gross efficiency responses to exercise in adult males of various ages. J Sports Sci 1991; 9(4): 383-91

14. Green HJ, Coates G, Sutton JR, Jones $\boldsymbol{S}$. Early adaptions in gas exchange, cardiac function and heamatology to prolonged exercise training in man. Eur J Appl Physiol 1991: 63 (1): 17-23

15. Greenleaf JE, Ertl AC, Bernauer EM. Submaximal exercise $\dot{\mathrm{V}} \mathrm{O}_{2}$ and Qc during 30-day 6 degrees head-down bed rest with isotonic and isokinetic exercise training. Aviat.Space. Enviro. Med. 1996: 67 (4): 314-9

16. Handel van PJ, Katz A, Morrow JR, Troup JP, Daniels TD, Bradley PW. Aerobic economy and competetive performance of US elite swimmers. Swimming Science $V$ Human Kinetics Champaign III: 225-34

17. Hambrecht $\boldsymbol{R}$, Niebauer J, Fiehn E, et al. Physical training in patients with stable chronic heart failure: Effects on cardiorespiratory fitness and ultrastructural abnormalities of leg muscles. J Am Coll Cardiol 1995; 25: 1239-49

18. Heck H, Mader A, Hess G, Mucke M, Muller M, Hollmann W. Justification of the 4mmo/ll lactate threshold. Int J Sports Med 1985; 6: 117-30 
19. Hoogeveen AR, Schep G Hoogsteen J. The ventilatory threshold, heart rate and endurance performance: relationships in elite cyclists. Int J Sports Med 1999; 20: 114-7

20. Londeree BR. Effects of training on lactate/ventilatory thresholds: a meta-analysis. Med Sci.Sports Exerc 1997; 29(6): 837-43

21. Mero A, Rusko H, Peltola ESA, Pullinen T, Nummela ARI, Hirvonen J. Aerobic characteristics, oxygen debt and blood lactate in speed endurance athletes during training. J Sports Med Phys Fitness 1993; 33: 130-6

22. Miyamoto $\boldsymbol{Y}$, Niizeki $\boldsymbol{K}$. Dynamics of ventilation, circulation, and gas exchange to incremental and decremental ramp exercise. J Appl Physiol 1992; 72: 2244-54

23. Morgan DW, Daniels JT. Relationship between $\mathrm{VO}_{2}$ max and the anaerobic demand of running in elite distance runners. Int J Sports Med 1994; 15: 426-9

24. Norris $\boldsymbol{S} \boldsymbol{R}$, Petersen $\boldsymbol{S} \boldsymbol{R}$. Effects of endurance training on transient oxygen uptake responses in cyclists. J Sports Sci 1998; 16: 733-8

25. Potteiger JA, Weber $\boldsymbol{S} \boldsymbol{F}$. Rating and perceived exercertion and heart rate as indicators of exercise intensity in different environmental temperatures. Med Sci Sports Exerc 1994: 26: 791-6

26. Wasserman $\mathbf{K}$, Stringer WW, Casaburi R, Koike A, Cooper CB. Determination of the anaerobic threshold by gas exchange. Biochemical considerations, methodology and physiological effects. Z Kardiol 1994; 83: 1-12

27. Wilmore JH, Costill. DL. Physiology of sport and exercise. Human Kinetics Champaign 1994; 111: 221

28. Xu F, Rhodes EC. Oxygen uptake kinetics during exercise. Sports Med 1999; 27: 31327

29. Zhang $\mathbf{Y Y}$, Johnson MC, Chow N, Wasserman $\boldsymbol{K}$. Effect of exercise testing protocol on parameters of aerobic function. Med Sci Sports Exerc 1991; 23: 625-30 


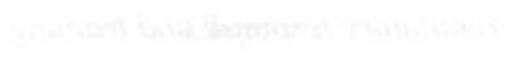

4⿻5

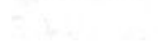

$$
\sqrt{2}
$$

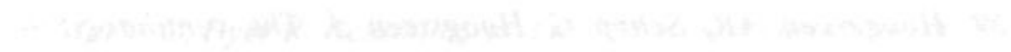

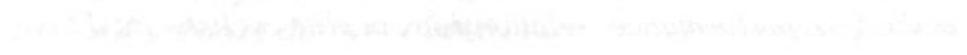

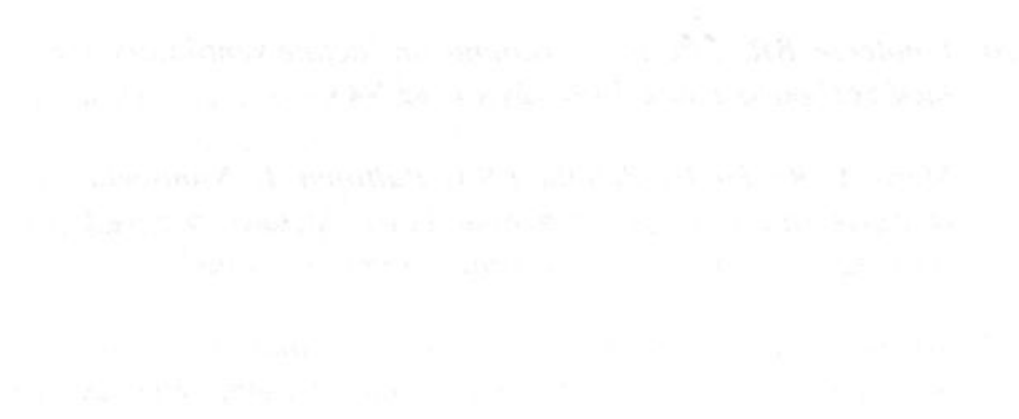

(1)

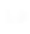

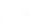




\section{Chaptere}

The $\mathrm{VO}_{2}$ overshoot at the onset of constant-load exercise in elite cyclists: an undescribed phenomenon

A.R. Hoogeveen and H.A. Keizer

Submitted to the European Journal of Applied Physiology.

Acknowledgements: The authors thank Dr. B. de Vries for his advises concerning the curve analysis. 


\section{Summary}

The $\mathrm{VO}_{2}$ response following a step increase in work rate can be characterised as consisting of an early cardiodynamic component and a subsequent metabolic component. The metabolic component is expected to fit into a mono- or bi-exponential mathematical equation. In previous exercise tests in two independent laboratories we observed a remarkable $\mathrm{VO}_{2}$ overshoot at the onset of constant-load exercise in well-trained cyclists. The purpose of this study was to investigate this remarkable phenomenon.

Fifteen male elite cyclists (age $26.3 \pm 3.3$ years, height $180.7 \pm 5.3 \mathrm{~cm}$, body mass $72.5 \pm 3.6$ $\mathrm{kg}$ ) underwent a constant-load exercise test $(250 \mathrm{~W})$ on a cycle-ergometer. Ventilation and gas exchange kinetics were determined during this constant-load exercise. Gas exchange data were measured breath-by-breath and signal-averaged data were fit with a sixth degree polynomial function.

The mean submaximal $\mathrm{VO}_{2}$ during steady state was $3320 \pm 120 \mathrm{ml} \cdot \mathrm{min}^{-1}$. The mean $\mathrm{R}^{2}$ of the polynomial functions was $0.93 \pm 0.04$. The mean maximum $\mathrm{VO}_{2}$ at the curve maximum derived from the polynomial function was $3528 \pm 144 \mathrm{ml} \cdot \mathrm{min}^{-1}$. The mean maximum $\mathrm{V}_{2}$ overshoot was reached after $76.9 \pm 13.0 \mathrm{~s}$ (range $65-90 \mathrm{~s}$ ) following the onset of exercise. In three subjects we did not observe a clear $\mathrm{VO}_{2}$ overshoot and the curve clearly showed a mono-exponential pattern.

The $\mathrm{VO}_{2}$ overshoot is in contrast with the classic exponential kinetic models in which the $\mathrm{VO}_{2}$ is continuously increasing. The $\mathrm{VO}_{2}$-overshoot phenomenon will highly influence the analysis of the $\mathrm{VO}_{2}$ response with mono- or bi-exponential models and the determination of the oxygen deficit. In this article, we introduce an additional switch-on component at the onset of exercise. For analysing the $\mathrm{VO}_{2}$ response in the future we advise to add the mathematical equation of this component to the classic equations. The physiological mechanism of the $\mathrm{VO}_{2}$ overshoot has to be investigated. 


\section{Introduction}

The oxygen uptake kinetics has been extensively studied since the first report of the exponential nature of gas exchange responses during constant-load exercise in 1913 (8$10,13,15,16)$. The oxygen uptake $\left(\mathrm{VO}_{2}\right)$ following a step increase in work rate can be characterised as consisting of an early cardiodynamic component with unchanged mixedvenous $\mathrm{O}_{2}$-content (phase I) and a subsequent metabolic component (phase II) starting when venous blood from the muscle arrives at the lungs $(9,10,15,16)$. The cardiodynamic component plays a role in $\mathrm{VO}_{2}$ kinetics in the first 20-30 s following a rest-exercise transition $(9,16)$.

Xu and Rhodes (15) have recently reviewed the second phase or metabolic component of the $\dot{\mathrm{V}}_{2}$ response at the onset of exercise. The response at exercise intensity below the lactate threshold can be described by a mono-exponential mathematical equation (see discussion). During heavy exercise the $\mathrm{VO}_{2}$ response becomes more complex and consists of two components. The initial response increases still exponentially, however after some minutes an additional component is developed slowly causing an increase in $\mathrm{VO}_{2}$ during the constant load ( $\mathrm{VO}_{2}$ drift). The possible mechanisms underlying these fast and slow components are not quite clear.

Over the last few years and in two independent laboratories we observed in very well-trained endurance athletes a remarkable phenomenon at the beginning of constant-load tests. Just before reaching the level of steady state, in the first two minutes of exercise, the $\mathrm{V}_{2}$ peaks clearly above the steady-state level reached in the following minutes. As far as we know this observation has never been described before. This $\mathrm{VO}_{2}$ overshoot would be in contrast with the conventional mono- or bi-exponential model.

The purpose of this study was to describe and discuss this remarkable phenomenon at the onset of constant-load exercise. The initial $\mathrm{VO}_{2}$ response was investigated in well-trained endurance cyclists and the characteristics and the possible mechanisms are discussed.

\section{Materials and Methods}

\section{Subjects}

Fifteen professional and elite amateur cyclists volunteered to take part in this study (age 26.3 \pm 3.3 years, height $180.7 \pm 5.3 \mathrm{~cm}$, body mass $72.5 \pm 3.6 \mathrm{~kg}$ ) and gave their written informed consent. The subjects were free from serious diseases and took no drugs or medication during the course of the study.

On the test days, none showed any sign of disease or infection. The subjects had been training regularly for at least 6 years $(9.1 \pm 3.6$ years.). The exact volume and intensity of training and competition can not easily be established. The mean training duration including competition was $13.3 \pm 4.6$ hours a week in the period before the test.

\section{Test procedure}

The subjects refrained from intensive exercise in the previous 24 hours. They were instructed to take a carbohydrate rich diet before the exercise test. In the three days before the test the subjects had not competed. The subjects underwent a constant-load test of $250 \mathrm{~W}$. Before starting, a warming-up of 5 minutes was allowed. After the warming-up period of 5 minutes 
the subjects took a two-minute rest without pedalling. Subsequently, the workload increased to $250 \mathrm{~W}$ for 5 minutes.

All measurements took place under the same conditions of temperature $\left(22^{\circ} \mathrm{C}\right)$ and humidity $(55 \%)$. The sitting position on the cycle-ergometer (Excalibur-sport, Lode, Groningen) was adapted individually for each subject to create the same position as in competition. A 12-lead ECG was performed every minute.

The subjects used their own choice of pedalling speed but above 80 and below $100 \mathrm{rpm}$, in which range the work load remained constant, but they were not allowed to change this pedalling speed during the test.

The subjects breathed through a mask, which was connected by an elastic tube to an oxymeter (Oxycon, Jaeger BeNeLux BV, Breda, Netherlands). The mask dead space was 65 $\mathrm{ml}$. Expired gases were continuously sampled and analysed for $\mathrm{O}_{2}, \mathrm{CO}_{2}$ and volume. These instruments were coupled to a computer, which plotted workload against $\dot{\mathrm{VO}}_{2}, \dot{\mathrm{V}} \mathrm{CO}_{2}$, minute ventilation (V́) and heart rate (Software Jaeger, Netherlands).

The volume transducer was calibrated before every test using a calibration syringe. The $\mathrm{CO}_{2}$ and $\mathrm{O}_{2}$ gas analyser were calibrated manual by means of a gas bag with a known calibration gas sampled via the twin tube, and automatically using a bottle of calibration gas by means of a computer controlled manoeuvre. A fully automatic pneumatic system check of the analysers and sampling system was performed every test including the tubes, valves, and the calibration factors of the analysers.

Gas-exchange data were continuously measured breath-by-breath and signal-averaged data were fit with a sixth degree polynomial function using Microsoft Excel 1997. The $\dot{V O}_{2}$ used for sampling and calculations was the mean of every 5 seconds (Fig 1). Heart rate, VE, and $\dot{\mathrm{VCO}}_{2}$ were analysed by the same way. Steady-state values at the different workloads were defined as the mean values in the last 120 seconds.

\section{Figure 1}

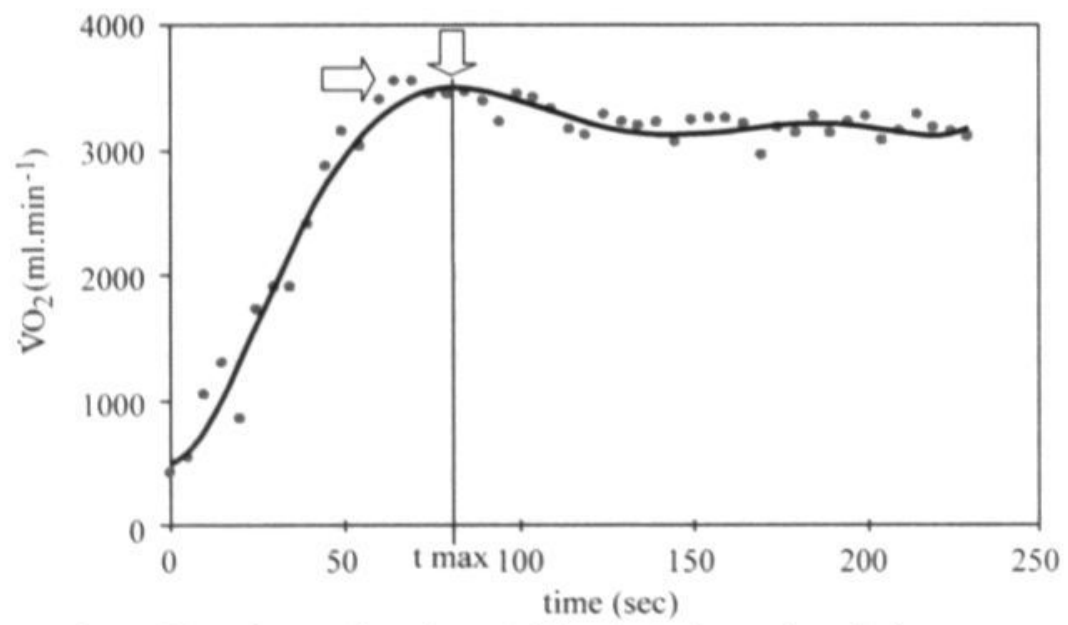

Typical $\mathrm{VO}_{2}$ response of one of the subjects. The polynomial function is drawn through the measurements. The vertical arrow marks the maximum of this function. The horizontal arrow marks the highest 5 second average.

The $\mathrm{VO}$, in the first mimutes can be described as follows:

$\mathrm{VO}_{2} t=2.1 E^{-9} t^{6}-1.3 E^{6} t^{5}+3.8 E^{4} t^{4}-4.8 E^{-2} t^{3}+2.4 t^{2}+9.5 t+488$

$R^{2}=0.97$ 


\section{Results}

The percentage of body fat, estimated using the measurements of four skin folds according to Durnin and Womersley (4) was $9.3 \pm 1.4 \%$. The mean $\mathrm{VO}_{2}, \mathrm{VCO}_{2}, \dot{\mathrm{VE}}$, and heart rate during steady state are shown in Table 1 . The mean maximum of the $\mathrm{VO}_{2}$ curve using the polynomial function was $3528 \pm 144 \mathrm{ml} \cdot \mathrm{min}^{-1}$. The maximum of the $\mathrm{VO}_{2}$ overshoot was reached at a time of $76.9 \pm 13.0 \mathrm{~s}$ (range 65-90 s) after the onset of exercise (Fig 1). The highest 5 second $\mathrm{VO}_{2}$ average (Fig 1) was $3655 \pm 188 \mathrm{ml} \cdot \mathrm{min}^{-1}$ and this maximum was reached after $73.1 \pm 11.4 \mathrm{~s}$ (range $58-88 \mathrm{~s}$ ). The mean $\mathrm{R}^{2}$ of the polynomial function was 0.93 \pm 0.04 .

The cadence rate was $91.5 \pm 3.1 \mathrm{rpm}$ (range $85-96$ ). The curves of $\mathrm{VE}, \dot{\mathrm{V}} \mathrm{CO}_{2}$ and heart rate did not show any sudden increase and fit well into a mono-exponential model. In three subjects we did not observe a clear $\mathrm{VO}_{2}$ overshoot and the curve clearly showed a monoexponential pattern (Fig 2).

Table 1. The mean and standard deviation of the steady-state levels of $\mathrm{VO}_{2}, \mathrm{VCO}_{2}$, $\hat{V E}$, and heart rate during the constant-load exercise.

\begin{tabular}{|c|c|c|c|}
\hline & & mean & \pm sd \\
\hline$\dot{\mathrm{VO}}_{2}$ & $\mathrm{ml} \cdot \mathrm{min}^{-1}$ & 3320 & \pm 120 \\
\hline$\dot{\mathrm{VCO}}_{2}$ & $\mathrm{ml} \cdot \mathrm{min}^{-1}$ & 3129 & \pm 113 \\
\hline$\dot{V E}$ & 1. $\min ^{-1}$ & 75 & \pm 11 \\
\hline HR & beats. $\min ^{-1}$ & 134 & \pm 11 \\
\hline
\end{tabular}

Figure 2

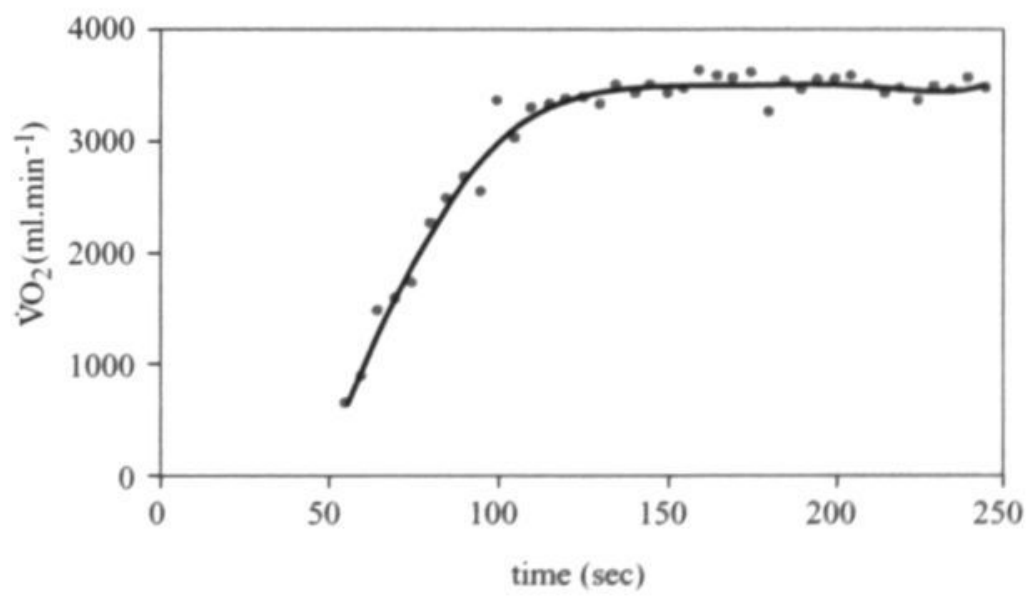

One of the subjects who did not show a clear vi $\mathrm{O}_{2}$ overshoot. 


\section{Discussion}

In this study, the initial $\mathrm{VO}_{2}$ response to constant-load exercise was investigated in trained cyclists. A curious observation in this study is the $\mathrm{VO}_{2}$ overshoot within the first two minutes before reaching the steady-state $\mathrm{VO}_{2}$. The $\mathrm{VO}_{2}$ overshoot has been also demonstrated in the data of Green and Dawson (5) and Brunner-La Rocca et al. (3), however they did not remark on and describe this phenomenon.

The $\mathrm{VO}_{2}$ response following a step increase in work rate can be characterised as consisting of an early cardiodynamic component with unchanged mixed-venous $\mathrm{O}_{2}$-content (phase I) and a subsequent metabolic component (phase II) starting when venous blood from the muscle arrives at the lungs $(9,10,15,16)$. Yoshida et al. (16) investigated the rest-exercise transitions and observed that $\mathrm{VO}_{2}$ rapidly increased with time constants of 6.8-7.3 s. The cardiac output (CO) also showed a similar rapid increment with time constants of 6.0-6.8 s with an apparent increase in stroke volume (SV). In Yoshida's study (16) $\mathrm{VO}_{2}$ increased in phase I up to $30 \%-34 \%$ of the steady-state value and CO increased up to $58 \%-87 \%$ of the steady-state value. Thereafter, some $20 \mathrm{~s}$ after the onset of exercise, a mono-exponential increase to steady-state occurred both in $\mathrm{VO}_{2}$ and cardiac output with time constants of 26.732.3 and 23.7-34.4 s, respectively. Leyk et al. (9) also observed a first, mainly cardiovascular component over the first $30 \mathrm{~s}$, followed by a second, metabolic component at constant $\mathrm{CO}$. Leyk et al. (9) postulated two early features. First, a very rapid $\mathrm{VO}_{2}$ increase during the initial breathing cycles at the onset of exercise. This was probably caused by events in the lungs or the pulmonary circulation. Second, the $\mathrm{CO}$ attained its steady-state level in about 10 s. This suggested a sudden increase in venous return (9).

In the current study the maximum of the $\mathrm{V}_{2}$ overshoot was reached between $55-90 \mathrm{~s}$, while the early cardiodynamic phase is finished within $20-30 \mathrm{~s}(8,15)$. Furthermore the $\mathrm{VO}_{2}$ reached in phase II is only about $30 \%(16)$. So the early fast cardiodynamic phase will probably not be responsible for the overshoot in $\mathrm{VO}_{2}$ in the current study.

The metabolic component of the $\mathrm{VO}_{2}$ response (phase II) at the onset of exercise has been thoroughly studied and was recently extensively reviewed by Xu and Rhodes (15). The response at exercise intensity below the lactate threshold can be described by a monoexponential mathematical equation (Formula I). During heavy exercise the $\mathrm{VO}_{2}$ response becomes more complex and consists of two components (Formula II). The initial response increases still exponential. However after some minutes an additional response is developed

\section{Formula I and II}

The bi-exponential model is the sum of the fast mono-exponential component and the slow component. (see discussion). The bi-exponential model (2) included two amplitudes $\left(A_{1}\right.$ and $A_{2}$ ), two time constants ( $\tau_{1}$ and $\tau_{2}$ and two not-fixed delay times $\left(\operatorname{Td}_{1}\right.$ and $\left.T d_{2}\right) . A_{1}$, $\tau_{1}$ and $\mathrm{Td}_{1}$ are an indication of the primary, fast component, while $A_{2} \tau_{2}$ and $\mathrm{Td}_{2}$ express the slow component.

$$
\begin{aligned}
& \dot{V} O_{2}(t)=\dot{V} O_{2} \text { baseline }+A\left(1-e^{-(t-T d) / \tau}\right) \\
& \dot{V} O_{2}(t)=\dot{V} O_{2} \text { baseline }+A_{1}\left(1-e^{\left.-\left(t-T d_{1}\right) / \tau_{1}\right)}+A_{2}\left(1-e^{\left.-\left(t-T d_{2}\right) / \tau_{2}\right)}\right.\right.
\end{aligned}
$$


slowly causing an increasing $\mathrm{VO}_{2}$ during the constant load ( $\mathrm{VO}_{2}$ drift). The possible mechanisms underlying these fast and slow components are not clear. In both formulas, the $\mathrm{VO}_{2}$ as a function of time always increases. So this theoretical model does not fit with the observations in the current study in which a $\mathrm{VO}_{2}$ peak occurs between 50 and $100 \mathrm{~s}$ after the onset of exercise. In addition, the curve fitting in the exponential models will be highly affected by the $\mathrm{VO}_{2}$ overshoot and it will influence the calculation of the $\mathrm{O}_{2}$ deficit (6).

The dynamics and interpretation of ventilation and gas exchange during exercise have been studied thoroughly $(10,11,15)$. These issues are very complicated and not easy to explain. Perhaps the $\mathrm{VO}_{2}$ overshoot is a mechanism to overcome the early $\mathrm{O}_{2}$ deficit. Since other authors already described faster $\mathrm{V}_{2}$ kinetics following training and in already trained subjects the $\mathrm{VO}_{2}$ overshoot may be also an indication of an endurance-trained state $(1,2,7,12,13)$. Based on Fick's principles, an increased oxygen uptake is the result of an increased cardiac output or arterial-venous oxygen difference: $(\mathrm{a}-\mathrm{v}) \mathrm{O}_{2}$. In the current study the heart rate did not show a sudden initial increase in the first minutes so the increased oxygen uptake should be the result of an increased stroke volume or an increased (a-v) $\mathrm{O}_{2}$. Both mechanisms are possible or a combination of the two. Since heart rate did not show a sudden initial increase, the oxygen pulse showed the same phenomenon as the $\mathrm{VO}_{2}$. Thus a temporary maximum in stroke volume remains a possibility.

Another possible explanation may be that a sudden opening of arterioles and pre-capillary sphincters would enhance muscle perfusion resulting in faster and/or more oxygen extraction. Experiments in humans indeed have shown a sudden increase in perfusion of exercising muscles at the onset of work intensity $(5,14)$. Therefore, muscle perfusion is a good possibility to explain the new-described overshoot phenomenon. In addition, a peak of catecholamines or the activation of the muscle pump itself may play a role in the enhanced peripheral perfusion.

Another explanation may be the extra oxygen that is needed for the legs to start moving and for accelerating the pedals. However this counts only for the first seconds. Furthermore restexercise transitions are sometimes associated with contractions of trunk or arm muscles, which may induce effects on ventilation and circulation.

Apart from the question concerning the possible mechanism, it should be pointed out that the classic mono-and bi-exponential models do not agree with our observations. Our method of analyses using a polynomial function can be an issue of discussion but this mathematical function certainly fits well in the observed curves and made the analysis of the curves easier. A point of discussion in the present study may be that the sampling time of the ventilatory parameters was the mean of every 5 seconds. This may be a too short period at the beginning of the exercise when the breathing frequency is low. Indeed, some parameters using 5-second means showed fluctuations at the beginning. However, we calculated the ventilatory parameters also over a period of 10,15 and $20 \mathrm{~s}$ but the overshoot phenomenon remains and the polynomial function did not differ much.

To describe the $\mathrm{VO}_{2}$ response and $\mathrm{VO}_{2}$ kinetics to constant-load exercise, we introduce an additional component. The behaviour of this third component can be viewed as a switch-on phenomenon as a result of the start of a linear dynamic system. A possible mathematical equation is shown in formula III and an example of the curve of this component is shown in Figure 3 . In this equation a delay time can be inserted and a time constant can be used instead of the constant factor B. In Figure 4 this component is added to the fast component of the classic mono-exponential model (Formula 1). This results in the typical $\mathrm{VO}_{2}$ overshoot 
observed in the current study. At higher loads, the classic slow component can be added (second part of Formula 2). Our model with two or three components fits better than the classic mono-and bi-exponential model. For analysing $\mathrm{VO}_{2}$ kinetics in the future, we advise to use our theoretical model. Since computer programs to analyse this three-component model are not yet available, curve fitting with a higher degree polynomial function is an alternative.

To sum up, in this study we have described the $\mathrm{VO}_{2}$ response to constant-load exercise. We have observed a remarkable $\mathrm{VO}_{2}$ overshoot during the first minutes before reaching the steady-state $\mathrm{VO}_{2}$. The possible physiological explanations of this phenomenon have been discussed but are not clear. Further research will be necessary to clarify the observations of the current study. Especially the area-under-the-curve, representing the real amount oxygen overshoot or deficit, needs further investigation.

Formula III (see also text and Figure 3).

$\hat{\mathrm{VO}}_{2}(\mathrm{t})=$ A.t.e $\mathrm{e}^{-\mathrm{B} . \mathrm{t}}$

In which A and B are constant factors. A delay time (Td) can be added and B can be substituted by a time constant $(\tau)$ resulting in:

$\hat{V O}_{2}(t)=A \cdot(t-T d) \cdot e^{-(t-T d) / \tau}$

Figure 3

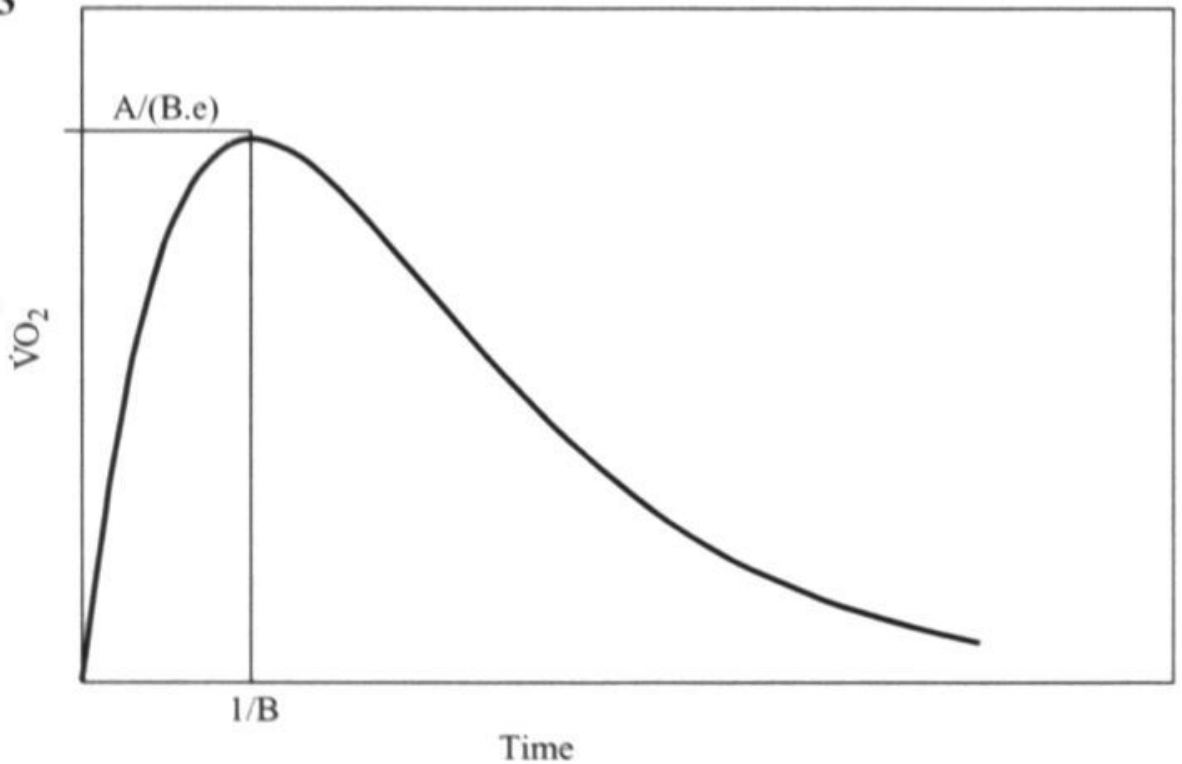

An example of a curve expressed by Formula III (see text). 


\section{Figure 4}

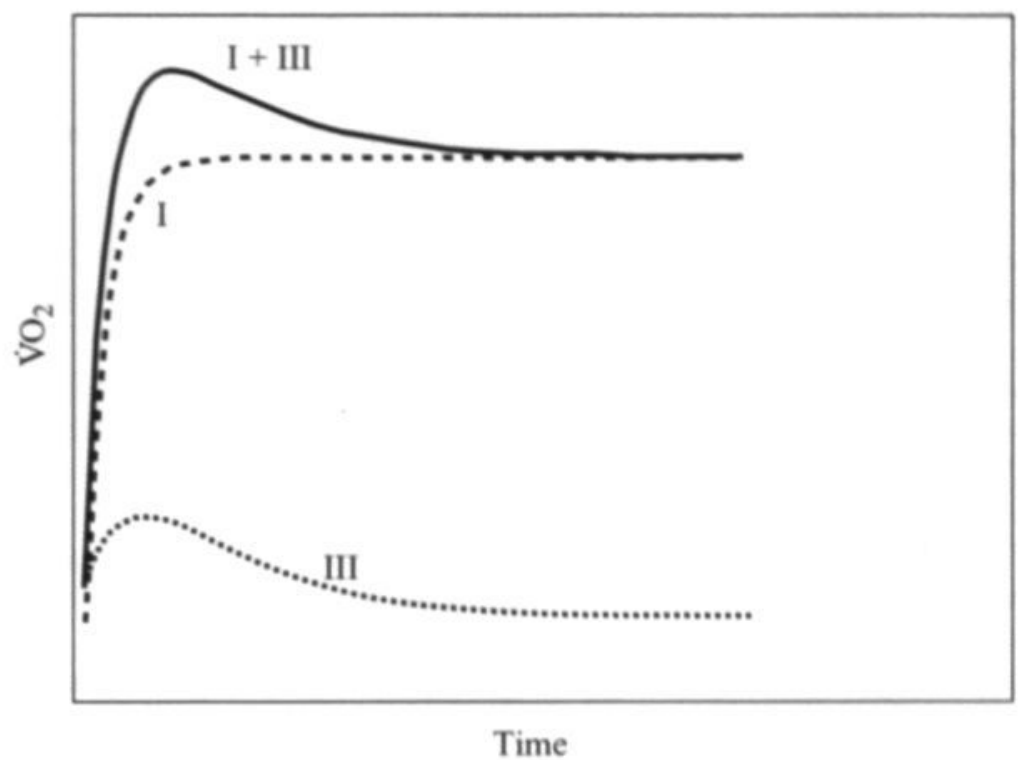

The third component (III) component is added to the fast component of the classic mono-exponential model

(I). This results in the typical $\mathrm{VO}_{2}$ overshoot obsenved in this study $(I+I I I)$.

\section{References}

1. Babcock MA, Paterson DH, Cunningham DA. Effects of aerobic training on gas exchange kinetics of older men. Med Sci Sports Exerc 1994; 26: 447-52

2. Bauer TA, Regensteiner JG, Brass EP, Hiat WR. Oxygen uptake kinetics during exercise are slowed in patients with arterial disease. J Appl Physiol 1999; 87: 809-16

3. Brunner-La Rocca HP, Weilenmann D, Schlumpf M, Rickli H, Schalcher C, Maly FE, Candinas $\boldsymbol{R}$, Kiowski $\boldsymbol{W}$. Oxygen uptake kinetics during low exercise in patients with heart failure: relation to neurohormones, peak oxygen consumption, and clinical finding. Heart 1999; 81:121-7

4. Durnin JVGA, Womersly J. Body fat assessed from total body density and its estimation from skinfold thickness: measurements on 481 men and women from 16 to 72 years. Br J Nutr 1974: 32: 77-97

5. Grassi B, Poole DC, Richardson RS, Knight DR, Erickson BK, Wagner PD. Muscle $\mathrm{O}_{2}$ uptake kinetics in humans: implications for metabolic control.J Appl Physiol 1996; 80: $988-98$

6. Green $\boldsymbol{S}$, Dawson BT. Methodological effects on the $\mathrm{VO}_{2}$-power regression and the accumulated O2 deficit. Med Sci Sports Exerc 1996: 28: 392-7 
7. Hoogeveen AR. The effect of endurance training on the ventilatory response to exercise in elite cyclists. Eur J Appl Physiol 2000; 82: 45-51

8. Krogh A, Lindhard $\boldsymbol{J}$. The regulation of respiration and circulation during the initial stages of muscular work. J Physiol 1913; 47: 112-36

9. Leyk D, Hoffmann U, Essfeld D, Baum K, Stegemann J. $\dot{V} \mathrm{O}_{2}$ and cardiac output during rest-exercise and exercise-exercise transients. Z Kardiol 1994; 83 Suppl 3: 61-5

10. Leyk D, Hoffmann U, Baum K, Essfeld D. Time courses of cardiac output and oxygen uptake following stepwise increases in exercise intensity. Int J Sports Med 1995; 16: 35763

11. Miyamoto $\boldsymbol{Y}$, Niizeki $\mathbf{K}$. Dynamics of ventilation, circulation, and gas exchange to incremental and decremental ramp exercise. J Appl Physiol 1992; 72: 2244-54

12. Norris SR, Petersen SR. Effects of endurance training on transient oxygen uptake responses in cyclists. J Sports Sci 1998; 16: 733-738

13. Phillips SM, Green JH, MacDonald JM, Hughson RL. Progressive effect of endurance training on $\mathrm{VO}_{2}$ kinetics at the onset of submaximal exercise. J Appl Physiol 1995; 79: 1914-20

14. Richardson RS, Harms CA, Grassi B, Hepple T. Skeletal muscle: master or slave of the cardiovascular system. Med Sci Sports Exerc 2000; 32: 89-93

15. Xи F, Rhodes EC. Oxygen uptake kinetics during exercise. Sports Med 1999: 27: 31327

16. Yoshida T, Yamamoto $\boldsymbol{K}$, Udo $\boldsymbol{M}$. Relationship between cardiac output and oxygen uptake at the onset of exercise. Eur J Appl Physiol 1993; 66: 155-60 


\section{Chaptere}

The effect of endurance training on the $\mathrm{VO}_{2}$ overshoot and the submaximal $\mathrm{VO}_{2}$ during steady-state exercise in competitive cyclists
A.R. Hoogeveen, H. Kuipers and H.A. Keizer
In print 


\section{Summary}

The purpose of this study was to investigate the effects of endurance training on $\mathrm{VO}_{2}$ kinetics in already endurance-trained subjects. Thirteen male competitive cyclists (mean \pm sd: age 31 \pm 3.7 year, height $185 \pm 7 \mathrm{~cm}$, body mass $78.9 \pm 8.8 \mathrm{~kg}$ ) underwent 2 exercise tests on a cycle ergometer. The first test was assessed in February, 4 weeks before the beginning of the cycling season. The second test was performed in July, in the middle of the season, during which period the cyclists were expected to be in a highly endurance-trained state.

Ventilation and gas exchange kinetics were determined during an incremental exercise test (100 W per $5 \mathrm{~min}$ ). Ventilation and gas exchange data during every load were measured breath-by-breath and signal averaged data were fit with a sixth degree polynomial function. The mean post-training $\mathrm{VO}_{2}$ max was increased from the pre-training level of $56.2 \pm 4.8$ $\mathrm{ml} \cdot \mathrm{min}^{-1} \cdot \mathrm{kg}^{-1}$ (range 49.2-65.8) to $60.4 \pm 5.3 \mathrm{ml}^{\mathrm{min}}{ }^{-1} \cdot \mathrm{kg}^{-1}$ (range 50-66) post training $(\mathrm{p}<0.01)$. The mean post-training $\mathrm{VO}_{2}$ during steady state was lower than the pre-training levels at $100 \mathrm{~W}(\mathrm{p}<0.05)$, and was not changed at 200 and $300 \mathrm{~W}$. Steady-state $\mathrm{VCO}_{2}$ levels at 100,200 and $300 \mathrm{~W}$ were decreased post training $(\mathrm{p}<0.05)$.

Pre training, 3 subjects did not show a $\mathrm{VO}_{2}$ overshoot at $100 \mathrm{~W}$, post training only one subject did. The post-training $\mathrm{VO}_{2}$ overshoot at 100 and at $200 \mathrm{~W}$ reached its maximum significantly earlier (duration $69 \pm 13 \mathrm{~s}$ at $100 \mathrm{~W}, 69 \pm 18 \mathrm{~s}$ at $200 \mathrm{~W}$ ) than pre training (duration $77 \pm 12 \mathrm{~s}$ at $100 \mathrm{~W}, 79 \pm 17 \mathrm{~s}$ at $200 \mathrm{~W}$ ). During both tests, the $\mathrm{VO}_{2}$ overshoot was clearer at lower loads: at the transition from 100 to $200 \mathrm{~W}$ only 7 subjects showed an overshoot pre and post training, at $300 \mathrm{~W}$ only 2 subjects showed a $\mathrm{VO}_{2}$ overshoot.

The results of this study suggest the following practical implications for training management: increased oxygen kinetics and lowered submaximal $\mathrm{VO}_{2}$ and $\dot{\mathrm{VCO}}_{2}$ levels at a workload with a low percentage of $\mathrm{VO}_{2}$ max (about $40 \%$ ) are indicators of an increased endurance-trained state. The need for a maximal incremental exercise test for the purpose of training monitoring may no be necessary. 


\section{Introduction}

The studies concerning the effect of endurance training on the ventilatory response are numerous. The majority of these studies were focused on the training effects of the maximal oxygen uptake $\left(\mathrm{VO}_{2}\right.$ max), the ventilatory threshold (VT), and lactate threshold (LT) $(7,21,29)$. It is commonly accepted that endurance training will improve $\mathrm{VO}_{2}$ max and the $\mathrm{VO}_{2}$ at $\mathrm{VT}$, and that detraining will reduce these parameters $(7,10,21)$. The $\mathrm{VO}_{2}$ kinetics has also been extensively studied $(3,15,19,25,31,32)$ since the first report of the exponential nature of gas exchange responses during a constant-load exercise in 1913 (20). The $\mathrm{VO}_{2}$ following a step increase in work rate can be characterised as consisting of an early cardiodynamic component with unchanged mixed-venous $\mathrm{O}_{2}$-content (phase I) and a subsequent metabolic component (phase II) starting when venous blood from the muscle arrives at the lungs $(31,32)$. The cardiodynamic component plays a role in $\mathrm{VO}_{2}$ kinetics in the first $20-30 \mathrm{~s}$ following a rest-exercise transition $(31,32)$. The $\mathrm{VO}_{2}$ during the metabolic component (phase II) during moderate-intensity exercise, below the ventilatory or lactate threshold, increases exponentially toward a steady-state level. During heavy exercise intensity the oxygen kinetics are more complex and a additional slower component causes $\mathrm{VO}_{2}$ to increase progressively and delays the attainment of a steady-state level (31). The possible mechanisms, which may influence these two components, are not yet elucidated $(19,31,32)$. In a recent study we reported a remarkable $\mathrm{VO}_{2}$ overshoot at the onset of constant-load exercise (19). This phenomenon was not in agreement with the traditional exponential model. This $\mathrm{VO}_{2}$ overshoot was also clear in the data of Green and Dawson (16), however they did not remark on and describe this phenomenon. We added an additional component to analyse the $\mathrm{VO}_{2}$ kinetics mathematically. The $\mathrm{VO}_{2}$-respons fitted better into a higher degree polynomial function then in the widely accepted exponential function (14,31). Few authors have investigated the effect of endurance training on the oxygen kinetics. In untrained healthy older subjects $(2)$, and trained subjects $(23,25)$ faster kinetics has been described following endurance training. Otsuka et al. (24) and Bauer et al. (6) described faster oxygen kinetics following training in patients with chronic obstructive pulmonary disease and peripheral arterial disease, respectively.

The purpose of this study was to investigate the effect of endurance training on the $\mathrm{VO}_{2}$ kinetics, in particular the $\mathrm{VO}_{2}$-overshoot phenomenon, and the steady-state levels in competitive cyclists.

\section{Materials and Methods}

\section{Subjects}

Fifteen male competitive cyclists volunteered for this study (mean \pm sd: age $31 \pm 3.7$ years, height $185 \pm 7 \mathrm{~cm}$, weight $78.9 \pm 9.9 \mathrm{~kg}$ ) after having given written informed consent. Two subjects complained of impaired performance and showed signs of overtraining during the course of the study and suffered from it during the post-training test. They were excluded from the study. The remaining 13 subjects were in good health and took no drugs or medication during the course of the study. Since a drug-free state of competitive cyclists is not easily ascertained, some blood was taken before every test to determine hematocrite values in order to rule out a major change in hematocrite value. The subjects underwent two incremental 
exercise tests. The first test was assessed in February, four weeks before the beginning of the cycling season (= pre training). The second test was performed in July, in the middle of the season in which the subjects where expected to be highly endurance trained (= post training). The subjects had trained regularly for at least 4 years $(8.1 \pm 3.5$ years. $)$. The exact volume of training and competition could not easily be established. The mean training duration including competition was $5 \pm 3$ hours a week before the first test and $12 \pm 3$ in the period before the second test. Competition started in March. The period between the second test they had 20-34 days of competition with a range in length of $60-125 \mathrm{~km}$ a day.

\section{Testing procedure}

All measurements took place under the same conditions of temperature $\left(22^{\circ} \mathrm{C}\right)$ and humidity $(55 \%)$. Subjects refrained from intensive exercise in the previous 24 hours. The diet before the tests and between the test was not changed and they were instructed to take a carbohydrate rich diet before the exercise tests. In the two days before the testing procedure the subjects had not competed. The sitting position on the cycle-ergometer (Excalibur-sport, Lode, Groningen) was adjusted individually for each subject to create the same position as in competition. A 12-lead ECG was performed every minute.

After a warming-up period of 5 minutes at $50 \mathrm{~W}$ the subjects took a two-minute rest without pedalling and then the workload increased was to $100 \mathrm{~W}$ for 5 minutes. Subsequently, the load was increased by $100 \mathrm{~W}$ for every $5 \mathrm{~min}$. They were expected to have reached their maximum when the subjects could not maintain a pedalling speed above $80 \mathrm{rpm}$ or when the oxygen uptake did not increase despite a higher workload. The subjects used their own choice of pedalling speed in the range of 80 and $110 \mathrm{rpm}$, in which range the workload calibrated. It was not allowed to change the chosen pedalling speed during the test.

The subjects breathed through a mask, which was connected by an elastic tube to an oxymeter (Oxycon, Jaeger BeNeLux BV, Breda, Netherlands). The mask dead space was 65 $\mathrm{ml}$. Expired gases were continuously sampled and analysed for $\mathrm{O}_{2}, \mathrm{CO}_{2}$ and volume. These instruments were coupled to a computer, which plotted workload against $\dot{\mathrm{VO}}_{2}, \dot{\mathrm{V}} \mathrm{CO}_{2}$, and heart rate (Software Jaeger, Netherlands).

The volume transducer was calibrated before every test using a calibration syringe. The $\mathrm{CO}_{2}$ and $\mathrm{O}_{2}$ gas analysers were calibrated with a calibration gas. A fully automatic pneumatic system check of the analysers and sampling system was performed every test including the tubes and valves and the calibration factors of the analysers.

Gas exchange data during every work load increment were measured breath-by-breath and signal averaged data were fit with a sixth degree polynomial function using Microsoft Excel 1997. The measurements used for sampling and calculations were the mean of every 5 seconds. Heart rate, $\dot{\mathrm{VE}}$ and $\dot{\mathrm{V}} \mathrm{CO}_{2}$ were analysed in the same way. Submaximal steady-state values at the different workloads were defined as the mean values of the last 120 seconds.

\section{Statistical methods}

Differences and relations between the $\mathrm{VO}_{2}$ levels, $\dot{\mathrm{VE}}$, heart rate, hematocrite values, and cadence rate were analysed using a paired T-test and using Pearson's Product Moment Correlation. The level of significance was set at 0.05 . 
Analytical methods

Hematocrite values were assessed using a Coulter STKS by means of a conductivity principal (Coulter, Mijdrecht, Netherlands.

\section{Results}

The pre- and post-training mean maximum work rate, $\mathrm{V}_{2} \max$, body mass and percentage of body fat, estimated using the measurements of four skin folds according to Durnin and Womersley (11), are shown in Table 1. The steady-state $\mathrm{VO}_{2}$ levels at 100 and 200 are shown in Table 2. At 300 Watt only 4 subjects showed a steady state during both tests, at $400 \mathrm{~W}$ no one did. The $\mathrm{VO}_{2}$ at $100 \mathrm{~W}$ was decreased post training ( $\mathrm{p}<0.05$ ), at $200 \mathrm{~W}$ the decrease was not significant and at 300 Watt there was a tendency to a post-training increase in $\mathrm{VO}_{2}$ (only 4 subjects).

Table 2 shows the highest mean $5-\mathrm{s} \mathrm{VO}_{2}$ average and the mean maximum of the polynomial curve ( $\mathrm{VO}_{2}$-curve max). Although there is no absolute post-training difference, the $\mathrm{VO}_{2}$ overshoot is relatively increased compared to the post training decreased steady-state levels. During both tests, the $\mathrm{VO}_{2}$ overshoot was clearer at lower loads: at the transition from 100 to $200 \mathrm{~W} 7$ subjects showed an overshoot pre and post training. At $300 \mathrm{~W}$ only 2 subjects showed a $\mathrm{VO}_{2}$ overshoot.

Table 2 also shows the time needed for reaching the maximum levels of $\mathrm{VO}_{2}$ after the onset of $\mathrm{VO}_{2}$ increasing, for both the polynomial function and the 5-second average maximum. Both duration times were decreased significantly post training, indicating faster kinetics.

In Table 3, $\mathrm{VE}, \mathrm{HR}, \dot{\mathrm{V}} \mathrm{CO}_{2}$, and the equivalents for $\mathrm{VO}_{2}$ and $\dot{\mathrm{VCO}}_{2}$ at the different workloads are shown. At $300 \mathrm{~W} 7$ subjects showed a $\mathrm{VCO}_{2}$ steady state. $\dot{\mathrm{V}} \mathrm{CO}_{2}$ levels at 100,200 , and $300 \mathrm{~W}$ were decreased post training $(\mathrm{p}<0.05)$.

There was no significant correlation between the difference in pre- and post-training $\mathrm{VO}_{2}$ max and the difference in pre-and post-training steady-state levels, neither was there a correlation between the difference in pre-and post-training $\mathrm{VO}_{2}$ max and the difference in pre- and post-training $\mathrm{VO}_{2}$-overshoot levels.

The mean pre- and post-training $\mathrm{R}^{2}$ of all the polynomial functions was $0.93 \pm 0.04$ and 0.95 \pm 0.04 respectively.

The mean cadence rate was pre training $91.7 \pm 3.6 \mathrm{rpm}$ (range $85-97$ ) and post training 92.1 $\pm 3.5 \mathrm{rpm}$ (range $86-97$ ). The difference between these values was not significant. The mean hematocrite values pre training was $43.7 \pm 3.2 \%$ and post training were $42.9 \pm 2.3 \%$. There was no significant difference between these values. 
Table 1. The body mass, fat percentage, $\mathrm{VO}_{2} \mathrm{max}$ and maximum work rate.

\begin{tabular}{|lcccl|}
\hline & Pre training & \multicolumn{3}{c|}{ Post training } \\
\hline & mean \pm sd & mean \pm sd \\
\hline Body mass $(\mathrm{kg})$ & $78.9 \pm 8.8$ & $77.9 \pm 8.5$ & $\mathrm{p}<0.05$ \\
Fat percentage $(\%)$ & $11.5 \pm 3.1$ & $9.3 \pm 2.4$ & $\mathrm{p}<0.01$ \\
$\mathrm{VO}_{2} \max \left(\mathrm{ml} . \mathrm{min}^{-1}\right)$ & 4413 & \pm 422 & $4679 \quad \pm 411$ & $\mathrm{p}<0.01$ \\
$\mathrm{Wmax}_{(\mathrm{W})}$ & 389 & \pm 45 & $407 \quad \pm 29$ & $\mathrm{p}<0.05$ \\
Height $(\mathrm{cm})$ & $185 \quad \pm 7$ & & & \\
\hline
\end{tabular}

\section{Table 2. Average pre- and post-training $\mathrm{V}_{2}$ levels; the highest mean $5 \mathrm{~s}-\mathrm{V}_{2}$ average and the mean maximum of the polynomial curve $\left(\mathrm{VO}_{2}\right.$-curve $\max$ ). From 0 to $100 \mathrm{~W} 10$ subjects showed an overshoot, from $100 \mathrm{~W}$ to $200 \mathrm{~W} 7$ subjects did.}

\section{pre training}

$\mathrm{VO}_{2}$ steady state $\left(\mathrm{ml} . \mathrm{min}^{-1}\right)$

$\mathrm{VO}_{2}$-curve $\max$

Reached at (s)

Highest 5-s $\mathrm{VO}_{2}$ average

Reached at (s)

\section{post training}

$\mathrm{VO}_{2}$ steady state $\left(\mathrm{ml} \cdot \mathrm{min}^{-1}\right)$

$\mathrm{VO}_{2}$-curve max

Reached at (s)

Highest 5-s $\mathrm{VO}_{2}$ average

Reached at (s)
$100 \mathrm{~W}$

$$
1870 \pm 176 \quad(n=13)
$$$$
2032 \pm 190 \quad(n=10)
$$$$
86 \pm 19
$$
$200 \mathrm{~W}$

$$
2912 \pm 227 \quad(n=13)
$$

$$
\begin{aligned}
3037 & \pm 205 \quad(n=7) \\
85 & \pm 23
\end{aligned}
$$

$$
\begin{array}{rlrl}
2056 & \pm 198 \quad(n=10) & 3130 & \pm 166 \quad(n=7) \\
77 & \pm 12 & 79 & \pm 17
\end{array}
$$

${ }^{*} \mathrm{p}<0.05$

** $\mathrm{p}<0.01$ 
Table 3. Average pre- and post-training steady-state levels of $\hat{\mathrm{V} E}, \dot{\mathrm{V}} \mathrm{CO}_{2}$, equivalents and heart rate. At $300 \mathrm{~W}$, only 7 subjects showed a steady state for $\hat{\mathrm{COO}}_{2}$ and heart rate.

\begin{tabular}{|c|c|c|c|c|c|c|}
\hline pre training & \multicolumn{2}{|c|}{$100 \mathrm{~W}(\mathrm{n}=13)$} & \multicolumn{2}{|c|}{$200 W(n=13)$} & \multicolumn{2}{|c|}{$300 W(n=7)$} \\
\hline$\dot{\mathrm{VCO}}_{2}\left(\mathrm{ml} \cdot \mathrm{min}^{-1}\right)$ & 1695 & \pm 193 & 2889 & \pm 278 & 4471 & \pm 240 \\
\hline$\dot{\mathrm{VE}}\left(1 \cdot \mathrm{min}^{-1}\right)$ & 40 & \pm 6 & 64 & \pm 8 & & \\
\hline Heart rate (beats. min $^{-1}$ ) & 108 & \pm 8 & 140 & \pm 11 & 167 & \pm 9 \\
\hline $\mathrm{VE} / \mathrm{VCO}_{2}$ & 23.7 & \pm 2.2 & 21.9 & \pm 3.1 & & \\
\hline$\dot{\mathrm{VE}} / \mathrm{VO}_{2}$ & 21.5 & \pm 2.5 & 21.9 & \pm 3.2 & & \\
\hline$\dot{\mathrm{VO}}_{2} / \mathrm{HR}$ & 17.6 & \pm 1.6 & 21.2 & \pm 2.3 & & \\
\hline \multicolumn{7}{|l|}{ post training } \\
\hline$\dot{\mathrm{VCO}}_{2}\left(\mathrm{ml} \cdot \mathrm{min}^{-1}\right)$ & 1578 & $\pm 122^{*}$ & 2790 & $\pm 113^{*}$ & 4300 & $\pm 160^{*}$ \\
\hline$\dot{V} E\left(1 \cdot \min ^{-1}\right)$ & 39 & \pm 3 & 62 & \pm 5 & & \\
\hline Heart rate (beats. $\mathrm{min}^{-1}$ ) & 109 & \pm 11 & 141 & \pm 10 & 163 & \pm 6 \\
\hline$\dot{\mathrm{VE}} / \mathrm{VCO}_{2}$ & 24.8 & \pm 1.9 & 22.2 & \pm 2.1 & & \\
\hline$\dot{\mathrm{VE}} / \mathrm{V}_{2}$ & 21.9 & \pm 2.0 & 21.6 & \pm 2.3 & & \\
\hline$\dot{\mathrm{VO}} \mathrm{O}_{2} / \mathrm{HR}$ & 16.5 & \pm 1.9 & 20.4 & \pm 1.9 & & \\
\hline
\end{tabular}

\section{Discussion}

In this study the effects of endurance training on the oxygen kinetic response to exercise were investigated in competitive cyclists. The most important observations in this study are accelerated $\dot{\mathrm{VO}}_{2}$ kinetics and lowered steady-state $\dot{\mathrm{VO}}_{2}$ and $\dot{\mathrm{VCO}}_{2}$ levels following endurance training.

The occurrence of faster kinetics following training is in accordance with the observations of other investigators. Babcock et al. (2) observed faster kinetics of gas exchange in older men following an aerobic training schedule of six months. In untrained men Philips et al. (25) showed that oxygen kinetics was accelerated already after 4 days of training. In already trained cyclists, Norris and Petersen (23) described increased oxygen kinetics following endurance training. Otsuka et al. (24) and Bauer et al. (6) described faster oxygen kinetics following training in patients with chronic obstructive pulmonary disease and peripheral arterial disease respectively. Philips et al. (25) and Norris and Peterson (23) stated that the adaptation of the post-training oxygen kinetics occurred before changes in $\mathrm{VO}_{2}$ peak and / or muscle oxidative potential. 
We recently described the $\mathrm{VO}_{2}$-overshoot phenomenon for the first time (19). Although there is no pre- and post-training difference in the absolute maximum values of the $\mathrm{VO}_{2}$ overshoot in the current study, the $\mathrm{VO}_{2}$ overshoot compared with the decreased post-training steadystate levels has increased. So the current study shows that the post-training $\mathrm{VO}_{2}$ overshoot has been increased relatively at $100 \mathrm{~W}$ and $200 \mathrm{~W}$. The overshoot phenomenon is less clear when the increase in workload is changed from 100 to $200 \mathrm{~W}$ : at $200 \mathrm{~W}$ only 7 subjects showed an overshoot pre and post training, at $300 \mathrm{~W} 2$ subjects showed a $\mathrm{VO}_{2}$ overshoot. In an earlier publication we reported a clear overshoot in elite cyclists when the load was increased from $0 \mathrm{~W}$ up to $250 \mathrm{~W}$, which exercise intensity was about $60 \%$ of the $\mathrm{VO}_{2}$ max of the subjects. In the present study the overshoot phenomenon was clearly at an intensity of up to $40 \% \mathrm{VO}_{2} \max$.

In the current study the steady-state $\mathrm{VO}_{2}$ at $100 \mathrm{~W}$ was significantly decreased post training, at $200 \mathrm{~W}$ the decrease was not significant and at 300 Watt there was a tendency to a posttraining increase in $\mathrm{VO}_{2}$ (only 4 subjects showed steady state and the increase was not significant). Barbeau et al. (4) studied the ventilatory and the heart rate response in elite cyclists during submaximal exercise during the season. $\mathrm{V}_{2}$ max and ventilation during steady-state exercise did not differ during the season in Barbeau's study (4) while heart rate and submaximal oxygen consumption was significantly lower in the period of May and July. Using a one-minute ramp protocol we observed in an earlier study higher post-training submaximal $\mathrm{O}_{2}$ costs for the same work rate (18). However, at lower workloads this may be explained by an accelerated $\mathrm{VO}_{2}$ overshoot, since the overshoot occurs within $50-70$ seconds. The post-training maximum overshoot is reached earlier and consequently higher $\mathrm{V}_{2}$ values are observed after 1 minute. Using longer steps, the post-training $\mathrm{V}_{2}$ levels probably would have been lower. At higher workloads the increase in post-training $\dot{\mathrm{VO}}_{2}(18)$ is in accordance with the current study. Bhambhani et al. (7) reported lowered equivalents for $\dot{\mathrm{VO}}_{2}\left(\dot{\mathrm{V} E} / \mathrm{VO}_{2}\right)$ and $\dot{\mathrm{V}} \mathrm{CO}_{2}\left(\mathrm{VE} / \mathrm{VCO}_{2}\right)$ at submaximal work rate following endurance training. This was the result of lowered ventilation volume, which is not observed in the current study. The possible mechanisms that explain the post-training accelerated kinetics and the lower $\mathrm{VO}_{2}$ costs at workloads below about $50 \% \dot{\mathrm{VO}}_{2} \max$ are not clear. The oxygen intake at any moment is determined by four systems: diffusing capacity, cardiac output, oxygen carrying capacity of the blood, and skeletal muscle characteristics $(5,22,28,31)$. The dynamics and interpretation of ventilation and gas exchange during exercise have been studied thoroughly and these issues are complicated $(9,22,31,32)$. The oxygen uptake $\left(\mathrm{V}_{2}\right)$ following a step increase in work rate can be characterised as consisting of an early cardiodynamic component with unchanged mixed-venous $\mathrm{O}_{2}$-content (phase I) and a subsequent metabolic component (phase II) starting when venous blood from the muscle arrives at the lungs $(31,32)$. The cardiodynamic component plays a role in $\mathrm{VO}_{2}$ kinetics in the first $20-30 \mathrm{~s}$ following a rest-exercise transition $(31,32)$. Since the overshoot of $\mathrm{V}_{2}$ takes place later than $30 \mathrm{~s}$, it seems unlikely that the cardiodynamic component explains the accelerated kinetics.

Based on Fick's principles, an increased oxygen uptake is the result of an increased cardiac output or arterial-venous oxygen difference: $(\mathrm{a}-\mathrm{v}) \mathrm{O}_{2}$. Stroke volume is likely to increase since it has been described as a consequence of training (8). A post-training faster adaptation of cardiac output may explain the faster kinetics. An accelerated opening of arterioles and pre-capillary sphincters could enhance muscle perfusion resulting in faster and / or more oxygen extraction. Experiments in humans have shown a sudden increase in perfusion of 
exercising muscles at the onset of work intensity $(13,26)$. Thus a post-training accelerated opening of arterioles and pre-capillary sphincters remains a possibility to explain the fastened overshoot phenomenon. It would suggest that accelerated kinetics and / or a more expressed $\mathrm{VO}_{2}$ overshoot might indicate the endurance-trained state of the muscles: i.e. a better oxygen uptake caused by more capillaries and / or more mitochondria. In addition, a post-training increased peak of catecholamines or faster or a more powerful activation of the muscle pump might play a role in the enhanced peripheral perfusion following training.

Anther (or supplemental) factor that may have played a role is perhaps the extra energy that is needed for the post-training increased-trained legs that have to start moving and for accelerating the pedals. Furthermore, contractions of trunk or arm muscles may induce effects on ventilation. Gissane et al. (12) studied the response to standardised exercise on a cycle ergometer and observed in untrained males a tendency that post-training oxygen consumption may be reduced due to an increased efficiency. Also in elite swimmers (17), runners (1), and cyclists (10), efficiency has been associated with lower $\mathrm{VO}_{2}$ values for the same work rate. The results of the current study are in accordance with these studies, especially at lower percentages of $\mathrm{VO}_{2}$ max. The increased post-training efficiency might explain the post-training decrease in $\mathrm{O}_{2}$ costs for the same (submaximal) workload in the current study. The lower post-training $\mathrm{VCO}_{2}$ at 100,200, and $300 \mathrm{~W}$ steady-state exercise may be explained by an increased fat oxidation. In addition, at higher workloads a posttraining decreased $\mathrm{CO}_{2}$ production may be the result of a decreased anaerobic part of the energy supply resulting in a decreased lactate production and less bicarbonate buffering.

In the present study the post-training heart rate was not significantly changed. The effect of endurance training on the heart rate response at submaximum levels has already been described but the literature is conflicting. Barbeau et al. (4) and Wilmore and Costill (30) reported a lowered heart rate at the same work rate post training. Babcock et al. (2) and Norris and Petersen (23) did not observe a change in heart rate following endurance training which is in accordance with the present study. Using a one-minute ramp protocol we also observed unchanged post-training heart rates (18).

A point of discussion in the present study may be that the sampling time of the ventilatory parameters was the mean of every 5 seconds. This may be a too short period at the beginning of the exercise when the breathing frequency is low. Indeed, some 5-second means showed some fluctuations at the beginning. However, we calculated the ventilatory parameters also over a period of 10,15 and $20 \mathrm{~s}$ but the results were the same as when the mean of 5 seconds were used.

Summarising, in this study the effect of endurance training was investigated on the oxygen response to exercise. The key finding is an accelerated $\mathrm{VO}_{2}$ overshoot and a decreased steady state level following endurance training. The implications and practical considerations of our observations concerning the training effects on oxygen kinetics are schematically shown in Fig 1. Apart from the possible mechanism, the increased posttraining oxygen kinetics may be a key finding leading to a short-duration submaximal test to evaluate the effects of endurance training in competitive cyclists. Although it is not permissible to extrapolate these observations to patients or fully untrained subjects, the results of this may also be a major observation in training management and revalidation schedules in patients. The results of this study are usable in sports medicine practice and training management of endurance athletes. The present study suggests the following practical recommendations in training management: the oxygen kinetics at submaximal work 
rate is an indicator of the endurance training state. Faster kinetics and / or a more pronounced $\mathrm{VO}_{2}$ overshoot in combination with lower $\mathrm{VO}_{2}$ and $\mathrm{VCO}_{2}$ levels at lower workloads indicate a higher endurance-trained capacity.

Figure 1

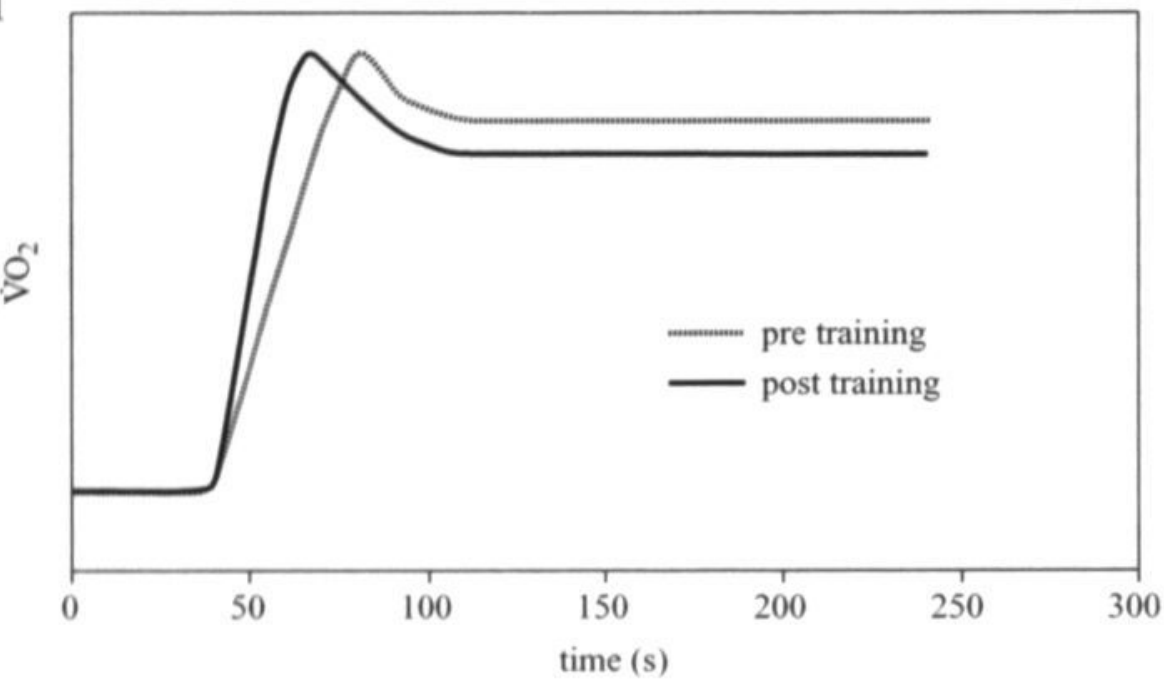

The general pre- and post-training pattern of the $\mathrm{VO}_{2}$ curve at the onset of exercise in the current study: following endurance training, an accelerated $\mathrm{VO}_{2}$ overshoot and a decreased steady-state level occurs

\section{References}

1. Anderson T. Biomechanics and running economy. Sports Med 1996; 22: 76-89

2. Babcock MA, Paterson DH, Cunningham DA. Effects of aerobic training on gas exchange kinetics of older men. Med Sci Sports Exerc 1994; 26: 447-52

3. Bangsbo J, Michalsik L, Petersen A. Accumulated $\mathrm{O}_{2}$ deficit during intense exercise and muscle characteristics of elite athletes. Int J Sports Med 1993; 14: 207-13

4. Barbeau P, Seresse O, Boulay MR. Using submaximal aerobic variables to monitor elite cyclists during a season. Med Sci Sports Exerc 1993; 25: 1062-9

5. Bassett DR, Howley ET. Limiting factors for maximum oxygen uptake and determinants of endurance performance. Med Sci Sports Exerc 2000; 32: 70-84

6. Bauer TA, Regensteiner JG, Brass EP, Hiat WR. Oxygen uptake kinetics during exercise are slowed in patients with arterial disease. J Appl Physiol 1999: 87: 809-16 
7. BhambhaniY, $\boldsymbol{M}$ Singh $\boldsymbol{M}$. The effects of three training intensities on $\mathrm{VO}_{2}$ max and $\dot{V} E / \dot{V} O_{2}$ ratio. Can J Appl Sport Sci 1985; 10:44-51

8. Charlton GA, Crawford MH. Physiologic consequences of training. Cardiol clin 1997; 15: $345-54$.

9. Cooper $\boldsymbol{C B}$, Beaver $\boldsymbol{W L}$, Cooper DM, Wasserman $\boldsymbol{K}$. Factors affecting the components of the alveolar $\mathrm{CO}_{2}$ output- $\mathrm{O}_{2}$ uptake relationship during incremental exercise in man. Exp Physiol 1992; 77: 51-64

10. Coyle EF, Coggan AR, Hopper MK, Walters TJ. Determinants of endurance in welltrained cyclists. J Appl Physiol 1988; 64: 2622-30

11. Durnin JVGA, Womersly J. Body fat assessed from total body density and its estimation from skinfold thickness: measurements on 481 men and women from 16 to 72 years. $\mathrm{Br}$ J Nutr 1974; 32: 77-97

12. Gissane C, Corrigan DL, White JA. Gross efficiency responses to exercise in adult males of various ages. J Sports Sci 1991; 9:383-91

13. Grassi B, Poole DC, Richardson RS, Knight DR, Erickson BK, Wagner PD. Muscle $\mathrm{O}_{2}$ uptake kinetics in humans: implications for metabolic control. J Appl Physiol 1996; 80: $988-98$

14. Green HJ, Coates $\mathbf{G}$, Sutton JR, Jones $\boldsymbol{S}$. Early adaptions in gas exchange, cardiac function and heamatology to prolonged exercise training in man. Eur J Appl Physiol 1991; $63: 17-23$

15. Green S, Dawson BT, Goodman C, Carey MF. Anaerobic ATP production and accumulated $O 2$ deficit in cyclists Med Sci Sports Exerc 1996; 28: 315-21

16. Green S, Dawson BT. Methodological effects on the $\dot{V} \mathrm{O}_{2}$-power regression and the accumulated O2 deficit. Med Sci Sports Exerc 1996; 28: 392-7

17. Handel van PJ, Katz A, Morrow JR, Troup JP, Daniels TD, Bradley PW. Aerobic economy and competetive performance of US elite swimmers 1988. Swimming Science V Human Kinetics Champaign I11: 225-34

18. Hoogeveen $\boldsymbol{A R}$. The effect of endurance training on the ventilatory response to exercise in elite cyclists. Eur J Appl Physiol 2000; 82: 45-51

19. Hoogeveen AR, Keizer HA. The $\mathbf{V}_{2}$ overshoot at the onset of constant-load exercise in elite cyclists: an undescribed phenomenon. In print.

20. Krogh A, Lindhard $\boldsymbol{J}$. The regulation of respiration and circulation during the initial stages of muscular work. J Physiol 1913; 47: 112-36 
21. Londeree BR. Effects of training on lactate/ventilatory thresholds: a meta-analysis. Med Sci.Sports Exerc 1997; 29: 837-43

22. Miyamoto $\boldsymbol{Y}$, Niizeki $\boldsymbol{K}$. Dynamics of ventilation, circulation, and gas exchange to incremental and decremental ramp exercise. J Appl Physiol 1992; 72: 2244-54

23. Norris $\boldsymbol{S R}$, Petersen $\boldsymbol{S}$. Effects of endurance training on transient oxygen uptake responses in cyclists. J Sports Sci 1998; 16: 733-38

24. Otsuka T, Kurihara K, Fujii T, Fujimoto S, Yoshikawa. Effect of exercise training and detraining on gas exchange kinetics in patients with chronic obstructive pulmonary disease Clin Physiol 1996; 17: 287-97

25. Phillips SM, Green JH, MacDonald JM, Hughson RL. Progressive effect of endurance training on $\mathrm{VO}_{2}$ kinetics at the onset of submaximal exercise. J Appl Physiol 1995; 79: 1914-20

26. Richardson RS, Harms CA, Grassi B, Hepple T. Skeletal muscle: master or slave of the cardiovascular system. Med Sci Sports Exerc 2000; 32: 89-93

27. Scott BC, Roby FB, Lohman TG, Bunt JC. The maximally accumulated oxygen deficit as an indicator of anaerobic capacity Med Sci Sports Exerc 1991; 23: 618-24

28. Shepard RJ and Astrand PO. Endurance in Sports. Oxford Blackwell Scientific Publications 1992: part 2

29. Wasserman K, Stringer WW, Casaburi R, Koike A, Cooper CB. Determination of the anaerobic threshold by gas exchange. Biochemical considerations, methodology and physiological effects. Z Kardiol 1994; 83: 1-12

30. Wilmore JH, Costill. DL. Physiology of sport and exercise. Human Kinetics Champaign 1994: 111: 221

31. Xu F, Rhodes EC. Oxygen uptake kinetics during exercise. Sports Med 1999; 27: 313327

32. Yoshida $\boldsymbol{T}$, Yamamoto $\boldsymbol{K}, \boldsymbol{U}$ do $\boldsymbol{M}$. Relationship between cardiac output and oxygen uptake at the onset of exercise. Eur J Appl Physiol 1993; 66: 155-60 


\section{Chapterp}

General discussion 


\section{General Discussion}

During prolonged high-intensity exercise, a metabolic acidosis occurs which is compensated by several buffering systems and by the ventilatory system. Based on this concept, many authors have attempted to investigate the ventilatory and lactate response to exercise in order to measure the ability of prolonged high-intensity exercise $(10-12,14,38,39)$. In this thesis, a number of studies have been described concerning the lactate and ventilatory response to exercise by athletes participating in endurance sports. The main objective of this thesis was to gain insight into the reliability of the various lactate and ventilatory responses described in the literature as indicators for measuring performance, prescribed training schedules, and to assess the effects of training.

One of the issues of this study was to investigate the lactate response during maximum steady-state exercise. It was found that the plasma lactate levels during maximum steadystate exercise were remarkable high and there was a considerable individual variability $(23,24)$. The lactate levels during steady-state exercise did not correspond with the levels of the different lactate parameters derived from a lactate curve (lactate threshold, individual anaerobic threshold, onset of blood lactate accumulation) postulated by other investigators $(5,6,10-14)$. The predictive value of the endurance performance of the different lactate parameters was poor, mainly because of the high individual variability. The high plasma lactate levels during steady state in the present studies $(24,25)$ were not in accordance with the limited levels during steady-state exercise observed by other investigators $(5,6,14,39)$. As discussed in chapter III, this discrepancy may be due to the fact that these other studies involved moderately trained subjects, furthermore the studies were not validated for a practical situation. The results of Coyle et al. (10) who measured maximum lactate steady state (MaxLaSS) in a laboratory setting in less-trained subjects were in accordance with the observations made in the current study. The determination of an individual MaxLaSS in a laboratory entails the performance of several constant workloads on different days $(5,6)$. Only then will the results be comparable with our observations $(23,24)$, and those of Coyle et al. (10). This procedure is expensive and often does not fit into an athlete's training schedule.

There is no easy explanation for the high levels of lactate during steady-state exercise. The lactate metabolism is an extensively debated subject, and this issue has recently been the subject of different authors $(9,15,28)$. Brooks $(9)$ recently expanded his lactate-shuttle theory and introduced an additional intracellular lactate shuttle. The lactate levels during steadystate exercise are the result of the production and elimination of lactate $(9,15,44)$, so these levels do not reflect the net production of lactate. In addition, plasma or blood lactate levels do not reflect intracellular acidosis since the $\mathrm{pH}$ also depends on the intracellular buffer capacity. A possible mechanism that explains the high levels of plasma lactate during steadystate exercise may be the intracellular lactate transport mechanism. Lactate turnover and lactate transport across membranes occurs by means of facilitated exchange along $\mathrm{pH}$ and concentration gradients involving a family of lactate transport proteins, called monocarboxylate transporters (MCTs) $(8,9,15,21,44)$. MCTs are abundant in Type Ila and IIb muscles, and they are markedly less in Type I muscles (8). Eight different isoforms of MCTs (MCT1 to MCT8) have been identified in human tissues $(21,44)$. Skeletal muscle exhibits MCT1 and MCT4, heart muscle exhibits high levels of MCT1 in both human and rats (21). Based on the distribution of MCT1 and MCT4, it has been postulated that MCT1 in skeletal 
muscle may reflect the need to absorb lactate for oxidative purposes, whereas MCT4 may be important for lactate efflux $(21,44)$. The lactate efflux across the membrane regulates intracellular muscle $\mathrm{pH}$. With training, MCTI is increased in human muscle $(7,8)$ while in rat muscle the isoforms $\mathrm{MCT1}$ and MCT 4 are increased following training (8). In humans, the training-induced increase in MCTs may be associated with an increased lactate efflux from the muscle $(7,21,32)$. Consequently, the results of the study by McDermott and Bonen (32) may be an explanation for the high plasma lactate levels observed in highly endurancetrained subjects described in chapters II and III. Training may induce an increase in lactate efflux out of the muscle into the blood causing higher levels of lactate during steady state. Furthermore, we hypothesised that the high plasma lactate levels during exercise may be necessary to provide a carbohydrate energy source for tissues to compensate for the higher metabolic demand. The heart is particularly a major consumer of lactate during exercise $(9,15,44)$. In addition, a slight acidosis may be necessary for a shift of the oxyhaemoglobin dissociation curve and a vasodilatation of the vascular bed in the contracting muscle.

Some aspects that have to be considered with respect to studies with lactate measurements, are the sampling and measurement sites in whole blood or in plasma. The lactate concentration in the studies presented in chapter II and III was assessed in plasma while in some of the studies mentioned above, lactate was assessed in whole blood (10-12,14). Since it is known that there is little difference in the lactate concentrations of whole blood and plasma $(31,41)$, this may have influenced the comparison with the data of other studies. In addition, persistent diffusion after storage and over-protracted cooling of the samples could also have influenced the results (31). However, the resting values and maximum levels of plasma lactate in our studies were comparable with those studies, which assessed lactate concentration in whole blood $(10,11,38)$, so a significant error may be excluded. With respect to the possibility of persistent perfusion and the cooling-down procedure, we demonstrated that these factors did not play a role in our measurements in an experiment in our own laboratory (25).

In summary, the studies of this thesis concerning the lactate response suggest that it is difficult to derive a certain threshold from a single lactate curve $(23,24)$. Although measurements of lactate levels may be useful to indicate early overtraining (37) and monitoring training effects $(13,27)$, the role of lactate parameters as an indicator of endurance performance is questionable. Concerning endurance performance, lactate parameters do not contribute more information about performance than for example the maximum workload. A single exercise test with a short-step incremental protocol including lactate assessment will not result in usable parameters for training management. The different lactate parameters described are poorly defined and the exercise protocol, the method of detection, and the evaluator influence the determination. The determination of an individual MaxLaSS in a laboratory is a time-consuming alternative since it requires the performance of several constant workloads on different days $(5,6)$.

In future, investigations will have to be focused on the muscle metabolism, lactate transport, and the different buffer systems in order to elucidate the limits of endurance performance.

The present study also addressed the value of ventilatory parameters as indicators of performance and the maximum steady-state intensity exercise. In chapter IV, the ventilatory parameters measured during a short-step incremental exercise test seem to be a better predictor of performance and the ability to maintain high-exercise intensity than lactate 
measurement is. This is in accordance with the observations of Wasserman et al. (40) in patients. The V-slope method using heart rate, in particular, can be used as an indicator of performance and in heart rate training management. This parameter is usable in sports medicine practice and training management of elite endurance-sports athletes. As in other publications $(10,11,14)$, the predictive value of performance in similarly trained subjects is limited owing to a large interval of reliability, since the variation in performance is considerable.

The progressive carbon dioxide output $\left(\mathrm{VCO}_{2}\right)$ by ventilation can be viewed as an ultimate mechanism to compensate for the intra- and extracellular acidosis. The hydrogen carbonate buffer is the major extracellular buffer system in which hydrogen carbonate absorbs protons and the carbonic acid formed decomposes into water and $\mathrm{CO}_{2}$. Consequently, when the intracellular buffering system and the extracellular buffering system fail to maintain an adequate $\mathrm{pH}$, an excess of $\mathrm{CO}_{2}$ has to be removed. Consequently, a progressive $\mathrm{VCO}_{2}$ is perhaps a better marker for an acidosis then lactate is, resulting in a better predictive value of the ventilatory parameters.

One of the observations of this study was that training appears to have an effect on the ventilatory response to a stepwise $\left(20 \mathrm{~W} \cdot \mathrm{min}^{-1}\right)$ increase in workload (26). Endurance training results in a higher $\mathrm{VO}_{2}$ for the same workload during a short-step incremental exercise test. This observation is not easily explained, but the newly described overshoot phenomenon and its training effect in chapter VI and VII may be a key finding in the solution to this problem. This phenomenon is present at the beginning of a certain workload: just before reaching the steady-state level, in the initial minutes of exercise, the $\mathrm{VO}_{2}$ clearly peaks above the steady-state level reached in the following few minutes. This overshoot phenomenon is also clearly demonstrated by the data of Green and Dawson (18), however they did not remark on and describe this phenomenon.

The observed overshoot phenomenon does not easily fit into the current theoretical models of oxygen kinetics. The $\dot{\mathrm{VO}}_{2}$ response following a rest-exercise transition can be characterised as consisting of an early cardiodynamic component with unchanged mixedvenous $\mathrm{O}_{2}$-content (phase I) and a subsequent metabolic component (phase II) at constant cardiac output which occurs some $20 \mathrm{~s}$ after the onset of exercise $(29,30,43)$. Yoshida et al. (43) investigated rest-exercise transitions and observed that $\mathrm{VO}_{2}$ rapidly increased with time constants of $7.0 \mathrm{~s}$. The cardiac output $(\mathrm{CO})$ also showed a similar rapid increment with time constants of $6.5 \mathrm{~s}$ with an apparent increase in stroke volume (SV). In Yoshida's study (43) $\dot{\mathrm{V}_{2}}$ increased in phase I to about $30 \%-34 \%$ of the steady-state value and CO increased to about $58 \%-87 \%$. This may be caused by events in the lungs or the pulmonary circulation. The $\mathrm{VO}_{2}$ kinetics of the metabolic phase II that occurs after 20-30 s is expected to fit into a mono-or bi-exponential model (42). In both formulae, the $\mathrm{VO}_{2}$ as a function of time is always increasing. So this theoretical model does not fit with the observed response in which an initial rise occurs between 50 and $100 \mathrm{~s}$ after the onset of exercise. In addition the curve fitting in the exponential models will be highly affected by the $\mathrm{VO}_{2}$ overshoot and it will influence the analyses of curves and the calculation of the $\mathrm{O}_{2}$ deficit $(3,18,33)$.

The physiological background of the overshoot phenomenon described above is not easy to explain. Based on Fick's principles, an increased oxygen uptake is the result of an increased cardiac output or increased arterial-venous oxygen difference: $(\mathrm{a}-\mathrm{v}) \mathrm{O}_{2}$. In our study the heart rate did not exhibit a sudden increase so it is reasonable to assume that the increased oxygen uptake is the result of an increased stroke volume or an increased (a-v) $\mathrm{O}_{2}$. Since heart rate 
did not exhibit a sudden initial increase, the oxygen pulse, which reflects the stroke volume, exhibited the same phenomenon as the $\mathrm{VO}_{2}$. Thus a temporary maximum in stroke volume in the first minutes remains a possibility. The cardiodynamic phase at the onset of exercise may play a role in the occurrence of a $\mathrm{VO}_{2}$ overshoot. However, in the current study the maximum of the $\mathrm{VO}_{2}$ overshoot was reached between $55-90 \mathrm{~s}$, while the cardiodynamic phase is finished within $20-30 \mathrm{~s}(29,30,43)$. Furthermore, the $\mathrm{VO}_{2}$ reached in phase II is only about $30 \%$ (43). So the early fast cardiodynamic phase will probably not be responsible for the overshoot in $\mathrm{VO}_{2}$ in the current study.

A sudden opening of arterioles and pre-capillary sphincters could enhance muscle perfusion resulting in faster and / or increased oxygen extraction. Experiments in humans have shown a sudden increase in perfusion of exercising muscles at the onset of work intensity $(16,36)$. Consequently, it is quite likely that a sudden opening of arterioles and pre-capillary sphincters provide an explanation for the newly described overshoot phenomenon. In addition, a peak of catecholamines or the activation of the muscle pump itself may play a role in the enhanced peripheral perfusion. Perhaps a part of the oxygen deficit in the muscles is compensated by the overshoot phenomenon. Another (or supplemental) possibility may be the extra energy that is needed for the legs, which have to start moving, and for accelerating the pedals. However this only counts for the first few seconds and not for the transition from $100-200 \mathrm{~W}$ presented in chapter VII. Furthermore rest-exercise transitions are sometimes associated with contractions of trunk or arm muscles, which may induce effects on ventilation and circulation, but this would also not explain the phenomenon during the transition from $100-200 \mathrm{~W}$ presented in chapter VII.

As already mentioned, the overshoot phenomenon and its earlier occurrence following endurance training observed in chapter $\mathrm{VI}$ and $\mathrm{VII}$ may explain the higher post-training $\mathrm{VO}_{2}$ for the same workload during the incremental exercise test described in chapter V. Given that the pre- and post-training $\mathrm{VO}_{2}$ in chapter $\mathrm{V}$ was assessed during a one-minute incremental exercise test, near the moment of maximum $\mathrm{VO}_{2}$ overshoot.

The overshoot phenomenon is not present in every subject and it is more pronounced at lower exercise intensity (up to $60 \%$ of $\mathrm{VO}_{2}$ max and lower) and after training. Faster kinetics following endurance training has already been described $(20,34,35)$, and since the $\mathrm{VO}_{2}$ overshoot phenomenon is a component of the kinetics it is not surprising that it is also enhanced following training. The physiological explanation may be, that in the higher endurance-trained state, the capillarisation of the muscle has increased resulting in an increased peripheral perfusion and an increased (a-v) $\mathrm{O}_{2}$ (22). A higher post-training production of catecholamines may play a role as well.

In chapter VII, we also observed that the steady-state levels of $\mathrm{VO}_{2}$ at low workloads (up to about $50 \%$ of $\dot{\mathrm{V}}_{2} \max$ ) reached after a few minutes, decreased following endurance training. Post-training $\dot{\mathrm{VCO}} 2$ levels were lowered also at higher loads (up to $80 \% \mathrm{VO}_{2}$ max). For $\mathrm{VO}_{2}$ this phenomenon has already been described $(1,2,10,11,27)$ and it may be an indication a better trained-state or an enhanced efficiency. In the present study, $\mathrm{VO}_{2}$ levels remained unchanged at higher workloads. This is not in accordance with the observations of Jones and Carter (27) who observed a decrease in post-training $\mathrm{VO}_{2}$ at higher loads due to a reduction of the slow component of $\mathrm{VO}_{2}$ kinetics. Hagberg et al. (20) reported unchanged steady-state $\mathrm{VO}_{2}$ levels following training. However, in both studies $(20,27)$ the subjects were moderately trained. The lower post-training $\mathrm{VCO}_{2}$ at 100,200 , and $300 \mathrm{~W}$ steady-state exercise may be explained by an increased fat oxidation. In addition, at higher workloads a 
decreased post-training $\mathrm{CO}_{2}$ production may be the result of a decreased anaerobic part of the energy supply resulting in a decreased lactate production and less bicarbonate buffering. The observations in chapter VI and VII explain the conflicting results concerning the training effects on the submaximal $\mathrm{VO}_{2}$ levels in the literature during incremental exercise test $(4,19,26)$ i.e: using a short-step $(< \pm 2 \mathrm{~min})$ incremental exercise test, post-training submaximal $\mathrm{VO}_{2}$ will be higher due to the faster kinetics (and overshoot). If longer steps are used, post-training submaximal $\mathrm{VO}_{2}$ will be lower. At higher loads (about $50 \%$ of $\mathrm{VO}_{2}$ max), there is no clear difference between pre- and post-training $\mathrm{VO}_{2}$, and no overshoot phenomenon is observed.

The results of the studies presented in chapter V, VI, and VII suggest that for the monitoring of training effects only a short submaximal exercise test is needed. The knowledge of $\mathrm{VO}_{2}$ kinetics and the $\mathrm{VO}_{2}$ during a 5-min lasting submaximal $\left(40 \% \mathrm{VO}_{2}\right.$ max $)$ exercise test may be sufficient for the determining of the endurance-training state of an athlete. Although it is not permissible to extrapolate the results of athletes to patients, the increase of the kinetics in patients compared to healthy subjects has already been described (4). A short lasting exercise test is efficient and untaxing for patients and athletes.

In the near future investigations have to be focused on $\mathrm{VO}_{2}$ kinetics in patients with different disabilities and athletes with overtraining syndromes. Concerning the $\mathrm{VO}_{2}$ overshoot, the area-under-the-curve representing the real oxygen overshoot or deficit, needs further investigation. Furthermore a computer program has to be developed for the analysing of $\mathrm{VO}_{2}$ kinetics.

\section{References}

1. Anderson T. Biomechanics and running economy. Sports Med 1996; 22: 76-89

2. Barbeau $\boldsymbol{P}$, Seresse $\boldsymbol{O}$, Boulay MR. Using submaximal aerobic variables to monitor elite cyclists during a season. Med Sci Sports Exerc 1993: 25:1062-9

3. Barstow TJ, Casaburi R, Wasserman $\mathrm{K} . \mathrm{O}_{2}$ uptake kinetics and the $\mathrm{O}_{2}$ deficit as related to exercise intensity and blood lactate. J Appl Physiol 1993; 75: 755-62.

4. Bauer TA, Regensteiner JG, Brass EP, Hiat WR. Oxygen uptake kinetics during exercise are slowed in patients with arterial disease. J Appl Physiol 1999; 87: 809-16

5. Beneke $\boldsymbol{R}$, Boldte $\boldsymbol{F}$, Meller $\boldsymbol{W}$, and Behn $\boldsymbol{C}$. Das maximale laktate-steady state (Maxclass) im eisschnellauf. Leistungsdiagnostik 1991: 10: 766-7

6. Beneke $\boldsymbol{R}$. Anaerobic threshold, individual anaerobic threshold, and maximal lactate steady state in rowing. Med Sci Sports Exerc 1995; 27: 863-7

7. Bonen A, McCullagh KJ, Putman CT, Hultman E, Jones NL, Heigenhauser GJ. Short-term training increases human muscle MCTI and femoral venous lactate in relation to muscle lactate. Am J Physiol 1998; 274: 102-7 
8. Bonen A. Lactate transporters (MCT proteins) in heart and skeletal muscles. Med Sci Sports Exerc 2000; 32: 778-89

9. Brooks GA. Intra- and extra-cellular lactate shuttles. Med Sci Sports Med 2000; 32: 790-9

10. Coyle EF, Coggan AR, Hopper MK, Walters TJ. Determinants of endurance in welltrained cyclists. J Appl Physiol 1988; 64: 2622-30

11. Coyle EF, Feltner ME, Kautz S, Hamilton MT, Montain SJ, Baylor AM, Abraham ID, Petrek GW. Physiological and biomechanical factors associated with elite endurance cycling performance. Med Sci Sports Exerc 1990; 23: 93-107

12. Craig NP, Norton KI, Bourdon PC, Woolford SM, Stanef T, Squires B, Olds TS, Conyers $\boldsymbol{R} \boldsymbol{A J}$, Walsh $\boldsymbol{C B V}$. Aerobic and anaerobic indices contributing to track endurance cycling performance. Eur J Appl Physiol 1993; 67: 150-8

13. Davis JA. Anaerobic threshold: review of the concept and directions for future research. Med Sci Sports Exerc 1985; 17: 6-18

14. Föhrenbach $\boldsymbol{R}$, Mader A, Hollmann $\boldsymbol{W}$. Determination of endurance capacity and prediction of exercise intensities for training and competition in marathon runners. Int J Sports Med 8: 11-18, 1987

15. Gladden LB. The role of skeletal muscle in lactate exchange during exercise: introduction. Med Sci Sports Exerc 2000; 32: 753-5

16. Grassi B, Poole DC, Richardson RS, Knight DR, Erickson BK, Wagner PD. Muscle $\mathrm{O}_{2}$ uptake kinetics in humans: implications for metabolic control. J Appl Physiol 1996: 80: $988-98$

17. Green HJ, Coates G, Sutton JR, Jones $\boldsymbol{S}$. Early adaptions in gas exchange, cardiac function and heamatology to prolonged exercise training in man. Eur J Appl Physiol 1991; $63: 17-23$

18. Green $\boldsymbol{S}$, Dawson $\boldsymbol{B T}$. Methodological effects on the $\dot{V} \mathrm{O}_{2}$-power regression and the accumulated $O 2$ deficit. Med Sci Sports Exerc 1996; 28: 392-7

19. Greenleaf JE, Ertl AC, Bernauer EM. Submaximal exercise $\mathrm{VO}_{2}$ and Qc during 30-day 6 degrees head-down bed rest with isotonc and isokinetic exercise training. Aviat.Space.Enviro. Med. 1996; 67 (4): 314-9

20. Hagberg JM, Hickson RC, Ehsani AA, Holloszy JO. Faster adjustment to and recovery from submaximal exercise in the trained state. J Appl Physiol 1980:48: 218-24 
21. Halestrap AP, Price NT. The proton-linked monocarboxylate transporter (MCT) family: structure, function and regulation. Biochem 1999; 343: 281-99

22. Holloszy JO, Coyle EF. Adaptions of skeletal muscle to endurance exercise and their metabolic consequences. J Appl Physiol 1984; 56: 831-8

23. Hoogeveen $\boldsymbol{A R}, \boldsymbol{S c h e p} \boldsymbol{G}$ The plasma lactate response to exercise and endurance performance. Relationships in elite triathletes. Int J Sports Med 1997; 18: 526-9

24. Hoogeveen $\boldsymbol{A R}$, Hoogsteen $\boldsymbol{J}, \boldsymbol{S}$ chep $\boldsymbol{G}$ The maximal lactate steady state in elite endurance athletes. Jap J of Physiol 1997; 47: 481-5

25. Hoogeveen AR, Schep G, Vader HL. The problems to study plasma lactate. Reply. Int J Sports Med 1998; 19: 224-5

26. Hoogeveen AR. The effect of endurance training on the ventilatory response to exercise in elite cyclists. Eur J Appl Physiol 2000; 82: 45-51

27. Jones AM, Carter $\boldsymbol{H}$. The effect of endurance training on parameters of aerobic fitness. Sports Med 2000; 29; 373-86

28. Katz A, Sahlin K. Regulation of lactate acid production during exercise. J Appl Physiol 1988: 65: $509-18$

29. Leyk D, Hoffmann U, Essfeld D, Baum K, Stegemann J. VंO and cardiac output during rest-exercise and exercise-exercise transients. Z Kardiol 1994; 83 Suppl 3: 61-5

30. Leyk D, Hoffmann U, Baum K, Essfeld D. Time courses of cardiac output and oxygen uptake following stepwise increases in exercise intensity. Int J Sports Med 1995; 16: 357-63

31. Lormes $\boldsymbol{W}$, Lehmann $\boldsymbol{M}$, Steinacker $\boldsymbol{J}$. The problems to study plasma lactate. Int J Sports Med 1998, 223

32. McDermott JC, Bonen A. Endurance training increases skeletal muscle lactate transport. Acta Physiol Scand 1993; 147: 323-7

33. McMiken DF. Oxygen deficit and repayment in submaximal exercise.

34. Norris SR, Petersen SR. Effects of endurance training on transient oxygen uptake responses in cyclists. J Sports Sci 1998: 16: 733-8

35. Phillips SM, Green JH, MacDonald JM, Hughson RL. Progressive effect of endurance training on $\mathrm{VO}_{2}$ kinetics at the onset of submaximal exercise. J Appl Physiol 1995; 79: 1914-20 
36. Richardson RS, Harms CA, Grassi B, Hepple T. Skeletal muscle: master or slave of the cardiovascular system. Med Sci Sports Exerc 2000; 32: 89-93

37. Snyder AC, Jeukendrup AE, Hesselink MKC, Kuipers H, Foster C. A physiological / psychological indicator of overreaching during intensive training. Int J Sports Med 1993; 14: 29-32

38. Steed J, Gaesser GA, Weltman A. Rating of perceived exertion and blood lactate concentration during submaximal running. Med Sci Sports Exerc 1994; 26: 797-803

39. Wasserman K, Mcllroy MB. Detecting the threshold of anaerobic metabolisme in cardiac patients during exercise. Am J Cardiol 1964; 14: 844-52

40. Wasserman $\boldsymbol{K}$, Stringer WW, Casaburi R, Koike A, Cooper CB. Determination of the anaerobic threshold by gas exchange. Biochemical considerations, methodology and physiological effects. Z Kardiol 1994; 83: 1-12

41. Williams JR, Amstrong N, Kirby BJ. The influence of the site of sampling and assay medium upon the measurements and interpretation of blood lactate responses to exercise. J Sports Sci 1992; 10: 95-107

42. Xu F, Rhodes EC. Oxygen uptake kinetics during exercise. Sports Med 1999; 27: 31327

43. Yoshida T, Yamamoto $\boldsymbol{K}$, Udo $\boldsymbol{M}$. Relationship between cardiac output and oxygen uptake at the onset of exercise. Eur J Appl Physiol 1993; 66: 155-60

44. Zorzano A, Fandos C, Palacin M. Role of plasma membrane transporters in muscle metabolism. Biochem J. 2000; 349: 667-88. 



\section{Chapter}

Summary / Samenvatting 


\section{Chapter 9}

\section{Summary}

During prolonged high-intensity exercise, a metabolic acidosis occurs which is compensated by several buffering systems and by the ventilatory system. Based on this concept, many authors attempted to investigate the ventilatory and lactate response to exercise in order to measure the ability of prolonged high-intensity exercise. Numerous confusing terms and definitions have been introduced in order to define the ability for maintaining high-exercise intensity. The determination of the different parameters is poorly defined and the interpretation is difficult. The different parameters and the implications are often difficult to interpret in a practical training situation. The main objective of this thesis was to gain insight into the reliability and usefulness of the various lactate and ventilatory responses described in the literature as indicators for training prescription, measuring performance, and to assess training effects.

In chapter II, a study is presented in which the relationships are described between different lactate responses and performance in elite triathletes. The main question in this study was which of the various lactate responses described in the literature during an incremental exercise test was the best indicator of endurance performance assessed during a field test. The conclusion of this study was that the different proposed lactate responses as indicators of performance, and for prescribing training schedules, are less reliable than generally assumed. Especially when similar-trained subjects are involved, lactate parameters do not add information concerning performance. In moderate-trained subjects, when the performance of subjects varies considerably, significant correlations between the lactate response and performance are easily found, but the predictive value in similar-trained subjects is limited due to a large interval of confidence.

In chapter III, a study is presented in which the maximal lactate steady state (MaxLaSS) is described during a field test in elite endurance athletes. MaxLaSS is expected to correspond to the anaerobic threshold (AT) which reflects the transition of aerobic to anaerobic conditions. In this study the observed plasma lactate levels during maximal steady-state exercise did not corresponded with the levels of lactate observed in a laboratory setting by other investigators. The plasma lactate levels during MaxLaSS were high and there was a remarkable individual variability. The determination of an individual MaxLaSS in a laboratory requires several constant workloads on different days. Only then, the results may be comparable with our observations. This procedure is expensive and it often does not fit into an athlete's training schedule. It is difficult to derive MaxLaSS and heart rate at MaxLaSS from a single lactate curve.

Although measurements of lactate concentrations may be useful to indicate early overtraining and the monitoring of training effects, the role of lactate parameters as indicator of a certain threshold or endurance performance in well-trained subjects is questionable. Concerning performance, lactate parameters do not add more information about performance than a maximal workload attained during an incremental exercise test. A single exercise test with an incremental protocol including lactate assessment will not result in usable parameters for training management. 
In chapter IV, the ventilatory response to exercise was evaluated using a field test in elite cyclists. The purpose of this study was to evaluate the relationships between the different ventilatory thresholds assessed during an incremental exercise test, the heart rate, and endurance performance assessed during a field test. Using a one-minute incremental exercisetest $\left(20 \mathrm{~W} \cdot \mathrm{min}^{-1}\right)$ the $\mathrm{V}$-slope method and an increasing $\mathrm{VE} / \mathrm{VO}_{2}$ are the preferred methods to predict heart rate during prolonged high-intensity exercise. Using a one-minute incremental exercise test $\left(20 \mathrm{~W} \cdot \mathrm{min}^{-1}\right)$ the $\mathrm{V}$-slope method and an increasing $\mathrm{VE} / \mathrm{VO}_{2}$ are the preferred methods to predict endurance performance. However, in this group of similar trained subjects the predictive value was limited due to the high interval of confidence. An additional observation in this study was that the maximal heart rate during the incremental exercise showed a relationship with the heart rate during prolonged high-intensity exercise.

In chapter $\mathbf{V}$, a study is presented in which the effect of training on the ventilatory response to incremental exercise test has been described. The aim of this study was to investigate the ventilatory response to incremental exercise in a group of elite cyclists during a relatively untrained period compared to an extensively endurance-trained state. Using a one-minute incremental exercise ( $\left.20 \mathrm{~W} \cdot \mathrm{min}^{-1}\right)$, the post-training $\mathrm{VO}_{2}$ levels at a certain work load were higher as a consequence of increased kinetics which is described more extensively in chapter $\mathrm{VI}$ and VII. The need for multiple determinations of the heart rate at the ventilatory threshold (VT) during a cycling season is doubtful since the heart rate at VT does not appear to differ much during the season.

In chapter $\mathrm{VI}$, a new phenomenon in exercise physiology concerning $\mathrm{VO}_{2}$ kinetics has been described: a remarkable $\mathrm{VO}_{2}$ overshoot at the onset of steady-state exercise. This phenomenon is characterised by an increase in oxygen uptake that occurs within the first two minutes after the onset of exercise. The $\mathrm{VO}_{2}$ overshoot is more pronounced at lower exercise levels. The maximum level of the $\mathrm{VO}_{2}$ peak shows a higher level than the steady-state level, which is reached after 2 minutes. The metabolic phase of the $\mathrm{VO}_{2}$ kinetics is expected to fit into a mono-or bi-exponential model. In both models, the $\mathrm{VO}_{2}$ as a function the time is always increasing. So this theoretical model does not fit in the observed response in which an initial rise occurs between 50 and $100 \mathrm{~s}$ after the onset of exercise. In addition the curve fitting in the exponential models will be highly affected by the $\mathrm{VO}_{2}$ overshoot and it will influence the analysing of curves and the calculation of the $\mathrm{O}_{2}$ deficit.

In this chapter, we have introduced an additional component for describing the $\mathrm{VO}_{2}$ kinetics to constant-load exercise. The behaviour of this third component can be viewed as a switchon phenomenon as a result of the start of a linear dynamic system. This component is added to the fast component of the classic mono-exponential model. This results in the typical $\mathrm{VO}_{2}$ overshoot that we have observed. This model fits better than the classic mono-and biexponential model.

The physiological background of the overshoot phenomenon is, like the classic model, not easy to explain. A sudden opening of arterioles and pre-capillary sphincters could enhance muscle perfusion resulting in faster and / or more oxygen extraction, which seems to be a likely possibility. In addition, a peak of catecholamines or the activation of the muscle pump itself may play a role in the peripheral vasodilatation. Other possibilities that have to be mentioned may be the extra energy that is needed for the legs that have to start moving and 
for accelerating the pedals, and contractions of trunk or arm muscles. The early cardiodynamic response seems not responsible for the overshoot phenomenon since it is known to occur in the first 20 seconds.

In chapter VII, a study has been presented in which the effect of training on the $\mathrm{V}_{2}$ response to steady-state exercise has been investigated. Main objective of this study was to investigate the earlier described $\mathrm{VO}_{2}$-overshoot phenomenon at the onset of constant-load exercise in a group of competitive cyclists during a relatively untrained period compared to an extensively endurance-trained period. Post training, an earlier maximum of the $\mathrm{V}_{2}$ overshoot was observed. The steady-state levels reached after several minutes were lowered following endurance training. The overshoot phenomenon and its earlier occurrence following endurance training may explain the higher post-training $\mathrm{VO}_{2}$ for the same workload in chapter $\mathrm{V}$, since the $\mathrm{VO}_{2}$ in chapter $\mathrm{V}$ was assessed during a one-minute incremental exercise test, near the moment of the maximum of the $\mathrm{VO}_{2}$ overshoot. Steadystate levels reached after several minutes are lowered following endurance training. If longer steps ( $>2 \mathrm{~min}$ ) during an incremental exercise test are used, post-training submaximal $\mathrm{VO}_{2}$ will be lower. The results of the studies presented in chapter $\mathrm{V}, \mathrm{Vl}$, and $\mathrm{VII}$ suggest that for the monitoring of training effects only a short submaximal exercise test is needed. This is efficient and untaxing for athletes, and perhaps applicable in patients.

In chapter VIII, the different studies are overviewed and the possible mechanisms to explain the observations are discussed. Especially the recent discovered lactate transporters are discussed and they may explain the high lactate levels during steady-state exercise.

\section{Conclusions}

The main conclusions from the various studies described in this thesis are:

- The lactate responses proposed in the literature as indicators of performance and for prescribing training schedules in endurance athletes, are less reliable than generally assumed.

- The plasma lactate level during the maximal lactate steady state in endurance athletes is higher than expected and there is a large individual variability in lactate level.

- A single incremental exercise with lactate measurements does not provide reliable information for training management.

- The determination of the maximal lactate steady state in a laboratory requires the performance of several constant workloads on different days. Only then the steady-state levels are comparably with those in practice.

- Using a one-minute incremental exercise test $\left(20 \mathrm{~W} \cdot \mathrm{min}^{-1}\right)$, the heart rate assessed using $\mathrm{V}$-slope method and an increasing $\mathrm{VE} / \mathrm{VO}_{2}$ are the preferred methods to predict heart rate during prolonged high-intensity exercise.

- Using a one-minute incremental exercise test $\left(20 \mathrm{~W} \cdot \mathrm{min}^{-1}\right)$, the $\mathrm{VO}_{2}$ assessed using the $\mathrm{V}$-slope method and an increasing $\mathrm{VE} / \mathrm{VO}_{2}$ are the preferred methods for predicting endurance performance. 
- Without the assessment of ventilatory or lactate parameters, the heart rate during prolonged high-intensity exercise can be predicted out of the maximum heart rate during an incremental exercise test $\left(20 \mathrm{~W} \cdot \mathrm{min}^{-1}\right)$ using the formula in chapter V.

- The need for multiple exercise tests for determining HR at VT during a cycling season is doubtful since this parameter does not differ much following endurance training.

- The $\mathrm{VO}_{2}$ overshoot is a new phenomenon in $\mathrm{VO}_{2}$ kinetics and occurs within the first two minutes after the onset of exercise.

- Using a one-minute incremental exercise $\left(20 \mathrm{~W} \cdot \mathrm{min}^{-1}\right)$, the post-training $\mathrm{VO}_{2}$ levels at a certain workload are higher as a consequence of increased kinetics.

- The $\mathrm{VO}_{2}$ overshoot occurs more pronounced at lower exercise intensity and disappears at higher exercise intensity $\left(>60 \% \mathrm{VO}_{2} \max \right)$

- The post-training $\mathrm{VO}_{2}$ overshoot at submaximum workload is fastened.

- At lower workloads, the post-training $\mathrm{VO}_{2}$ and $\mathrm{VCO}_{2}$ during submaximal steady-state exercise intensity for a certain workload are lowered.

- The accelerated post-training $\mathrm{VO}_{2}$ overshoot and the decreased steady-state $\mathrm{VO}_{2}$ make it possible to describe training effects using an exercise test of short duration (minutes). 


\section{Samenvatting}

Tijdens intensieve fysieke inspanning ontstaat een metabole acidose die gecompenseerd wordt door diverse buffersystemen. Gebaseerd op dit concept hebben vele onderzoekers de lactaat en ventilatoire respons tijdens inspanning onderzocht om parameters te verkrijgen voor het prestatievermogen, trainingseffecten en trainingsbegeleiding. Deze parameters worden op verschillende manieren gedefinieerd en de precieze interpretatie is vaak onduidelijk. De verschillende parameters zijn vaak niet getoetst aan de praktijk. In dit proefschrift worden een aantal onderzoeken beschreven bij zeer goed getrainde duursporters. Een aantal geaccepteerde methoden om duursporters te testen en te adviseren worden getoetst aan de praktijk. De ventilatoire respons en de $\mathrm{V}_{2}$-kinetiek worden uitgebreider onderzocht en beschreven. Doel van dit proefschrift was om de diverse lactaat en de ventilatoire responsen te beschrijven en te analyseren om zodoende praktische handvatten te verkrijgen voor het geven van trainingsadviezen, het beoordelen van de trainingstoestand en het voorspellen van prestaties.

In hoofdstuk II worden de diverse in de literatuur gepropageerde lactaatparameters, bepaald in een laboratorium, vergeleken met een praktijktest in de vorm van een tijdrit. De plasma lactaatrespons bleek geen goede indicator te zijn voor het prestatievermogen van toptriathleten. Wat het prestatievermogen betreft, levert het maximaal vermogen tijdens een inspanningstest met een oplopend vermogen $\left(20 \mathrm{~W} . \mathrm{min}^{-1}\right)$ meer informatie dan lactaatparameters.

In hoofdstuk III wordt de maximale lactaat steady-state bij topwielrenners en toptriatleten bepaald gedurende een tijdrit van $40 \mathrm{~km}$. De lactaatwaarden tijdens deze tijdrit vertoonden een enorme individuele spreiding en de gemiddelde lactaat waarden overtroffen die van eerdere publicaties.

De eerste twee hoofdstukken suggereren sterk dat een éénmalige laboratorium test met lactaatbepalingen weinig bruikbare informatie oplevert voor begeleider en atleet. Met behulp van lactaatcurven zijn wel overtrainingstoestanden of trainingseffecten aan te tonen, maar een lactaatcurve levert geen bruikbare informatie voor de advisering ten aanzien van bijvoorbeeld trainen met de hartslag.

In hoofdstuk IV worden de in literatuur gepropageerde ventilatoire drempels bepaald in een laboratorium getoetst aan een praktijktest. Geconcludeerd wordt dat bij topwielrenners de zogenaamde $\mathrm{V}$-slope methode en een stijgende $\dot{\mathrm{V} E} / \mathrm{V}_{2}$ indicatoren zijn voor het prestatievermogen en de hartslag tijdens een tijdrit. Ook de maximale hartfrequentie bepaald in het laboratorium bleek een redelijke indicator voor de hartslag tijdens de tijdrit.

In hoofdstuk $\mathbf{V}$ worden de trainingseffecten op de ventilatoire respons beschreven tijdens een inspanningstest met snel oplopend vermogen $\left(20 \mathrm{~W} \cdot \mathrm{min}^{-1}\right)$. Opvallend was dat er na een periode van training een hogere $\mathrm{VO}_{2}$ wordt waargenomen bij een zelfde vermogen. Bij het gebruik van een 1-minuten protocol blijkt een hogere $\mathrm{VO}_{2}$ bij een bepaald vermogen een indicator te zijn voor een betere trainingstoestand. Waarschijnlijk is dit het gevolg van een toegenomen $\mathrm{V}_{2}$-kinetiek. Dit wordt duidelijk door de observaties gepresenteerd in hoofdstuk VI en VII. Het nieuw beschreven $\mathrm{VO}_{2}$-overshoot fenomeen valt namelijk rond de 


\section{Hoofdstuk 9}

minuut, precies op het moment van verzwaren van de belastingt. Uit dit onderzoek blijkt tevens dat het niet zinvol lijkt om vele malen de hartslag bij de ventilatoire drempel gedurende het seizoen te bepalen aangezien deze hartslag niet duidelijk verandert.

In hoofdstuk VI wordt een nieuw fenomeen besproken wat optreedt bij het begin van een steady-state belasting. Er is een initiële korte stijging met een maximum tussen 50-100 seconden met nadien een daling van de zuurstofopname naar de steady-state waarde. In de discussie van dit artikel wordt dit fenomeen ingebouwd in het klassieke exponentiële model van de $\mathrm{VO}_{2}$-kinetiek tijdens submaximale inspanning. De mogelijke verklaring is een verhoogde perifere doorbloeding door opening van de pre-capillaire sphincters aan het begin van de inspanning. Een ander mogelijkheden om dit fenomeen te verklaren is de extra energie benodigd voor het in gang zetten van de trappers en de benen of het gebruik van rompmusculatuur.

In hoofdstuk VII worden de trainingseffecten onderzocht op de $\mathrm{VO}_{2}$-kinetiek en in het bijzonder op het $\mathrm{VO}_{2}$-overshoot fenomeen. Dit fenomeen verloopt sneller na een periode met duurtraining, terwijl de submaximale steady-state $\mathrm{VO}_{2}$ na training iets lager blijkt te liggen bij de lagere belastingen. De $\mathrm{VO}_{2}$-overshoot is meer uitgesproken bij lagere belastingen. Het ten gevolge van training eerder optredende $\mathrm{V}_{2}$-overschoot en de lagere steady-state $\mathrm{V}_{2}$ zijn belangrijke indicatoren voor de trainingstoestand. De resultaten verklaren de eerdere observaties in hoofdstuk $\mathrm{V}$. Het protocol gebruikt in hoofdstuk $\mathrm{V}$ laat het vermogen per minuut een stap omhoog gaan, terwijl het overschoot fenomeen optreedt rond de eerste minuut. Indien langere stappen waren genomen had de $\mathrm{V}_{2}$ bij een zelfde belasting na training misschien wel lager geweest.

In hoofdstuk VIII worden van de diverse onderzoeken de mogelijke mechanismen die aan de waarnemingen ten grondslag liggen besproken. Met name de recent beschreven lactaattransporters worden aangehaald als mogelijke verklaring voor de hoge lactaatwaarden tijdens steady-state inspanningen. Verder wordt de $\mathrm{VO}_{2}$-kinetiek in de nabije toekomst een belangrijke rol toebedacht voor de bepaling van de trainingstoestand. Het fenomeen van de $\mathrm{VO}_{2}$-overshoot treedt al op bij zeer lage belastingen en is daarom ook een ingang voor verder onderzoek bij patiënten. Een korte inspanningstest met een submaximale belasting is immers genoeg om de trainingstoestand te monitoren. Een submaximale test om de conditie te meten is efficiënt, tijdsparend en patiënt- en sporter- vriendelijk.

\section{Conclusies}

De belangrijkste conclusies en praktische richtlijnen voor de begeleiding van wielrenners van dit proefschrift zijn:

- De waarde van lactaatmetingen als indicator voor het prestatievermogen en voor trainingsadvisering bij duursporters is beperkt.

- De plasma lactaatwaarden tijdens een inspanning met een intensiteit rond de maximale lactaat steady-state zijn bij getrainde duuratleten veel hoger dan beschreven in de literatuur. 
- De maximale lactaat steady-state is met een éénmalige lactaattest niet te bepalen en vereist meerdere lactaattesten op verschillende dagen.

- $\mathrm{Bij}$ topwielrenners is de ventilatoire respons ( $\mathrm{V}$-slope methode en een stijgende $\mathrm{V} E / \mathrm{V}_{2}$ ) tijdens een inspanningstest met oplopend vermogen $\left(20 \mathrm{~W} \cdot \mathrm{min}^{-1}\right)$ een indicator voor het prestatievermogen en de hartslag tijdens een duurprestatie met zo hoog mogelijke intensiteit.

- Bij wielrenners is de hartslag gedurende een duurprestatie met een zo hoog mogelijke intensiteit te bepalen door middel van een maximale inspanningstest met oplopend vermogen $\left(20 \mathrm{~W} \cdot \mathrm{min}^{-1}\right)$, met behulp van de maximaal behaalde hartslag.

- Het is niet nodig om vele malen in een wedstrijdseizoen de hartslag bij de ventilatoire drempel te bepalen aangezien deze hartslag door het seizoen weinig verandert.

- Tijdens een inspanningstest met oplopend vermogen $\left(20 \mathrm{~W} \cdot \mathrm{min}^{-1}\right)$ is de $\mathrm{VO}_{2}$ bij een bepaald vermogen na een trainingsperiode hoger door een toegenomen $\mathrm{V}_{2}$-kinetiek.

- Er wordt in dit proefschrift een nieuw fenomeen beschreven bij de aanvang van een inspanning, de $\mathrm{VO}_{2}$-overshoot. Dit fenomeen is aanwezig bij inspanningen met een intensiteit tot ongeveer $60 \%$ van de $\mathrm{VO}_{2} \max$.

- $\mathrm{Na}$ een periode van training bij wielrenners bereikt de $\mathrm{V}_{2}$-overshoot sneller een maximum.

- Na een periode van training is de zuurstofopname en de kooldioxide afgifte bij eenzelfde submaximale steady-state belasting verlaagd.

- De versnelde $\mathrm{VO}_{2}$-kinetiek en de lager submaximale waarden voor $\dot{\mathrm{VO}}_{2}$ en $\mathrm{V}_{\mathrm{CO}}$ als gevolg van training maakt het mogelijk een submaximale test voor duuratleten en wellicht ook voor patiënten te ontwikkelen. 



\section{Alfabetische Dankwoordenlijst}

Omdat het curriculum en de dankwoordenlijst de eerste en meest gelezen gedeelten zijn van een proefschrift is heb ik het gemakkelijk gemaakt door de mensen die ik wil bedanken hieronder in alfabetische volgorde te vermelden.

\section{Bedankt:}

Berg van de Ton, omdat je een vriend bent waarbij ik altijd kon langskomen, maar ook omdat je de manager van onze cursus in Zuid-Frankrijk bent waar we al vele mooie momenten met elkaar hebben doorgebracht aan de voet van jouw berg.

Bos, Annemieke, voor je onvoorwaardelijke steun.

Dinnissen, Henk, voor de hulp bij het maken van de lay-out van dit proefschrift en al je dias in het verleden.

Functielaboranten en secretaressen, voor het collega zijn en de interesse die jullie toonden in mijn onderzoek. Vooral degenen die mij in het verleden hebben geholpen en in het bijzonder Ad, Ester en Rob, omdat jullie vrolijke collegas zijn die altijd klaar stonden om te helpen bij de testen. Jullie wisten de sporter met een praatje altijd op zijn gemak te laten voelen.

Hoogeveen, John, simpel weg omdat je mijn broer bent, mij altijd hebt gesteund en nu ook nog mijn paranimf bent.

Hoogeveen, Rob en Cilia, voor het aanmoedigen en de steun op alle fronten.

Hoogeveen, Pa en Ma, voor jullie opvoeding, de begeleiding bij de wedstrijden en de steun.

Hoogsteen, Jan, voor je medeauteurschap en onze altijd prettige samenwerking. Voor onze gezellige dinsdagmiddagen als we samen spreekuur deden. De cursus in Zuid-Frankrijk die wij vanuit ons enthousiasme organiseren is een belangrijke drijfveer geweest voor dit proefschrift.

Huige, Rien, voor de hulp bij mijn allereerste publicatie in 1989. De Sportgeneeskunde in het Sint Joseph Ziekenhuis heeft enorm veel aan je te danken. De cursus Zuid-Frankrijk die wij destijds vanuit ons enthousiasme hebben opgezet is een belangrijke drijfveer geweest voor dit proefschrift.

\section{Iedereen die ik vergeten ben.}

Keizer, Hans, voor de steun en het geloof in mijn ideeën, ondanks dat je soms zelf overliep van de drukte. Je enthousiasme over mijn ideeën steunde mij.

Koersen, Egbert, voor de planning en de medewerking tijdens de onderzoeken.

Kuipers, Harm, voor je rechtlijnigheid, je begeleiding en je adviezen. "Kom maar eens langs als je een aantal publicaties hebt" zei je in 1996. En dat deed ik.

Nibbering, Bart, bedankt oude collega en vriend voor je participatie als paranimf en leuk om je eens in een kostuum te zien.

Proefpersonen, TVM-renners, triathleten, AGU-wielerploeg en de renners van TWCTempo voor het proefpersoon zijn.

Sala, Harm, voor de eerste aanzet van de Sportgeneeskunde, toen niemand nog wist wat sportgeneeskunde was. De cursus die wij vanuit ons enthousiasme hebben opgezet is een belangrijke drijfveer geweest voor dit manuscript.

Schep, Goof, voor de samenwerking de afgelopen jaren en voor de eerste aanzet van de lactaatonderzoeken. Met name je drang naar subsidies heeft geleid tot de eerste twee 
hoofdstukken van dit proefschrift. Ik hoop de samenwerking nog lang te continueren.

Specialisten diversen, cardiologen en pulmonologen, vroeger als baas en nu als collega voor de steun en samenwerking.

Vries de, Bert, bedankt voor je spontane hulp bij de analyse van de curven.

Werkgroep Sportgeneeskunde, voor de steun die nodig was om een afdeling sportgeneeskunde op te zetten in een algemeen ziekenhuis. Van de stuurgroep is alleen Mies de Maat in deze lijst nog niet eerder genoemd.

Zaagman, Rob, omdat je ondanks je drukke baan toch tijd vond om mijn Engels te corrigeren.

Zonderland, Maria, voor de hulp bij mijn eerste wetenschappelijke passen. Ik heb daar echt veel aan gehad. Bedankt ook dat je in de beoordelingscommissie wilde plaatsnemen. 


\section{Curriculum Vittae}

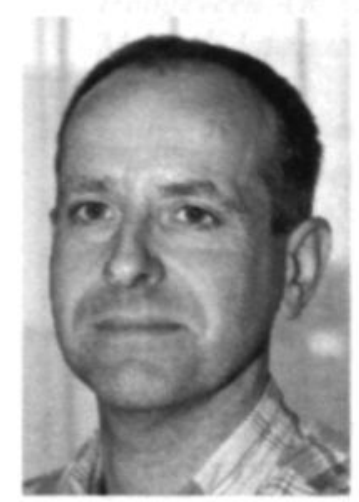

Adwin Hoogeveen werd geboren op 31 augustus 1961 in Utrecht, alwaar hij van 1974 tot 1980 het VWO doorliep (Atheneum "F.de Munnik"). Van september 1980 tot november 1981 vervulde hij de dienstplicht in Ermelo. In 1981 maakte hij een aanvang met de studie Geneeskunde aan de Rijks Universiteit Utrecht, alwaar hij in 1984 zijn kandidaats examen aflegde. De senior co-schappen werden doorlopen in het Elisabeth Ziekenhuis in Tilburg. In oktober 1988 behaalde hij het artsen diploma. Vanaf januari 1989 was hij werkzaam op de afdeling cardiologie in het Sint Joseph Ziekenhuis in Veldhoven, waar hij in 1993 startte met de opleiding tot sportarts. In 1997 werd deze opleiding afgerond. Vanaf begin 1990 was hij actief betrokken bij de begeleiding van topsporters. De interesse in de inspanningsfysiologie was reeds gedurende het begin van de studie Geneeskunde nadrukkelijk aanwezig, wat uiteindelijk uitmondde in dit proefschrift.

Van 1972 tot 1980 was hij actief voetballer bij de voetbalclub "Hercules" in Utrecht. Vanaf 1982 tot 1991 was hij actief als wielrenner, schaatser en triatleet. Na enkele recreatieve jaren makte hij in 1995 zijn entree als amateur-wielrenner bij de amateur-formatie TWC Tempo in Veldhoven. 


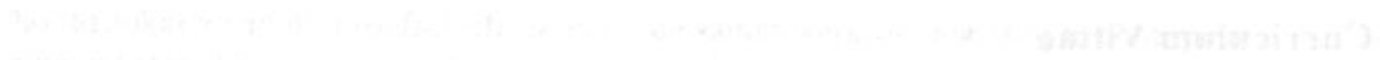

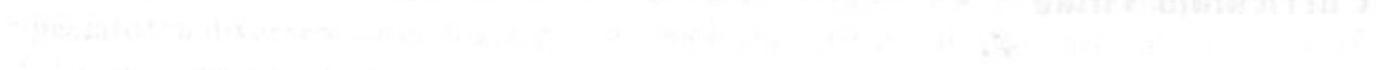
(2)

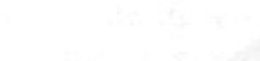

(1)

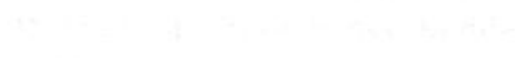

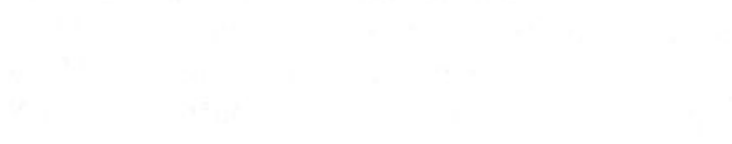

(n)
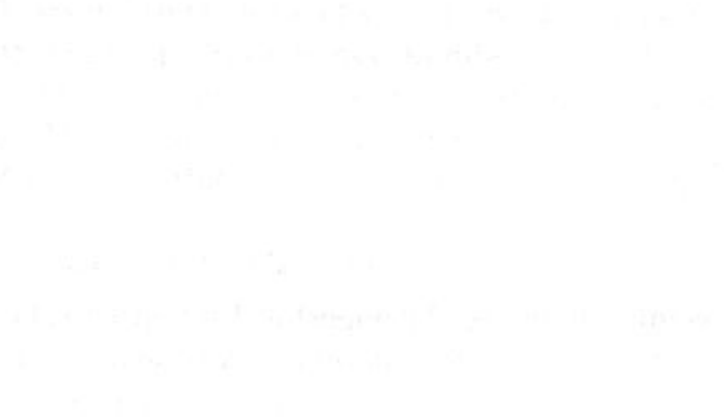

(1)

$\sqrt{2}$

$\left(\frac{10}{20}\right.$

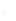

(1)

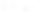

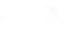

(2)

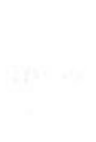

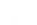

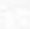
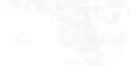

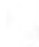

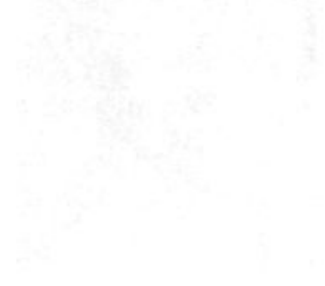




\section{Publications}

1. Hoogeveen $\boldsymbol{A R}$, Grubben $\boldsymbol{M C}$, Huige MC. Stille ischaemie; een dilemma in de praktijk. Medisch Journaal van het Sint Joseph Ziekenhuis 1989; 3: 182-6

2. Huige MC, Bosma AH, Hoogeveen AR, Werner MJ. Het sporthart. Medisch Journaal van het Sint Joseph Ziekenhuis 1991; 3; 143-9

3. Hoogeveen $\boldsymbol{A R}$, Werner $\boldsymbol{M J}$, Huige MC. De maximaaltest bij wielnenners. Een nauwkeurige voorspeller van het prestatievermogen. Medisch Journaal van het Sint Joseph Ziekenhuis 1991; 3: 157-61

4. Bosma AH, Huige MC, Werner MJ, Hoogeveen AR. Het echo-onderzoek bij marathonlopers en wielrenners. Medisch Journaal van het Sint Joseph Ziekenhuis 1991; 3: $163-6$

5. Huige MC, Bosma AH, Hoogeveen AR, Werner MJ. Cardiale problemen bij duursporters. Medisch Journaal van het Sint Joseph Ziekenhuis 1991; 3: 169-73

6. Werner MJ, Hoogeveen AR, AH Bosma, Huige MC. Eindhovense marathon 1990. Door tropische omstandigheden forse dehydratie. Medisch Journaal van het Sint Joseph Ziekenhuis 1991; 3: 175-80

7. Hoogeveen AR, Huige MC, Hoogsteen J. Onderzoek naar de waarde van de maximaaltest bij wielersporters. Medisch Journaal van het Sint Joseph Ziekenhuis 1993: 3: 90-3

8. Hoogeveen AR, Huige MC, Hoogsteen J, Schep G De maximaaltest bij wielrenners, een voorspeller van het klimvermogen. Geneeskunde en Sport 1994: 6: 189-93

9. Schep G, Hoogeveen AR, Sala HAGM. Massieve rupturen van de rotatorcuff. Geneeskunde en Sport 1995; 4: 105-8

10. Hoogeveen $\boldsymbol{A R}$, Zonderland $\boldsymbol{M L}$. Relations between testosterone, cortisol and performance in professional cyclists. Int J Sports Med 1996; 6: 423-8

11. Hoogeveen AR, Schep G, Hoogsteen J. De lactaatrespons ten gevolge van inspanning: opmerkelijke observaties bij top-triathleten. Geneeskunde en Sport 1997: 2: 37-42

12. Hoogeveen $\boldsymbol{A} \boldsymbol{R}$, Schep $\boldsymbol{G}$ The plasma lactate response to exercise and endurance performance. Relationships in elite triathletes. Int J Sports Med 1997: 18: 526-9

13. Hoogeveen $\boldsymbol{A R}$, Hoogsteen $\boldsymbol{J}$, Schep $\boldsymbol{G}$ The maximal lactate steady state in elite endurance athletes. Jap J of Physiol 1997: 47: 481-5 
14. Hoogsteen J, Schep G, Huige MC, Hoogeveen AR, Mosterd WL, PanhuijzenGoedkoop NM. Atrium fibrilleren en duursport. Cardiologie 1997; 4: 506-10

15. Hoogeveen AR, Schep G, Vader HL. The problems to study plasma lactate. Reply. Int J Sports Med 1998; 19: 2-3

16. Hoogeveen AR, Hoogsteen $\boldsymbol{J}$, Schep $\boldsymbol{G}$ De klinische toepassingen van inspanningsonderzoek met spiro-oxymetrie. Medisch Journaal van het Sint Joseph Ziekenhuis 1998; 2: $60-4$

17. Hoogeveen AR, Schep G, Hoogsteen J. The ventilatory threshold, heart rate, and endurance performance: relationships in elite cyclists. Int J Sports Med 1999; 20: 1147

18. Hoogeveen AR. Inspanningsonderzoek bij patiënten. Medisch Journaal van het Sint Joseph Ziekenhuis 2000; 1: 12-3

19. Hoogeveen $\boldsymbol{A R}$. The effect of endurance training on the ventilatory response to exercise in elite cyclists. Eur J Appl Physiol 2000; 82: 45-51

20. Hoogeveen AR, Keizer HA. The $\mathrm{VO}_{2}$-Overshoot at the Onset of Constant-Load Exercise exercise in well-trained cyclists: an undescribed Phenomenon. In print

21. Hoogeveen AR, Kuipers $\boldsymbol{H}$, Keizer HA. The Effect of Endurance training on the $\dot{V}_{2}-$ overshoot at the Onset of Constant-Load Exercise exercise in well-trained cyclists. In print.

22. Kuipers $\boldsymbol{H}$, Hoogeveen $\boldsymbol{A} \boldsymbol{R}$, Keizer $\boldsymbol{H A}, \boldsymbol{S c h e p} \boldsymbol{G}$ Heeft langdurige intensieve fysieke inspanning late gevolgen voor de gezondheid? Nederlands tijdschrift voor geneeskunde. In print 
"Physiology has a unique language that depends on abbreviations and symbols. These abbreviations and symbols allow for rapid reading and expression of ideas and mathematical relationships, but trying to accurately represent the symbols in a word processing document can result in maddening problems."

Will Hopkins, April 2000 
